\title{
User engagement with digital service innovation
}

Citation for published version (APA):

Ciuchita, R. P. A. (2016). User engagement with digital service innovation. [Doctoral Thesis, Maastricht University]. Maastricht University. https://doi.org/10.26481/dis.20161013rc

Document status and date:

Published: 01/01/2016

DOI:

10.26481/dis.20161013rc

Document Version:

Publisher's PDF, also known as Version of record

\section{Please check the document version of this publication:}

- A submitted manuscript is the version of the article upon submission and before peer-review. There can be important differences between the submitted version and the official published version of record.

People interested in the research are advised to contact the author for the final version of the publication, or visit the DOI to the publisher's website.

- The final author version and the galley proof are versions of the publication after peer review.

- The final published version features the final layout of the paper including the volume, issue and page numbers.

Link to publication

\footnotetext{
General rights rights.

- You may freely distribute the URL identifying the publication in the public portal. please follow below link for the End User Agreement:

www.umlib.nl/taverne-license

Take down policy

If you believe that this document breaches copyright please contact us at:

repository@maastrichtuniversity.nl

providing details and we will investigate your claim.
}

Copyright and moral rights for the publications made accessible in the public portal are retained by the authors and/or other copyright owners and it is a condition of accessing publications that users recognise and abide by the legal requirements associated with these

- Users may download and print one copy of any publication from the public portal for the purpose of private study or research.

- You may not further distribute the material or use it for any profit-making activity or commercial gain

If the publication is distributed under the terms of Article $25 \mathrm{fa}$ of the Dutch Copyright Act, indicated by the "Taverne" license above, 


\section{USER ENGAGEMENT WITH DIGITAL SERVICE INNOVATION}


(C) Robert Petrut Andrei Ciuchita, Maastricht 2016

ISBN: 978-94-6182-728-9

Cover design by Hye Studio (Laura Ristea and Alin Tamasan), Bucharest, Romania.

Layout by R. Elena Francu, Maastricht, The Netherlands.

Printing by Off Page, Amsterdam, The Netherlands.

All rights reserved. No part of this publication may be reprinted or utilized in any form or by any electronic, mechanical, or other means, now known, or hereafter invented, including photocopying and recording, or in any information storage or retrieval system, without permission from the copyright owner. 


\section{USER ENGAGEMENT WITH DIGITAL SERVICE INNOVATION}

DISSERTATION

to obtain the degree of Doctor at Maastricht University, on the authority of the Rector Magnificus Prof. dr. Rianne M. Letschert in accordance with the decision of the Board of Deans, to be defended in public on Thursday, 13th of October 2016, at 12.00 hours.

By Robert Petrut Andrei Ciuchita 
SUPERVISOR

Prof. Dr. Gaby Odekerken-Schröder CO-SUPERVISOR

Dr. Dominik Mahr

\section{ASSESSMENT COMMITTEE}

Prof. Dr. Jos Lemmink (Chairman)

Prof. Dr. Mariëlle Heijltjes

Prof. Dr. Frank Piller (RWTH Aachen, Germany)

Prof. Dr. Roland Rust (University of Maryland, USA) 
To my parents 



\section{ACKNOWLEDGEMENTS}

“Elektra Luxx: You could get a PhD, you know?

Holly Rocket: I know. That's why I get tested twice a year. [To the camera] Nobody thinks it can happen to them, but anyone can get a PhD. Make sure you get tested. Thank you."

(Women in Trouble, 2009) 
Five years ago I stumbled into doing a $\mathrm{PhD}$ with a relatively romantic understanding of academia and research, but I was young, curious, and ready to put in the work. Now that I am so close to the end, I look back at the bittersweet symphony of the last half a decade and realize how much I have grown, both on a professional and on a personal level. I've learned that doing a PhD is not just about attempting to conduct and publish high quality research, but about deconstructing and rebuilding everything I thought I knew about life. As much of a lonely journey as it may seem, you never really walk alone during the PhD. Therefore, I would like to take this opportunity to thank the people who have walked by my side and at times carried me on their backs.

I would not be writing this today if it were not for Prof. Dr. Gaby OdekerkenSchröder. Gaby, you saw something in me that I did not know I had! You are the walking, smiling representation of "always look on the bright side of life". Your positivity and enthusiasm are contagious and have picked me up and got me back on track so many times. I immensely respect that you have always been direct and honest with me in both praise, as well as in learning from failure. Your "to put it bluntly"-moments have greatly helped me regain focus, while your "I love it"-moments have refueled my passion for what I was doing. Most importantly, you have taught me that there is more to research than rigor and creativity: it is also about people, working together and trusting each other, trying your utmost, but also having fun! I would like to thank you for believing in me especially when I doubted myself, for giving me room to explore, for helping me learn from my mistakes, for teaching me that it is important to cherish success, and ultimately that it matters more to be true to yourself and to what you love. Thank you!

You would not be reading this today if it were not for Dr. Dominik Mahr. Dominik, you have been down in the trenches with me, you have been my mentor and foremost my friend. You are the walking, conceptual-thinking representation of "work hard, play hard"! I thank you for being so patient, so open, so approachable, and so generous with me! You always went the extra mile to provide feedback, to help me cross hurdles (both real and imaginary) and to bring me back on track lyour "we are running a bit out of time"moments were painful, but necessary reality checks). Constantly bouncing ideas and opinions with you and sometimes having "creative differences" has benefitted this dissertation greatly, but more importantly has taught me to think and feel like a researcher. Thank you for teaching me to be curious and 
passionate about innovation, for inspiring me to keep my work relevant and meaningful, for introducing me to many great people and communities and for reminding me that beyond all the hard work and dedication life also needs to be celebrated every once in a while. Thank you!

I would like to express my deep gratitude to the members of my assessment committee Prof. Dr. Jos Lemmink, Prof. Dr. Mariëlle Heijltjes, Prof. Dr. Frank Piller and Prof. Dr. Roland Rust. Thank you very much for the time and effort you put into reading and evaluating my dissertation!

This dissertation would not have been possible without the support of the companies that facilitated access to data for two of the empirical chapters. Thank you for your accessibility, your trust in our research team and for your willingness to explore and learn alongside us. Collaborating with you has helped me understand that, to be relevant for practice, research needs to translate into actionable managerial insights. Thank you for helping me comprehend the complexities of your companies and industries.

My PhD life would not have been the same without my two brothers in academic arms: Alex and Johannes. Our "Krakadil" office was such a special place where research ideas, random wisdom, general frustration and wholehearted banter were thrown around (sometimes literally). Alex, you are a great friend and a fine life-connoisseur! Thank you for teaching me to be more relaxed and to call it a day when necessary. I greatly miss those Friday evenings when everything made more sense after multiple IPAs. Thank you for the long talks and the long dog-walks, for your patience and support, for all the great food and wine, for all the great trips and for all the rock and roll! Johannes, I've learned more about academia from you than from reading a hundred papers. I am happy to have also known the side of you that is into philosophy, wrestling and rap music. Thank you for introducing me to BVB culture, for the G\&T afternoons, for the backpack dance and for the deep, though PC-questionable conversations.

Outside that office, I have benefitted greatly from the help and guidance of the colleagues in the Marketing \& Supply Chain Management Department. Thank you all! Jos L., you were always open to discussing my academic (and beyond) challenges and you have always provided thoughtful advice. Thank you for opening so many doors and for creating so many opportunities for me! Martin, under your guidance I have developed my analytical skills tremendously. Thank you for always pointing me in the right direction and for helping me overcome 
many methodological difficulties. Bram, teaching your courses during my first year provided the blueprint for the type of teacher I want to be. Thank you for giving me your time and your heartfelt opinions on many matters. Lisa, thank you for helping me navigate the academic world at conferences.

I would also like to thank my fellow $\mathrm{PhD}$ and postdoc colleagues, both from the old guard (Anne, Hannes, Jan M., Jan P., Jessica, Katja, Matthias, Nina, Stephan, and Theo), as well as the new (Anika, Ben, Fabian, Francisco, Kars, Leticia, Marleen, Martina, Nadine, Piet, Pieter, Ruud, Stefania, Susan, Teerawut, Tim, Vera, and Wiebke). While some of you I got to know better than others, I have learned a lot from and alongside all of you! Thank you all for the good times, be they work-related, or extracurricular. For whom it is still applicable, I wish you the best of luck in finalizing your dissertations.

I would also like to thank the wonderful SSF team: Anja, Conny, Damien, Gaby, Karol, Laszlo, Linda, and Sabine J.. It was enriching for me to be part of such a creative, enthusiastic, and friendly environment (nobody does Sinterklaas like SSF)! Anja, thank you for your kindness and for all your help in navigating Dutch society in the early days of my PhD. Laszlo, I am indebted to you for all your support, especially during one of my infamous data collections. Your professionalism and proactivity are unmatched! Karol, one of the chapters in this dissertation would not exist if it were not for your expertise. Thank you for your patience, for putting up with my long queries, and also for putting me up while in DC! Linda, you've been a great friend and a sight for sore eyes on our corridor. Thank you for the pizza evenings, the muffins and the great talks!

Beyond Maastricht University, I have had the opportunity to meet and collaborate with some inspiring individuals and greatly benefit from their expertise and wisdom. Roland, thank you for welcoming me as a visiting scholar at the University of Maryland. The time spent with you was pivotal in my formation as a researcher. Thank you for your patience and for all the feedback! Sabine B. (back then M.), sharing an office with you at the beginning of my PhD helped me jump-start my academic career. Thank you for involving me in your research and for all your guidance and friendship. Bart, you have been one of the most supportive people I have met during my PhD. Thank you for your openness and your advice. I would also like to extend my gratitude to Dwayne Gremler, Wafa Hammedi, P.K. Kannan, Mirella Kleijnen, Anouk Lievens, Parsu 
Parasuraman, Ko de Ruyter, and Michel Wedel for their constructive feedback and academic guidance.

Great many thanks to Arne, Freek, Kande, and Sarah, my wonderful Belgian colleagues whose company I have enjoyed at conferences, colloquia, and workshops over the years. Finally, great many thanks to my visiting scholar friends who made College Park and even better place: Ana, Emanuel, Lily, Manuel, and Wouter.

Ewa, thank you for your patience and understanding and sorry that our research kept Dominik away from home late in the evenings or during weekends. Muriel, thank you for being such a lovely neighbor and a caring friend. The drinks, dinners, talks and trips with you and Alex are very fond memories. Jos R., you are the real doctor amongst all of us! Thank you for being a good friend and an all-around nice guy. Jelle, it has been great knowing you and spending time with you and Wiebke. Chris, Sam and Verena, thank you for being awesome Dutchies. Johan and Panos, thank you for motivating me to stay fit!

A very big thank you to my friends based in Austria (Andreas, Christian, and Isabel), Finland (Eki, Pauli, and Paulina), Romania (Alex, Andrei B., Dragos, George, Vlad P., and Vlad T.), Sweden (Charlie and Niels), the UK (Dave and Mike) and the US (Jared and Pan Lei). Visiting you (as rare as that was) or having you over in Maastricht has always been a breath of fresh air! Thank you for keeping in touch and for reminding me that there is more to life than academia. Ristea and Tamasan, you are too cool for school! I look forward to our next festival together. Tudor, I look forward to the next time we go down to the river. Jan P., keep on rocking in the free world!

I feel especially indebted to my family, who has supported me unconditionally during the ups and especially the downs of my PhD. Mom and dad, thank you for believing in me and for trying your best to understand what I am doing. I know at times you could feel my frustration and the difficulties I was facing, but you kept encouraging me. I know I do not say it very often, but that really helped a lot! Thank you for your patience and optimism, for your love and for providing support when I needed it most. Adrian and Mona, thank you for your care, friendship and guidance over the years. I would not be so passionate about my work if you had not taken me under your wings almost a decade ago. 
Liz, I met you on the first day as a student at Maastricht University. How far we have come since then! Thank you for being such a dear friend and a monument of joy and positivity! Thank you for always speaking your mind and for being there for me at the best and at the worst of times. I feel very fortunate to be your friend! Mihnea, I have known you for half my life now! We used to share a desk when we started high school and over the years we learned more from each other than we ever learned during class. Thank you for your up-beat attitude, for always managing to lift my spirits, for being outrageously funny one moment and ridiculously deep the next. I am happy to know you have my back! I am honored and proud to have the two of you as my paranymphs!

Ile, you are the guns to my roses, the Rose to my Doctor, the Vesper to my Bond, the Monica to my Chandler. You had the heaviest weight to carry and you did a wonderful job. Thank you for all the understanding, for all the patience, and for all the love. Thank you for bringing Hemi into my life. Thank you for believing in me even long after my hope had dried out. Thank you for standing by my side even when everything was falling apart. Thank you for being a terrific person, my favorite person, my lobster. I am fortunate to have crossed paths with you again, because this would not have happened otherwise. Thank you!

To all of you I have forgotten, I am sorry and thank you!

Robert Ciuchita, Maastricht, September 2016 




\section{Table of Contents}

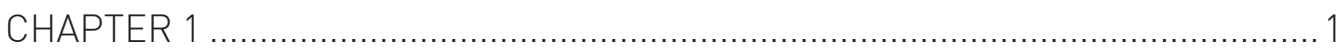

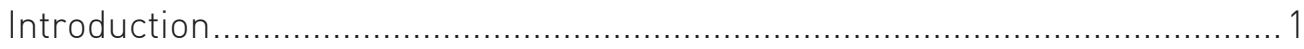

SERVICE INNOVATION AND THE DIGITAL REVOLUTION_......................... 2

DIGITAL SERVICE INNOVATION AND USER EXPERIENCE ....................... 2

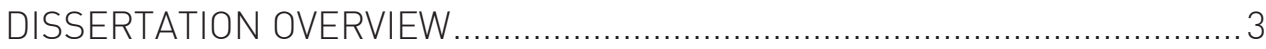

CHAPTER 2 - ENGAGEMENT WITH A NEW-TO-THE-MARKET DIGITAL

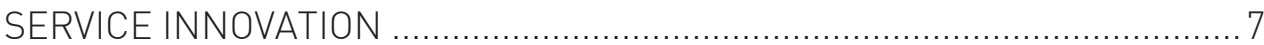

CHAPTER 3 - ENGAGEMENT WITH A SEQUENTIAL DIGITAL SERVICE INNOVATION

CHAPTER 4 - ENGAGEMENT WITH A GRADUAL DIGITAL SERVICE

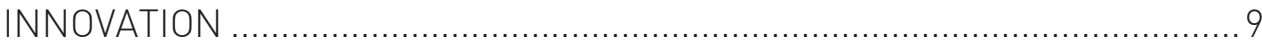

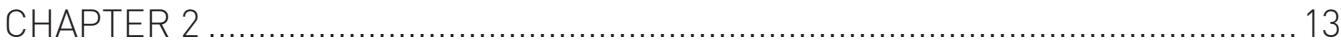

Engagement with a New-to-the-Market Digital Service Innovation............... 13

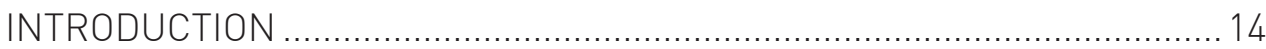

CONCEPTUAL DEVELOPMENT ............................................................ 17

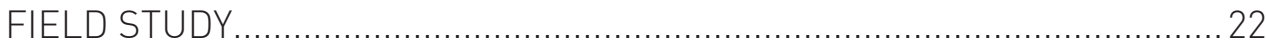

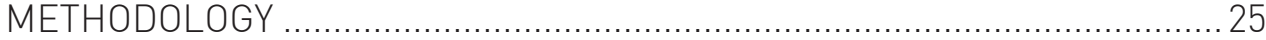

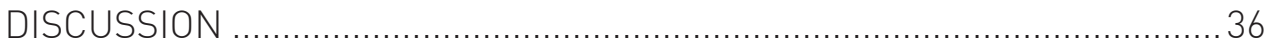

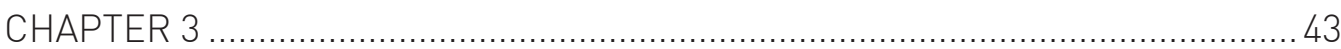

Engagement with a Sequential Digital Service Innovation................................. 43

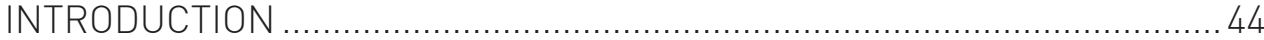

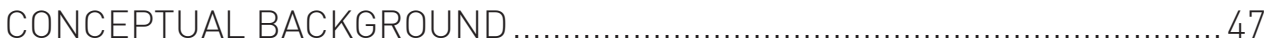

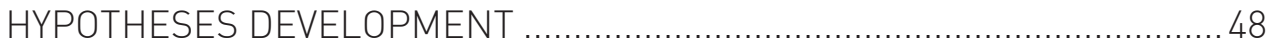

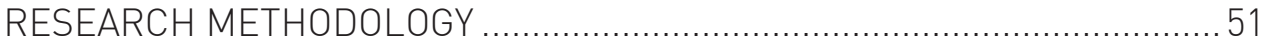

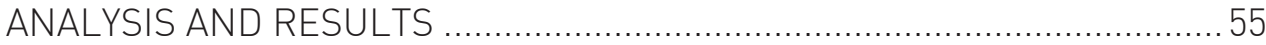

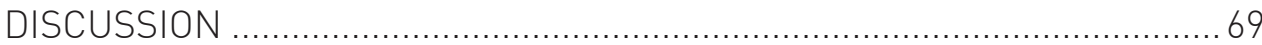




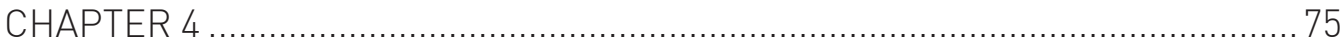

Engagement with a Gradual Digital Service Innovation ............................... 75

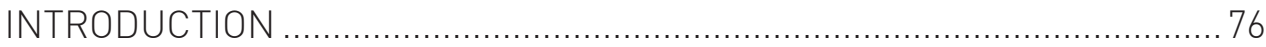

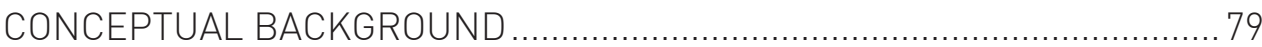

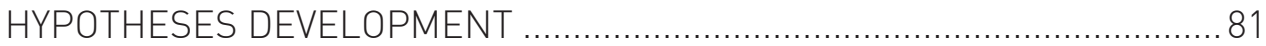

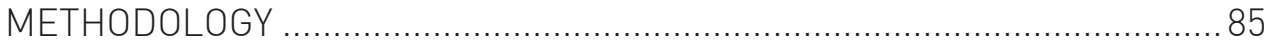

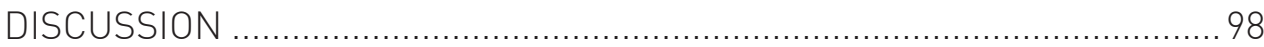

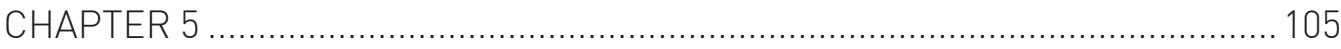

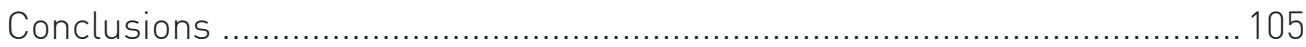

WHY USERS INTERACT WITH DIGITAL SERVICE INNOVATION............... 107

HOW USERS INTERACT WITH DIGITAL SERVICE INNOVATION ............... 108

WHAT ELEMENTS OF THE SERVICE EXPERIENCE AFFECT ENGAGEMENT

WITH DIGITAL SERVICE INNOVATION .................................................. 109

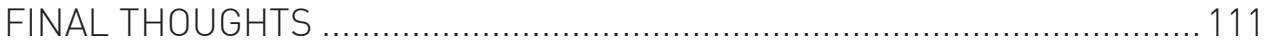

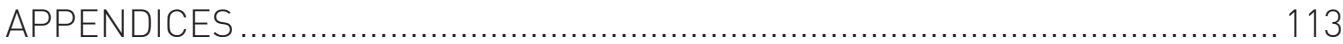

Appendix A. Chapter 4: Constructs, scale items, and scale reliability ...... 114

Appendix B. Chapter 4: Experimental study manipulations..................... 116

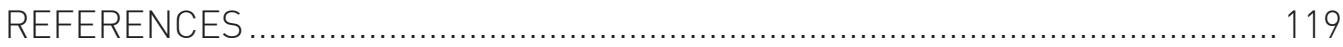

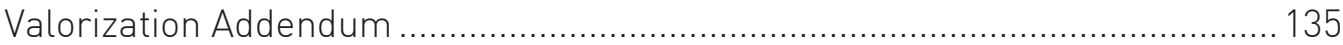

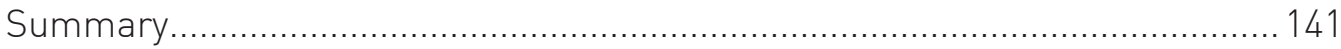

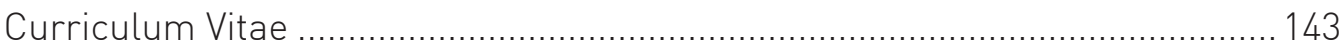






\section{List of Figures}

CHAPTER 2

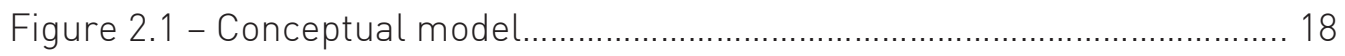

Figure 2.2 - Total amount spent during each CMP roll-out week..................... 24

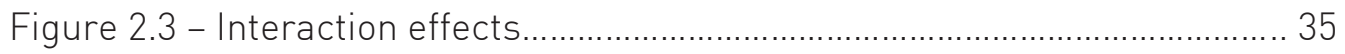

CHAPTER 3

Figure 3.1 - Individual user growth trajectories.............................................57

Figure 3.2 - Best fitting non-conditional growth model .................................. 62

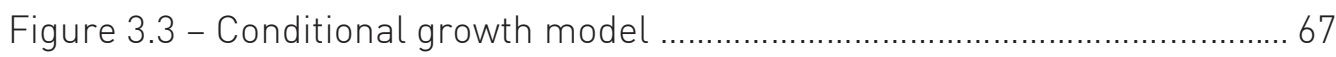

CHAPTER 4

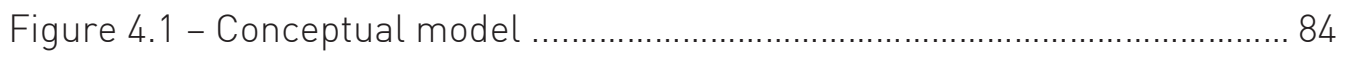

Figure 4.2 - Experimental study: Significant interaction effects........................ 96 



\section{List of Tables}

CHAPTER 1

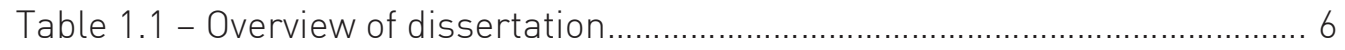

CHAPTER 2

Table 2.1 - Overview of variable measures and operationalizations.................. 26

Table 2.2 - Descriptive statistics and correlations............................................ 30

Table 2.3 - Overview of SUR equations............................................................... 31

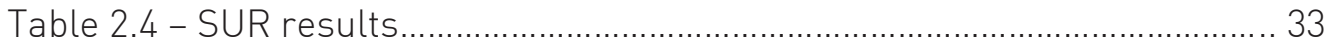

CHAPTER 3

Table 3.1 - Overview of variable operationalization................................................ 54

Table 3.2 - Overview of analysis steps.............................................................. 58

Table 3.3 - Correlations and descriptive statistics............................................. 59

Table 3.4 - Step 1 growth models....................................................................... 61

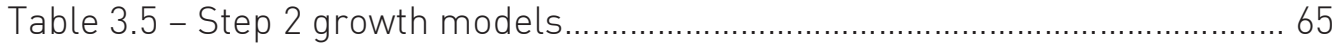

Table 3.6 - Step 3 growth models...................................................................... 68

CHAPTER 4

Table 4.1 - Field study: Descriptive statistics and correlations........................ 87

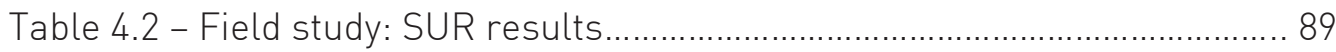

Table 4.3 - Experimental study: Descriptive statistics and correlations.......... 94

Table 4.4 - Experimental study: SUR results................................................... 95

CHAPTER 5

Table 5.1 - Overview of dissertation conclusions........................................... 106 



\section{CHAPTER 1}

\section{Introduction}

"Q: My complexion is hardly relevant.

James Bond: Your competence is.

$Q$ : Age is no guarantee of efficiency.

James Bond: And youth is no guarantee of innovation.

Q: Well, I'll hazard I can do more damage on my laptop sitting in my pajamas before my first cup of Earl Grey than you can do in a year in the field."

(Skyfall, 2012) 


\section{SERVICE INNOVATION AND THE DIGITAL REVOLUTION}

Developing service innovation (i.e., introducing new service offerings, or renewing existing service offerings; Snyder et al. 2016) is a top strategic priority for managers as it allows companies to stay competitive (Bettencourt, Brown, and Sirianni 2013) and can drive firm success and economic growth across industries (Thomson Reuters 2016) and countries (Jaruzelski, Schwartz, and Stack 2015). A recent survey of senior executives from a wide variety of industries and regions reveals that more than half the respondents think that developing new services or extending existing services will have the most impact on their industry over the next five years (BCG 2015). Reflecting the managerial relevance of this phenomenon, stimulating and managing service innovation have been recognized as key research priorities across disciplines including marketing (e.g., MSI 2016), information systems (e.g., Barrett et al. 2015), service research (e.g., Ostrom et al. 2015) and innovation management (e.g., O'Cass and Wetzels 2016).

Service innovation is empowered by digitalization - employing information and communication technology (ICT) to bring together physical and digital elements and create new experiences for users (Nylén and Holmström 2015; Yoo, Henfridsson and Lyytinen 2010). Digital services (sometimes referred to as technology-based or interactive services; Bolton and Saxena-lyer 2009) have flourished over the past decade with the proliferation of the Internet and communication platforms (e.g., cloud storage, social media), as well as the increased availability of faster and cheaper mobile communication devices (e.g., smartphones, tablets, wearables) (Rust and Huang 2014). Hence, analysts claim that we are in the midst of a "digital revolution" and predict that $25 \%$ of the world's economy will be digital by 2020, up from 15\% in 2005 (Accenture 2016). Consequently, the majority of top executives have high expectations for the influence of digital innovation on their companies' revenues and profitability (McKinsey \& Company 2015).

\section{DIGITAL SERVICE INNOVATION AND USER EXPERIENCE}

While an important strategic asset for companies, digital service innovation has important consequences for consumers (i.e., the users of digital services) since it introduces changes in user needs and behavior thus influencing the user experience (Accenture 2016). Both managerial (e.g., D'Emidio, Dorton and Duncan 2015) and conceptual work (e.g., Nylén and Holmström 2015) has 
pointed out that while digitalization permits service providers to introduce innovations at a faster pace with the aim of improving the user experience (i.e., the consumer's interaction with the digital service; De Keyser et al. 2015) its consequences for users are mixed. Faced with more frequent digital service innovation, users have to invest resources (e.g., time, effort, money etc.) to learn how to use the innovated services (Moeller et al. 2013), but such investments do not necessarily imply that they continue using the innovations in the long-run (e.g., because they do not find them valuable, or because they find better offers). To exemplify, while users may purchase smartphone applications lapps - a typical example of digital services) and invest time and effort learning how to use them, soon after download one third of users stop using installed apps or even uninstall them because of lost interest (Google 2015). Thus, maintaining user engagement with digital service innovation has become a top value-driving priority for managers across industries (McKinsey \& Company 2015) as it can drive consumer lifetime, referral, influencer and knowledge value (Kumar et al. 2010), ultimately leading to increased revenues and profitability (Dotzel, Shankar and Berry 2013). These managerial necessities have been mirrored by multiple recent calls for research (e.g., Barrett et al. 2015; MSI 2016; O'Cass and Wetzels 2016; Ostrom et al. 2015) emphasizing the need to better understand why and how users interact with digital service innovation and what elements of the resulting service experience affect their (long-term) engagement with the service (i.e., how they continue using the service, what they think and what they feel about it; Brodie et al. 2011). In this dissertation I aim to address these three research questions through a series of empirical studies described in chapters 2, 3 and 4 respectively (see Table 1.1 for an overview).

\section{DISSERTATION OVERVIEW}

In this dissertation I take the perspective of consumers as actual (not hypothetical) users of digital services. I examine consumers (not employees) as users of digital services because consumers ultimately decide the market success of most innovations (Bettencourt, Brown, and Sirianni 2013). Nevertheless, research has taken a predominantly organizational perspective focusing either on key firm-based drivers of successful new services le.g., Storey et al. 2015), or on what determines employees to adopt innovations (e.g., Venkatesh, Thong, and Xu 2012). 
In each chapter of my dissertation I leverage commonalities and differences in service innovation characteristics (Snyder et al. 2016) by analyzing how users interact with diverse types of digital service innovation: contactless mobile payment (CMP) in Chapter 2, multiplayer video gaming in Chapter 3 and online socialization in Chapter 4. These three contexts are representative for digital service innovation and reflect current, relevant themes in the discussion on how to drive user engagement (Ostrom et al. 2015). More specifically, CMP is a service that provides a new in-store experience for users, but has not yet taken off because of low engagement rates (Euromonitor International 2015); multiplayer video gaming is one of the fastest growing experiential digital service industries, but it is plagued by decreasing user engagement soon after the introduction of new titles in existing franchises (Marchand and HennigThurau 2013); online socialization platforms are constantly evolving digital services, but they struggle to improve their users' experience and maintain user engagement in the long-run (Pew Research Center 2015). Therefore, by analyzing these three rich contexts I aim to achieve a broader and deeper understanding of user engagement with digital service innovation.

Each chapter of my dissertation explores different facets of user engagement with a digital service (Brodie et al. 2010; van Doorn et al. 2010) from affective le.g., the positive affect stemming from the user experience or user passion for the innovation) to cognitive (e.g., the user's evaluation of the experience with the digital service or the perceived usefulness of the digital service) and behavioral (e.g., average time or amount spent) engagement.

The digital service innovations investigated in each chapter vary in (1) the degree of change brought to the user experience, (2) means of provision and (3) functionality (see Table 1.1). Relating to the degree of change, in Chapter 2 I focus on a introducing a new digital service, while in Chapters 3 and $4 \mathrm{I}$ focus on introducing different types of innovation in existing digital services (Heath et al. 2015). Hence, in Chapter 2 I examine CMP, a new-to-the-market service le.g., Evanschitzky et al. 2015) that allows users to pay with smartphones instead of cash or bank cards in retail locations. In Chapter 3 I zoom in on a new version of a video game, i.e., a sequential digital service innovation in an existing franchise. In Chapter $4 \mathrm{I}$ analyze an updated version of an online socialization platform, i.e., a gradual digital service innovation that introduces new features to an existing service. Therefore, my dissertation mirrors the market reality 
where most innovations launched are new versions or improvements of existing services, while some are completely new services (Storey et al. 2015).

Relating to the means of provision the digital service innovation in Chapter 2 requires user presence in brick-and-mortar locations, while the innovations in Chapters 3 and 4 are both delivered online. An Internet connection is sufficient to access the digital service in Chapter 4, whereas the digital services in Chapters 2 and 3 are contingent on additional ICT investment la specific type of smartphone and a video game console respectively). Furthermore, while CMP and online socialization are virtually free services, video gaming users have to purchase each new video game title.

Finally, the digital service innovations in each chapter also differ in terms of their functionality (Gill 2008): in Chapter 2 I discuss a predominantly utilitarian service (i.e., CMP), in Chapter 3 I refer to a predominantly hedonic service (i.e., multiplayer video gamingl and in Chapter 4 I examine a mixed-functionality service (i.e., online socialization).

In terms of data and analysis, in each chapter I employ different data collection methods (from field and experimental studies to analyzing archival data), with different temporal perspectives (longitudinal or cross-sectional) and different analysis methods (systems of regressions or latent curve models) with the aim of assessing external validity (Lynch 1999). 
Table 1.1 - Overview of dissertation

\begin{tabular}{|c|c|c|c|}
\hline & Chapter 2 & Chapter 3 & Chapter 4 \\
\hline \multicolumn{4}{|l|}{ Background } \\
\hline Goal & $\begin{array}{l}\text { Determine how users } \\
\text { of a new service } \\
\text { develop habitual } \\
\text { usage behaviors }\end{array}$ & $\begin{array}{l}\text { Determine how user } \\
\text { engagement with a } \\
\text { new service iteration } \\
\text { develops over time }\end{array}$ & $\begin{array}{l}\text { Determine how } \\
\text { users of an existing } \\
\text { service deal with } \\
\text { changes in the user } \\
\text { experience brought } \\
\text { by new features }\end{array}$ \\
\hline Context & $\begin{array}{l}\text { Contactless mobile } \\
\text { payment (CMP) }\end{array}$ & $\begin{array}{l}\text { Multiplayer video } \\
\text { gaming }\end{array}$ & Online socialization \\
\hline $\begin{array}{l}\text { Type of user } \\
\text { engagement }\end{array}$ & $\begin{array}{l}\text { Affective, cognitive } \\
\text { and behavioral }\end{array}$ & Behavioral & $\begin{array}{l}\text { Affective and } \\
\text { cognitive }\end{array}$ \\
\hline $\begin{array}{l}\text { Principal theoretical } \\
\text { lens }\end{array}$ & $\begin{array}{l}\text { Self-determination } \\
\text { (e.g., Deci and Ryan } \\
\text { 2000) }\end{array}$ & $\begin{array}{l}\text { Uses and } \\
\text { gratifications (e.g., } \\
\text { Katz, Blumler and } \\
\text { Gurevitch 1974) }\end{array}$ & $\begin{array}{l}\text { Appraisal and } \\
\text { coping (e.g., Lazarus } \\
\text { and Folkman 1984) }\end{array}$ \\
\hline \multicolumn{4}{|c|}{ Digital service innovation characteristics } \\
\hline $\begin{array}{l}\text { Degree of change } \\
\text { brought to user } \\
\text { experience }\end{array}$ & $\begin{array}{l}\text { New-to-the-market } \\
\text { service }\end{array}$ & $\begin{array}{l}\text { Sequential (new } \\
\text { version of an existing } \\
\text { service) }\end{array}$ & $\begin{array}{l}\text { Gradual (new } \\
\text { features in an } \\
\text { existing service) }\end{array}$ \\
\hline Means of provision & $\begin{array}{l}\text { Technology-enabled } \\
\text { ecosystem (NFC-near } \\
\text { field communication) } \\
\text { in brick-and-mortar } \\
\text { retail locations }\end{array}$ & $\begin{array}{l}\text { Technology-enabled } \\
\text { ecosystem (gaming } \\
\text { console and online } \\
\text { platform) via the } \\
\text { Internet }\end{array}$ & $\begin{array}{l}\text { Technology-enabled } \\
\text { ecosystem (online } \\
\text { platform) via the } \\
\text { Internet }\end{array}$ \\
\hline Functionality & $\begin{array}{l}\text { Predominantly } \\
\text { utilitarian }\end{array}$ & $\begin{array}{l}\text { Predominantly } \\
\text { hedonic }\end{array}$ & $\begin{array}{l}\text { Utilitarian and } \\
\text { hedonic }\end{array}$ \\
\hline \multicolumn{4}{|l|}{ Data and analysis } \\
\hline Data collection & Field study & $\begin{array}{l}\text { Telemetry (archival } \\
\text { data) }\end{array}$ & $\begin{array}{l}\text { Field study and } \\
\text { experimental study }\end{array}$ \\
\hline Participants & 695 users & 879 users & 140 and 109 users \\
\hline Data type & $\begin{array}{l}\text { Objective lusage } \\
\text { behavior) and } \\
\text { subjective ( } 2 \text { online } \\
\text { surveys) }\end{array}$ & $\begin{array}{l}\text { Objective lusage } \\
\text { behavior) }\end{array}$ & $\begin{array}{l}\text { Subjective ( } 2 \text { online } \\
\text { surveys) }\end{array}$ \\
\hline $\begin{array}{l}\text { Temporal } \\
\text { perspective }\end{array}$ & $\begin{array}{l}\text { Longitudinal (17 } \\
\text { weeks after } \\
\text { introduction) }\end{array}$ & $\begin{array}{l}\text { Longitudinal (4 } \\
\text { weeks after } \\
\text { introduction and one } \\
\text { year later) }\end{array}$ & Cross-sectional \\
\hline Methodology & $\begin{array}{l}\text { Seemingly unrelated } \\
\text { regressions (SUR) }\end{array}$ & $\begin{array}{l}\text { Growth curve } \\
\text { modeling } \\
\text { (GCM) }\end{array}$ & $\begin{array}{l}\text { Seemingly unrelated } \\
\text { regressions (SUR) }\end{array}$ \\
\hline
\end{tabular}


INTRODUCTION

\section{CHAPTER 2 - ENGAGEMENT WITH A NEW-TO-THE-MARKET DIGITAL SERVICE}

\section{INNOVATION}

This chapter focuses on CMP, one of the most promising digital service innovations of this decade (Deloitte 2015). CMP allows consumers to use their smartphones to make payments in stores, and is expected to exceed US\$1 trillion in payments over 2014-2019 and revolutionize brick-and-mortar retail experiences (Euromonitor International 2015). However, its use requires a complex service ecosystem and though consumers initially seem enthusiastic, they often fail to develop stable, automatic usage routines. This chapter argues that developing stable habitual behaviors is an effective lock-in mechanism and can increase users' engagement with the CMP service. Hence, drawing from self-determination theory (Ryan and Deci 2000) it proposes that habitual behaviors develop with the satisfaction of the psychological needs for autonomy, competence and relatedness and have varying contextual stability (i.e., in time, location, and merchant category) due to interactions with the environment. Additionally, it posits that the developed habitual behaviors have consequences for the different facets (i.e., affective, cognitive and behavioral; Brodie et al. 2011) of consumer engagement with CMP.

To test the proposed conceptual model a combination of transaction data and two-wave survey data from 695 consumers using CMP during a 17-week field study is employed. The results reveal that satisfying users' need for competence is pivotal to the development of habitual behaviors, especially when its interplay with the other psychological needs is considered le.g., high autonomy can compensate for low competence). While habitual behavior pertaining to stability in location is essential for a positive CMP experience across all facets of consumer engagement, stability in time and merchant category show mixed results (e.g., stability in time only increases affective engagement). The positive influence of more dispersed CMP usage across locations on engagement signals the importance of developing a common perspective among the actors in the CMP ecosystem. This study extends literature on the role of habit in technology usage by providing a synergistic conceptualization of habitual behaviors as driven by intrinsic goal fulfillment and interactions with the environment; it also disentangles the effects of habitual behaviors on consumer engagement with digital services. Finally, recommendations for companies playing different roles in the CMP ecosystem, 
as well as for companies contemplating entry in the CMP ecosystem are provided.

\section{CHAPTER 3 - ENGAGEMENT WITH A SEQUENTIAL DIGITAL SERVICE}

\section{INNOVATION}

A new-to-the-market digital service innovation was examined in the previous chapter, whereas this chapter focuses on a sequential digital service innovation le.g., a new iteration of an existing offering such as a new stand-alone title in a video game franchise). Introducing new iterations in digital service can leverage existing user bases, such that users actively engage in creating the user experience (Heath et al. 2015). Yet digital service providers struggle to assess users' dynamic engagement over time, including how their behavioral engagement varies following the introduction of a new iteration (Forbes 2015). Therefore, this chapter seeks to identify empirically if a homogenous user developmental trajectory might influence subsequent user engagement and experiences. Consequently, it draws on longitudinal behavioral data on a multiplayer video game (i.e., telemetry; Bauckhage et al. 2012), one of the fastest growing and most engaging types of digital services (Marchand and Hennig-Thurau 2013). Empowered by digital service innovation the video games industry in the US has grown to a total consumer spend on gaming content of $\$ 16.5$ billion in 2015 with the average gamer's age being 35 years and $41 \%$ of gamers being female (ESA 2016). In comparison, revenues from e-book sales in the US were estimated at $\$ 6.74$ billion in 2015 (Statista 2016)

This chapter draws upon the uses-and-gratifications theory le.g., Nambisan and Baron 2007) and employs growth curve modeling (e.g., Bollen and Curran 2006) to reveal that 879 randomly selected users of an online multiplayer video game follow a common developmental trajectory during the first four weeks after the game's introduction, featuring an initially positive behavioral engagement level and negative rate of change in this engagement. These two factors enhance user engagement with the video game for a year thereafter, with some positive influences on subsequent gratification. More specifically, both the initial engagement level and the rate of change in engagement positively influence utilitarian gratification, while the initial engagement level positively influences subsequent hedonic gratification, and the rate of change in engagement positively influences social gratification. This research contributes to user engagement literature by offering a dynamic perspective and 
demonstrating how engagement and user experiences reinforce each other. For managers, it emphasizes the importance of developing user engagement after introducing new digital service iterations.

\section{CHAPTER 4 - ENGAGEMENT WITH A GRADUAL DIGITAL SERVICE INNOVATION}

A sequential digital service innovation was examined in the previous chapter, whereas this chapter focuses on a gradual digital service innovation le.g., introducing new features to an existing offering such as introducing live broadcasting on Facebook). Innovating existing digital services can help providers maintain users already engaged with their services. Companies often introduce new features to enhance users' experiences, yet the changes stemming from such innovations can have unfavorable consequences if they tax or exceed users' resources, ruin user experiences, or prompt user disengagement (Bettencourt, Brown, and Sirianni 2013). In turn, it is crucial for digital service providers to understand how users evaluate and manage changes to their user experience brought about by an innovation in an existing digital service. This chapter adopts appraisal and coping theory (Lazarus and Folkman 1984) to develop a conceptual model of how users manage digital service innovation, and then tests the model empirically in a field study and an expanded experimental study. Both studies in this chapter focus on the online socialization platform Facebook, a type of digital service prone to receiving incremental innovations at relatively short periods of time. While it usually takes a couple of years for sequential, it only takes a couple of months for gradual digital service innovation to be introduced. To exemplify, Facebook Reactions was introduced in February 2016, while Facebook Live Video was introduced in April 2016; in comparison it took three years to launch the latest version in the Halo video game franchise with Halo 4 in 2012 and Halo 5: Guardians in 2015.

This chapter draws from a field study with 140 Facebook users and an experimental study with 109 Facebook users and shows that when faced with an innovation in their online socialization platform le.g., the introduction of Facebook Timeline), users might appraise the change positively (i.e., challenge) or negatively (i.e., threat) and employ problem-focused, emotion-focused, or social support coping strategies to manage the change (Duhachek 2005). Users who employ problem-focused coping believe the innovation to be more useful; those who rely on social support or emotion-focused coping become more 
passionate about the innovated service. Finally, the complexity of the innovation (Martinsuo and Poskela 2011) acts as an important boundary condition relative to users' self-efficacy (i.e., coping resource), the coping strategies they employ, and the affective and cognitive engagement outcomes. The results detail how service providers might use digital tools to encourage users to cope with changes in the user experience brought about by innovation. 


\section{CHAPTER 2}

\section{Engagement with a New-to-the-Market Digital Service Innovation}

\section{Making a Habit of Mobile Payments: How Habitual Behaviors Affect Consumer Engagement with a New Digital Service}

"Sophina: It only takes 30 days to form a habit, and then it becomes second nature.

Oscar Grant: Who says that?

Sophina: Oprah."

(Fruitvale Station, 2013) 


\section{INTRODUCTION}

Recent reports in the business press (Rogowsky 2014) and from market analysts (Euromonitor International 2015) predict that contactless mobile payment (CMP) will revolutionize offline shopping, offering a more interactive experience for consumers and lower costs and more revenue for stores and payment providers. Deloitte (2015) thus predicts that by the end of 2015, 30-32.5 million smartphones will have been used at least once a month to make instore contactless payments, a 14-fold increase compared to 2014. A digital service ecosystem (Lusch and Nambisan 2015), CMP requires three types of actors: (1) end users (consumers with smartphones equipped for CMP), (2) supporters (stores with terminals that accept CMP), and (3) enablers (companies offering CMP terminals, smartphones or applications for payments). Companies determined to join the CMP service ecosystem include traditional payment providers such as credit card companies (e.g., VISA) and banks (e.g., HSBC), as well as retailers (e.g., Starbucks), mobile operators (e.g., Vodafone), and high-tech firms (e.g., Apple). Their recent roll-outs have triggered wide curiosity and trials among potential end users, though CMP thus far has failed to translate into a mass phenomenon or reach widespread usage (Ostrom et al. 2015).

We propose that its advancement has been limited because CMP has yet to break end users' traditional, in-store payment habits (e.g., cash, bank cards), which are frequent, require little effort, and have become automatic, unconscious choices (Aarts and Dijksterhuis 2000). If CMP instead were to become a preferred payment method, such that consumers automatically took out their smartphones to make contactless payments in stores, it would provide a powerful lock-in effect (Polites and Karahanna 2012) potentially generating consumer engagement with CMP (Ostrom et al. 2015). While the expansion of the CMP ecosystem is in the interest of all its actors (Euromonitor International 2015), CMP habitual behaviors have varying contextual stability (i.e., over time, locations, and merchant categories), with different implications for the actors involved. For example, some consumers might form a habit of using CMP to buy coffee from a store at the train station during their weekday commute li.e., across multiple points in time). The stability of this type of habitual behavior is relevant for that $\mathrm{CMP}$-supporting store, but a CMP enabler is more interested in consumers developing a stable habit of using CMP in different coffee shops (i.e., across multiple locations) and different types of stores, including 
supermarkets and hair dressers, as well as coffee shops (i.e., across multiple merchant categories). Obtaining a finer-grained view of end users' habitual behaviors, and testing what drives them, and what the consequences of developing habitual behaviors of different stability are for the entire ecosystem would offer managers a better understanding of how to more successfully rollout CMP, and digital service ecosystems in general.

Developing habitual behaviors originates in social psychology (Aarts and Dijksterhuis 2000; Wood, Tam and Witt 2005), though in recent years it has also come to the attention of information systems (IS) le.g., Limayem, Hirt, and Cheung 2007; Polites and Karahanna 2012), marketing (e.g., Liu-Thompkins and Tam 2013; Shah, Kumar, and Kim 2014), and health research (e.g., Conroy et al. 2013; Gardner and Lally 2013), as well as to that of practitioners (e.g., Eyal 2014). Though habit has been conceptualized in multiple ways (Ortiz de Guinea and Markus 2009), researchers agree that automaticity (i.e., unconscious behavior), prompted by stable contextual cues, distinguishes habit from related constructs such as convenience, inertia, or routines (Limayem, Hirt, and Cheung 2007; Liu-Thompkins and Tam 2013; Polites and Karahanna 2012). Two distinct perspectives in IS research address habit as either a behavioral tendency or mind-set (e.g., Limayem, Hirt, and Cheung 2007; Polites and Karahanna 2012; Venkatesh, Thong, and Xu 2012) or as an action or behavioral repetition (e.g., Kim 2009; Kim and Malhotra 2005; Kim, Malhotra, and Narasimhan 2005). Both perspectives have merits, and reconciling them can provide a much needed, more comprehensive understanding of habitual behaviors (Ortiz de Guinea and Markus 2009). To accomplish a synergistic conceptualization of habitual behaviors, we consider the psychological needs that motivate people to fulfill their CMP usage goals (e.g., Ryan and Deci 2000) to examine the mind-set side of habitual behaviors. We then consider the contextual stability of behaviors resulting from interactions with the environment (e.g., Liu-Thompkins and Tam 2013) to examine the behavioral repetition side of habitual behaviors. We thus conceptualize habitual behaviors as unconscious behaviors that (1) are prone to develop from the satisfaction of psychological needs for autonomy, competence, and relatedness and (2) can be characterized by time, merchant category, and location stability. This conceptualization is relevant for digital service ecosystems in which habitual behaviors depend on how consumers (e.g., CMP end users) repeatedly use the service in interaction with other actors (e.g., CMP supporters). That is, the contextual stability of CMP usage across points in time, different store 
locations, and different merchant categories determines consumers' habitual behaviors.

The aim of this article is to determine (1) how different habitual behaviors develop with CMP usage, (2) how the satisfaction of psychological needs facilitates CMP habitual behaviors, and (3) to what extent CMP habitual behaviors affect how consumers engage with CMP. To answer these research questions, we draw on data from a unique, longitudinal CMP field study in a mid-sized Western European city. During a 17-week CMP roll-out, we observed when, where, in what merchant category, and in what amount a group of 695 consumers equipped with smartphones made payments at $122 \mathrm{CMP}-$ supporting stores. These objective behavioral data were augmented with selfreported data about the extent to which consumers felt their psychological needs for motivation were met after an introductory period of CMP usage (first survey), as well as their attitudes about the CMP experience later (second survey).

By investigating these research questions, we strive to make four key contributions. First, we advance literature on the role of habitual behaviors in IS continuance (Ortiz de Guinea and Markus 2009) by conceptualizing habitual behavior as an environmental interaction (based on behavioral traits), driven by goal fulfillment (based on motivation). This synergistic approach can capture unconscious behaviors and offers a remedy against current approaches that focus on either self-reported motives or simple behavioral repetition. Second, we test our conceptualization using a longitudinal approach that combines objective and subjective data from CMP end users (i.e., consumers). The consumer focus enriches the prevalent focus in IS usage research on employees' technology usage within firms (Venkatesh, Thong, and Xu 2012). Third, we contribute to the growing field of service ecosystems in IS (Lusch and Nambisan 2015), by considering different actors and the varying implications of different types of user habitual behaviors for them. By capturing several actors jointly, we can identify their interdependencies and the key usage drivers across the entire digital service ecosystem. Fourth, we advance the developing consumer experience field (Barrett et al. 2015) by unveiling habitual behaviors as antecedents of consumer engagement and delving into its affective, cognitive and behavioral facets. The multifaceted outcome provides a finer-grained view of the beneficial and detrimental impacts of CMP habitual behaviors on 
consumer engagement while extending the application from brands to digital services as the focal object of engagement.

The remainder of this article is structured as follows: First, we elaborate on the concept of habitual behavior, from the perspectives of both social psychology and IS. Second, drawing from IS, marketing, and social psychology literature, we develop a conceptual model that describes how satisfying the psychological needs that keep people intrinsically motivated can lead to the formation of CMP habitual behaviors, which then affect consumer engagement with the CMP service. Third, we describe our field study and the variable operationalizations. Fourth, we present our analysis and results, which lead in to a discussion of our findings and their implications for theory and practice.

\section{CONCEPTUAL DEVELOPMENT}

\section{Habitual Behavior}

Habitual behaviors generally are defined as a learned form of automaticity, based on behavioral repetition in a stable context (Verplanken and Aarts 1999; Wood, Quinn, and Kashy 2002). The process of developing habitual behaviors has been established by social psychology researchers in varied contexts, such as transportation choices (Aarts and Dijksterhuis 2000), alcohol consumption (Sheeran et al. 2005), snacking (Neal, Wood, and Drolet 2013), sedentary preferences (Conroy et al. 2013), and other everyday behaviors, such as watching television or reading (Wood, Tam, and Witt 2005). Habit has come to the attention of IS research more recently, in relation to IS usage and continuance. Various studies describe habit as a self-reported behavioral tendency (i.e., intention) and highlight its positive effects for IS continuance (Limayem, Hirt, and Cheung 2007), potential to predict technology usage (Venkatesh, Thong, and Xu 2012), and role in building resistance to new system adoption (Polites and Karahanna 2012). Other studies (e.g., Kim 2009; Kim and Malhotra 2005; Kim, Malhotra, and Narasimhan 2005) take a behavioral perspective (i.e., frequency or duration of usage) and show that with usage across time, habitual behavior becomes a better predictor of future usage than behavioral intentions. With the exception of Kim (2009), these studies also rely on self-reported data. 
Ortiz de Guinea and Markus (2009) point out that IS could benefit from different conceptualizations of habit and recommend reconsidering habitual behaviors in relation to (1) fulfilling goals that were not consciously intended, as opposed to self-reported intentions, and (2) complex interactions with the environment rather than simple repetitions of behavior. Consumers experiencing CMP likely form unconscious usage goals, rather than conscious usage intentions, because of the low involvement required (Bolton and Saxena-lyer 2009). The CMP service ecosystem also features interactions with varying contextual stability between end users and the environment (Lusch and Nambisan 2015). Therefore, applying these recommendations in a CMP context seems very relevant. In the following section, we elaborate on how we conceptualize goal fulfillment and its interaction with the environment of CMP habitual behaviors, to reconcile the two major habit perspectives. In addition, we clarify how the contextual stability of habitual behaviors affects consumer engagement with the CMP service. We introduce the conceptual model in Figure 2.1.

GOAL

FULFILLMENT

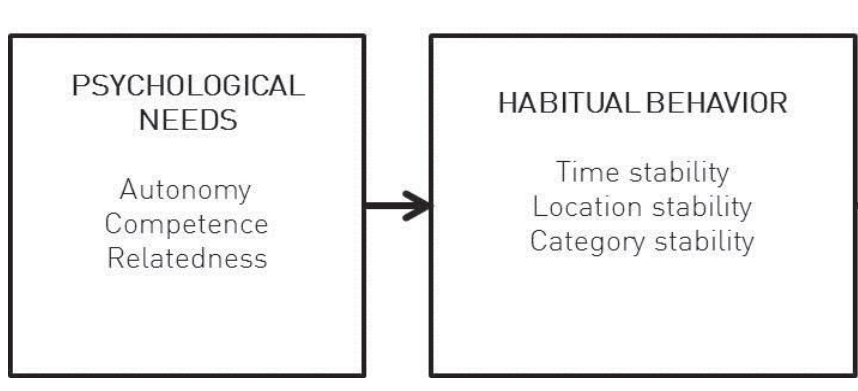

INTERACTION WITH

THE ENVIRONMENT

Figure 2.1 - Conceptual Model
ATTITUDINALAND BEHAVIORAL CONSEQUENCES

CONSUMER ENGAGEMENT WITH CMP

Affective

Cognitive

Behavioral 


\section{Goal Fulfillment}

Self-determination theory (SDT) frequently provides an explanation of individual motivations to pursue and attain goals (Deci and Ryan 2000; Ryan and Deci 2000). This theory has been employed extensively to investigate the effects of motivation on various facets of psychological well-being le.g., Deci, Koestner, and Ryan 1999; see also Burton et al. 2006), as well as applied more broadly to IS (e.g., open source software development, von Krogh et al. 2012) and marketing (e.g., consumers' creative experiences, Dahl and Moreau 2007). In essence, SDT asserts that people perform an activity because they are extrinsically motivated (to achieve a separable outcome, such as monetary rewards or avoiding punishment) or intrinsically motivated (inherent satisfaction, due to a desire to try new things and learn; Ryan and Deci 2000). We draw from SDT to capture the goal fulfillment side of CMP habitual behavior, in that consumers want to fulfill their goals of using a new digital service. We also focus on the conditions that keep consumers intrinsically motivated to achieve their CMP usage goal and develop automatic behaviors (i.e., use CMP because they are curious or because they enjoy it, but not for external rewards).

According to SDT, people are intrinsically motivated to fulfill their CMP usage goal when doing so satisfies their psychological needs for autonomy, competence, and relatedness. Autonomy is a feeling of volition and personal agency; competence refers to a sense of efficacy; and relatedness implies a feeling of social connectedness (Deci and Ryan 2000). In the CMP context, we conceptualize of autonomy as the extent to which consumers perceive that they have the opportunity to use CMP (i.e., there are sufficient supporting stores in the service ecosystem to facilitate their CMP usage goal), competence as the extent to which consumers believe they are able to use CMP (i.e., they have the necessary skills to fulfill their CMP usage goal), and relatedness as the extent to which consumers feel connected to other people through their CMP usage (i.e., they believe others would support them in fulfilling their CMP usage goal).

Ryan and Deci (2000) recommend studying the satisfaction of the psychological needs for autonomy, competence, and relatedness concomitantly; yet extant research assigns them different priority. Depending on the context, some authors focus on satisfying one (e.g., autonomy in the energy service sector, Wunderlich et al. 2013), two (e.g., autonomy and relatedness in a bottom of the 
pyramid context, Martin and Hill 2012) or all three (e.g., consumer-brand attachment, Thomson 2006) psychological needs. We aim to determine how goal fulfillment affects habitual behavior development; accordingly, we predict that satisfying psychological needs for autonomy, competence, and relatedness, both directly and in interaction with one another, influence the contextual stability of habitual behaviors.

\section{Interaction with the Environment}

Recent marketing studies that describe the development of behavioral traits with repeat purchases (e.g., DeKinder and Kohli 2008; Liu-Thompkins and Tam 2013; Shah, Kumar, and Kim 2014) provides a foundation for capturing the complex interaction with the environment side of habitual behavior. These studies do not focus on technology usage but on start-up sales growth (DeKinder and Kohli 2008), improving loyalty programs (Liu-Thompkins and Tam 2013), or making consumers more profitable (Shah et al. 2012; Shah, Kumar, and Kim 2014). Nevertheless, it is useful to extend their approach, because they employ objective, longitudinal data to describe different purchasing behaviors, with varying contextual stability, resulting from interactions with distinct types of actors (e.g., retailers, venture capitalists).

We conceptualize of CMP habitual behaviors as the contextual stability of consumers' CMP spending over time, merchant categories, and locations. Time stability is the extent to which their usage behavior fluctuates across time. Merchant category stability indicates whether their behavior is dispersed across different categories (e.g., restaurants, supermarkets, and clothing outlets). Location stability signals whether consumers' usage behavior is dispersed across different stores. Both time and location have been employed to describe contextual stability (e.g., Liu-Thompkins and Tam 2013; Wood, Tam, and Witt 2005), but stability across merchant categories also is required to describe consumers' interaction with the environment, because the CMP service ecosystem comprises an extensive, finite number of locations in many merchant categories, with varying levels of cognitive distance (Lusch and Nambisan 2015).

With this conceptualization, we can (1) observe objective CMP usage and how it develops over time, without needing to prompt consumers for their assessments (i.e., we observe habit development as an unconscious process) (Aarts and Dijksterhuis 2000) and (2) leverage the CMP service ecosystem by 
observing how consumers use CMP in interaction with specific stores that support it, in specific merchant categories (Lusch and Nambisan 2015). The latter perspective is important; some actors in the CMP ecosystem might be more inclined to prefer the development of particular behavioral traits, to the detriment of others. For example, CMP enablers might be more interested in location stability, to make a case for the success of the technology, whereas individual CMP supporters might be less interested in location stability, provided that consumers use CMP in their stores. We seek to test which types of habitual behaviors keep consumers engaged, and on what engagement facet. Therefore, we predict that the contextual stability of habitual behaviors influences the affective, cognitive and behavioral facets of consumer engagement with the CMP service differently.

\section{Consumer Engagement with the CMP Service}

Service research (e.g., van Doorn et al. 2010; Verhoef, Reinartz, and Krafft 2010) conceptualizes of consumer engagement as a behavioral manifestation, rooted in contextual interactions between consumers and service providers. Typical consumer engagement manifestations include spreading word of mouth, providing feedback, or making additional purchases. Consumer engagement is a relevant consequence of habitual behaviors, in that it originates in complex interactions between end users and other actors in the ecosystem le.g., CMP supporters). Moreover, consumer engagement helps provide a finer-grained view of the consequences of developing habitual behaviors, because it encompasses both attitudinal and behavioral facets (Hollebeek, Glynn, and Brodie 2014) and thus goes beyond related concepts such as involvement, satisfaction, or IS continuance. Finally, a recent call for research signals the need to establish what generates consumer engagement, especially in contexts that demand increased consumer participation (Ostrom et al. 2015), as in CMP service ecosystems.

By integrating extant research, Brodie et al. (2011) provide a first, comprehensive definition of consumer engagement, as a psychological state that occurs by virtue of positive interactive consumer experiences with a focal object in service relationships. Brands and organizations have been the main focus of consumer engagement, but Brodie et al. (2011) point out that products, services, and categories are equally as important in maintaining consumers engaged. Thus, we focus on consumer engagement with the CMP service li.e., 
using CMPJ and not with different actors in the CMP service ecosystem. We argue that CMP habitual behaviors precede consumer engagement with the CMP service, because they are rooted in the satisfaction of psychological needs and develop on the basis of consumers' interactive experiences with the CMP service ecosystem.

Hollebeek, Glynn, and Brodie (2014) specify that consumer engagement is subject to context-dependent manifestations of its affective (emotional), cognitive and behavioral facets; each facet can be variably influenced by antecedents and have different consequences. Therefore, we conceptualize of consumer engagement with the CMP service as having affective (positive affect stemming from the CMP experience), cognitive (rational elaboration on the CMP experience), and behavioral (usage behavior following the CMP experiencel facets. Then we capture the context-dependent antecedents of consumer engagement with the CMP service according to the time, merchant category, and location stability of habitual behaviors. We focus on these three separate facets rather than on consumer engagement as a second-order, multidimensional construct (Wetzels, Odekerken-Schröder, and van Oppen 2009) to provide a finer-grained view of the beneficial or potentially detrimental effects of habitual behaviors (e.g., beneficial for behavioral engagement but not for affective engagement).

\section{FIELD STUDY}

\section{Participants and Procedure}

The CMP roll-out was organized by a consortium of companies; it took place during the second half of 2013 in a mid-sized Western European city. The field study included 695 consumers recruited by the roll-out organizers via a marketing agency to reflect the demographic profile of the country's adult population. Thus, $50 \%$ of the participants were women, and their average age was 35.53 years $(S D=14.17)$. Furthermore, $56 \%$ of the participants were employed, $28 \%$ were students, and $4 \%$ were pensioners. More than threequarters (76\%) of the participants held at least a high school degree; $46 \%$ were not married; and $36 \%$ of the participants earned less than 2,000 € net monthly, while $17 \%$ earned more than 4,000 € monthly and $16 \%$ chose not to disclose their monthly income. Finally, though $12 \%$ of the participants had never used a smartphone before the roll-out, those with previous experience had been using 
smartphones for four years, had 34 applications installed on their phones, and used their smartphones for 114 minutes daily, on average.

At the beginning of the roll-out, each participant received the same near field communication (NFC) compatible smartphone model, on which a CMP application was previously installed. The application was connected to each participant's bank account, so the new smartphones could be used for in-store payments just like a regular debit card would (i.e., each participant could spend as much as they had in their bank accounts). To conduct a CMP, participants tapped their smartphone at the point-of-sale (POS) terminal in a participating store and typed in their preset personal identification number in the payment application for authorization.

\section{Setting}

Initially, participants were informed that they could use these smartphones for a duration of 13 weeks. For our field study, we split this period into the introduction and focus phases. The introduction comprised the first five weeks, during which participants had the opportunity to try out and become familiar with the service. At the end of the introduction period, they completed a questionnaire, in which they rated their perceptions of autonomy, competence, and relatedness for using CMP. The focus period, from weeks 6 to 13, enabled us to assess the contextual stability of participants' habitual behaviors. At the end of this period, they completed a second questionnaire and rated how engaged they felt with CMP on affective and cognitive levels. In addition, towards the end of the focus period the organizers announced that participants could continue using CMP for an additional four weeks (the supplementary period for our field study). During the 17 weeks of the field study, the 695 participants conducted 24,728 transactions, with a total value of $266,263.51 €$. Figure 2.2 depicts the CMP roll-out setting, breaking down the total CMP amount spent during each week and each of the three study periods. After the 17 weeks the participants could keep the smartphones, and the supporting stores could continue using the NFC compatible POS terminals. 


\section{Rounded total amount spent via CMP (euros)}

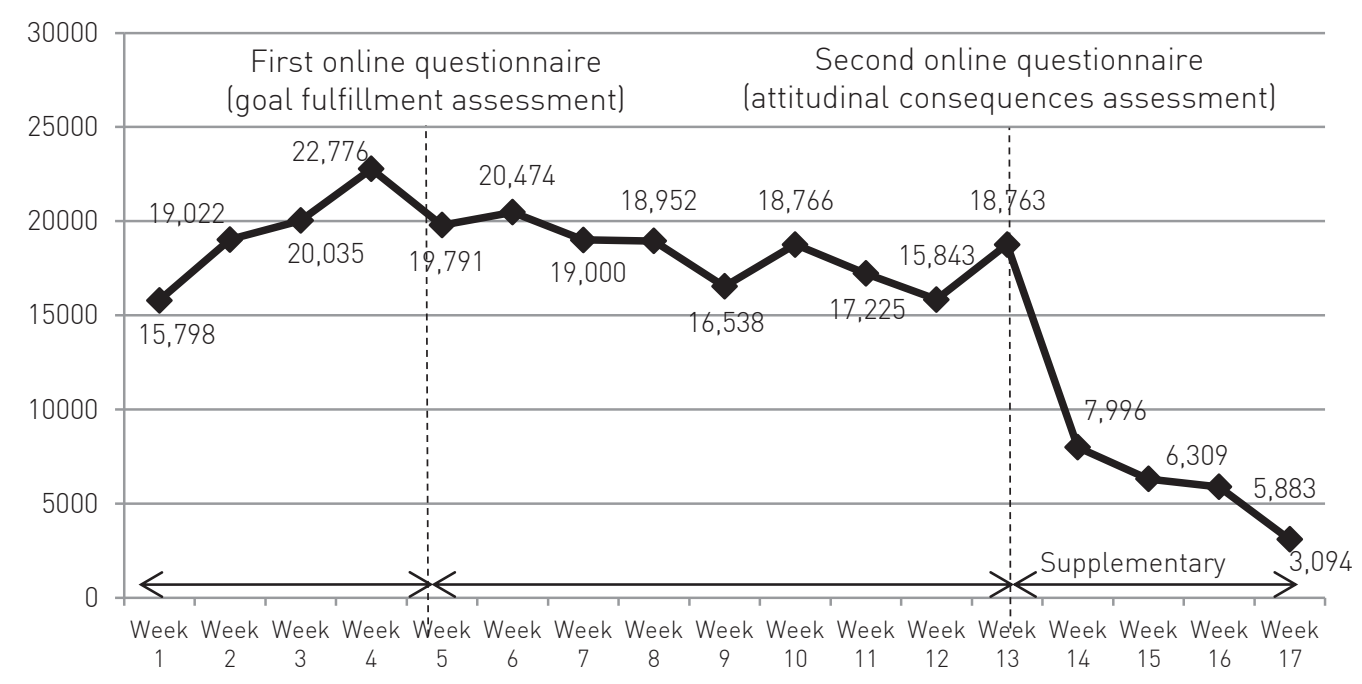

Figure 2.2 - Total amount spent during each CMP roll-out week

During the roll-out, participants could use the smartphones to make payments at any of the 122 supporting stores equipped with NFC compatible POS terminals. With their smartphone, each participant received an information package that listed all the supporting stores and their locations. Moreover, the NFC compatible POS terminal in each supporting store signaled its CMP availability on a proximal banner. Nonparticipating consumers could still use their regular bank cards to make payments at these NFC compatible terminals, but it was not possible for them to use CMP. Therefore, our data set is complete; it contains all CMP transactions conducted during the field study.

Each store supporting CMP represented one of 13 merchant categories, according to the merchant category codes assigned by the bankcard industry to classify suppliers into market segments (VISA 2014): (1) caterers, restaurants, bars; (2) charitable and social organizations; (3) discount, general merchandise stores (e.g., department stores); (4) fast-food restaurants; (5) food, daily stores, drug, liquor stores (e.g., grocery stores, supermarkets, pharmacies, convenience stores); (6) fuel dealers; (7) healthcare providers (e.g., opticians, eyeglasses); (8) legal costs, payments (e.g., government services); (9) mail, phone order businesses (e.g., direct marketing, catalog merchants); (10) miscellaneous and specialty retail stores (e.g., men, women clothing stores, stationery stores, home supply warehouse stores, hardware stores); (11) 
miscellaneous business services (e.g., publishing and printing, consulting, public relations); (12) miscellaneous personal services (e.g., health and beauty spas, barber and beauty shops); and (13) schools, educational services and day care (e.g., elementary, secondary schools). On average, over the entire roll-out period, the combined participants spent $20,654.56 €$ per category $(S D=$ 42,700.98).

\section{METHODOLOGY}

\section{Variable Operationalization}

Table 2.1 provides an overview of the variables and their measures or operationalizations. The level of satisfaction of psychological needs for autonomy, competence, and relatedness was assessed after the introduction period (first questionnaire); the affective and cognitive facets of consumer engagement were assessed after the focus period (second questionnaire). Participants should have conducted at least one CMP to be able to evaluate the extent to which their psychological needs were satisfied during the introduction period, so we removed 17 participants (2\%) who did not make any CMP during the introduction period, leaving a sample of 678 participants. On average, these 678 participants spent $143.69 €(S D=115.68)$ and conducted 12.96 transactions (SD $=7.44)$ during the introduction period, spent $209.04 €(S D=171.95)$ and conducted 20.20 transactions (SD $=9.03$ ) during the focus period, and spent $33.19 €(S D=68.31)$ and conducted 2.74 transactions $(S D=4.58)$ during the supplementary period.

To operationalize the contextual stability of the three habitual behaviors, we used each participant's CMP usage behavior during the focus period. The behavioral facet of consumer engagement reflected each participant's CMP usage during the supplementary period. A participant's CMP usage behavior was equivalent to the amount spent through CMP; each CMP produces a record of when the transaction was made, where (store location and merchant category), and in what amount (in $€$ ). We focus on consumers' absolute CMP spending, to achieve a common perspective within the service ecosystem (Lusch and Nambisan 2015). 


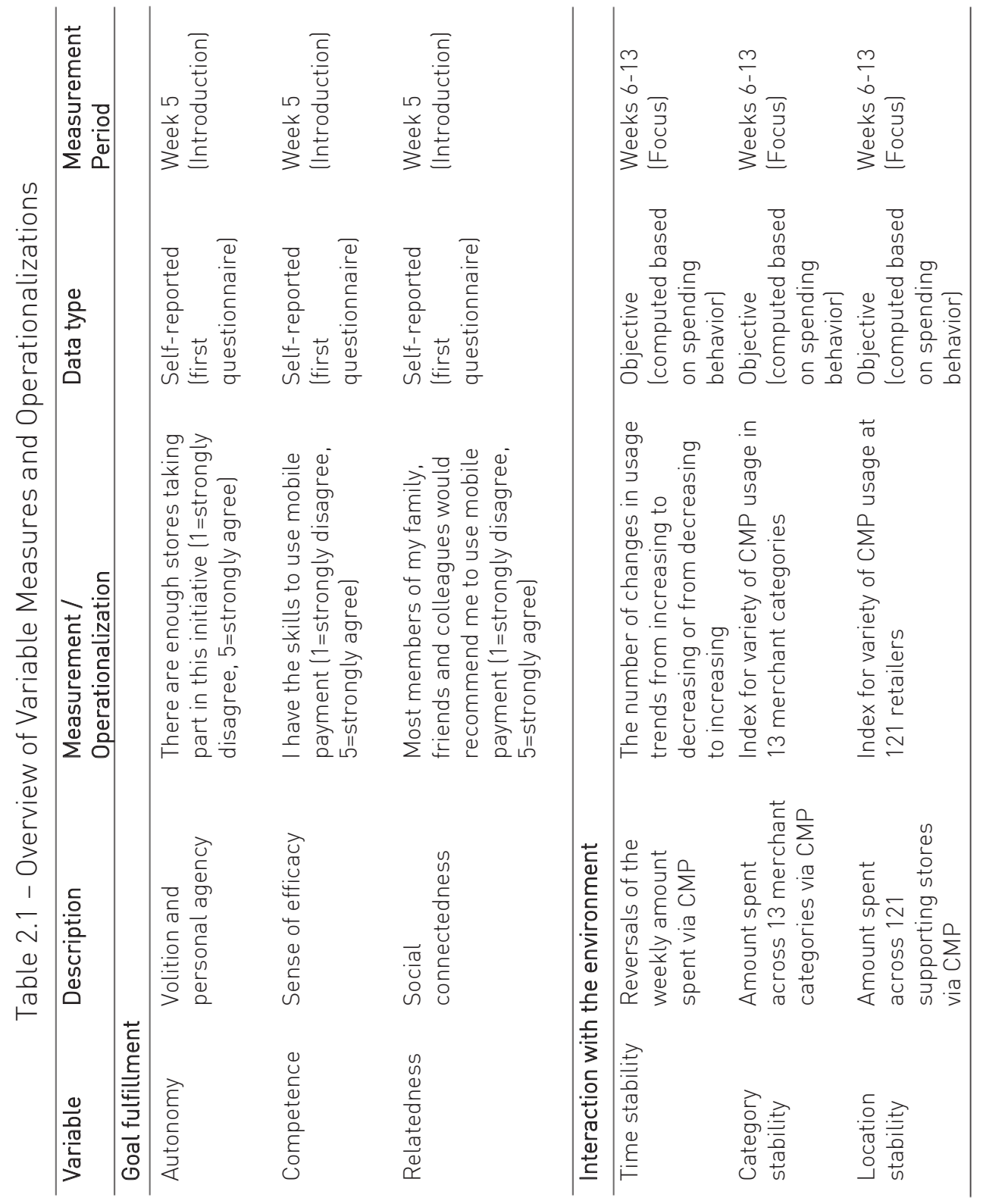




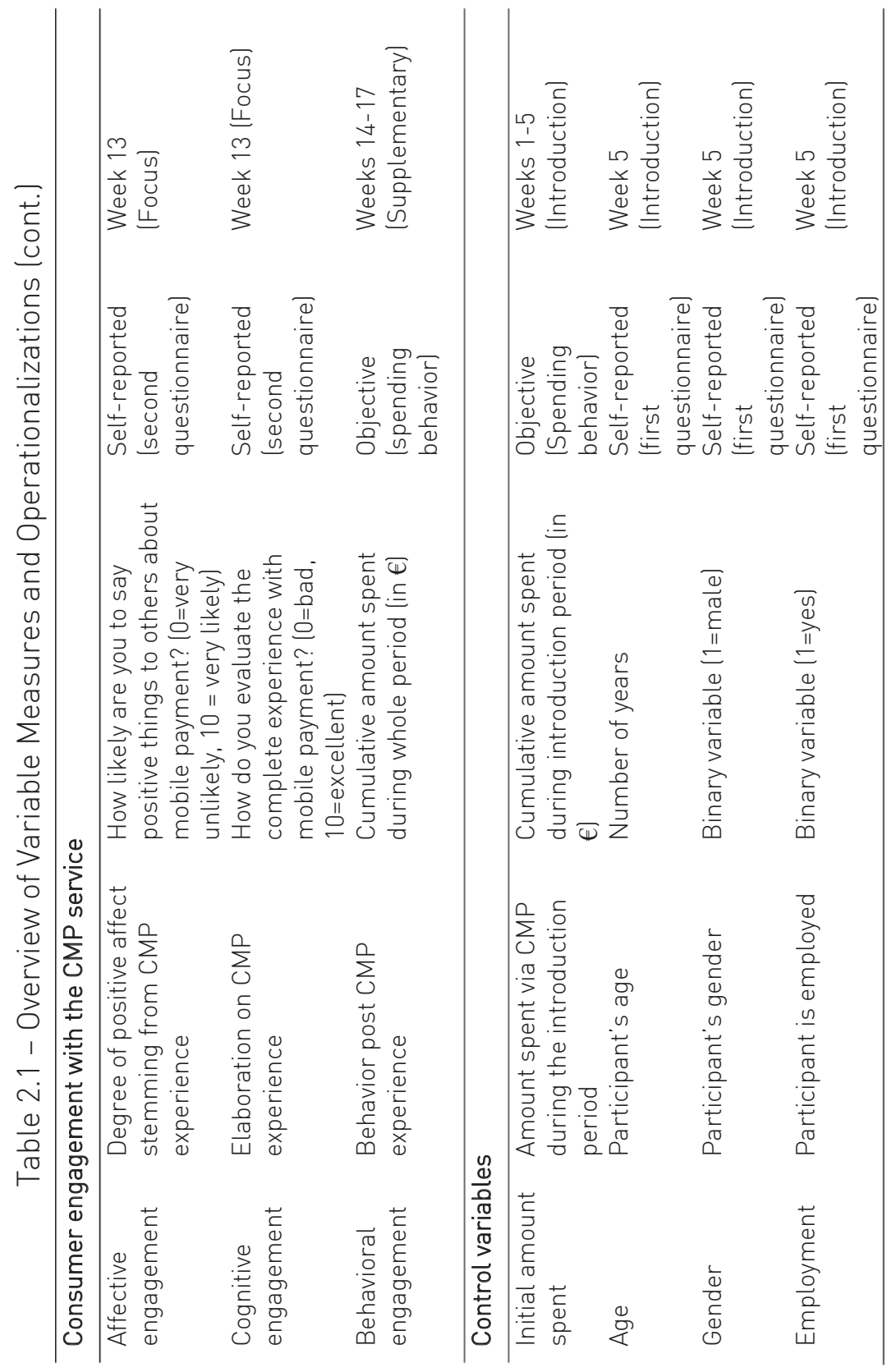


We used the amount spent during the focus period to compute indices for the contextual stability of the different habitual behaviors and thus capture participants' behavior after they experience the digital service. We avoided an overemphasis on initial peaks in usage behavior, which might reflect the novelty of the technology (Chandrasekaran and Tellis 2011). Rather, we accounted for the amount spent by each person during the introduction period as a control variable. In addition, we controlled for participants' age, gender, and employment status.

With time stability, we capture how the CMP amount spent by each participant during the focus period varied in relation to the total number of reversals in spending trends (Ludwig et al. 2014). That is, time stability reflects the number of times the CMP spending trend changed from increasing to decreasing or from decreasing to increasing (DeKinder and Kohli 2008):

$$
\text { Time stability }_{i}=6-\sum_{t=7}^{12} \text { Reversal }_{i,(t-1), t,(t+1)}
$$

where i represents each participant, and $\operatorname{Reversal}_{i,(t-1), t,(t+1)}$ is equal to 1 if the CMP amount spent by participant $i$ in week $t$ is higher than that in week $t-1$ and week $t+1$ or vice versa lamount in week $t$ is lower than in week $t-1$ and in week $t+1$ l, but 0 otherwise. The focus period spanned eight weeks, so the total number of reversals could take values between 0 and 6 . To obtain time stability, we subtracted each participant's number of reversals from the maximum possible number of reversals (i.e., reverse code), so that a time stability score of 0 indicates the maximum number of reversals during the focus period (i.e., participant's spending fluctuated each week), whereas a value of 6 indicates no reversals (participant's spending constantly grew, decreased, or stagnated during the focus period).

With merchant category stability, we capture how the CMP amount spent by each participant during the focus period was dispersed across the $13 \mathrm{CMP}$ merchant categories, using Blau's index (Harrison and Klein 2007):

$$
\text { Category stability }_{i}=1-\sum_{j=1}^{13}\left(\frac{\text { Amount }_{i, j}}{\text { Amount }_{i}}\right)^{2}
$$


where $i$ represents each participant, $j$ indicates each of the 13 CMP merchant categories, Amount $_{i, j}$ is the total CMP amount spent during the focus period by

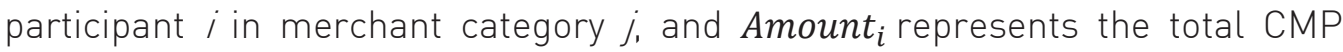
amount spent by participant $i$ during the focus period. A 0 value for location stability indicates that during the focus period, a participant conducted all CMP spending in just one merchant category, whereas category stability closer to 1 indicates a more even spread of total CMP amounts across merchant categories (e.g., restaurants, supermarkets, clothing outlets).

Finally, with location stability, we capture how the CMP amount spent by each participant during the focus period dispersed across the stores supporting CMP, again using Blau's index (Harrison and Klein 2007):

$$
\text { Location stability }_{i}=1-\sum_{k=1}^{121}\left(\frac{\text { Amount }_{i, k}}{\text { Amount }_{i}}\right)^{2}
$$

where $i$ represents each participant, $k$ represents each of the 121 supporting stores, ${ }^{1}$ Amount $_{i, k}$ is the total CMP amount spent by participant $i$ at store $k$ during the focus period, and Amount $t_{i}$ is the total CMP amount spent by participant $i$ during the focus period. If location stability is 0 , a participant used CMP in only one supporting store, but if location stability is closer to 1 , it indicates a more even spread of the total CMP amount across supporting stores.

\footnotetext{
1 We used 121, not 122, supporting stores for this calculation, because one of the stores was not visited by any participants during the focus period.
} 


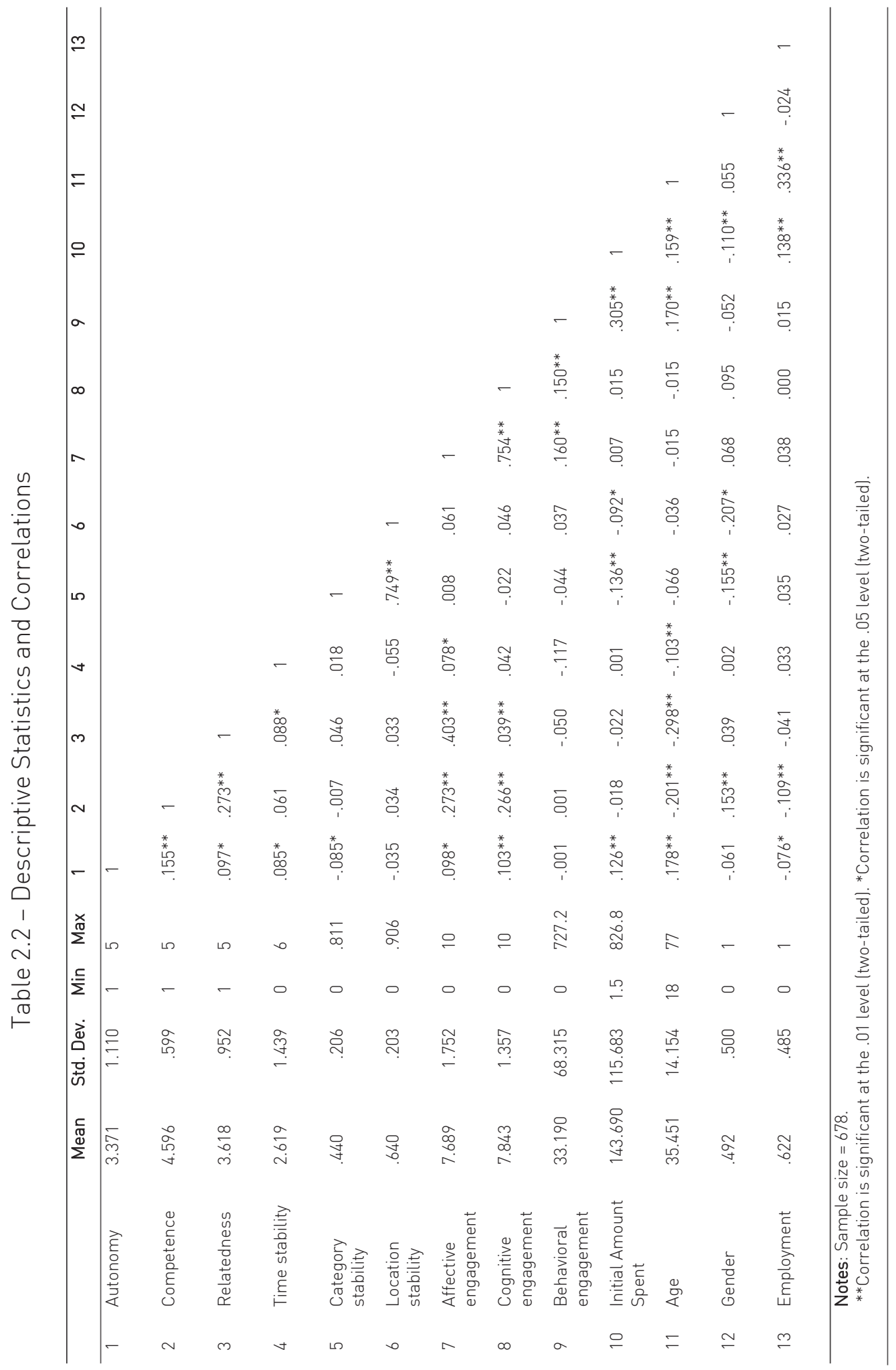


Table 2.2 provides an overview of the descriptive statistics and correlations between the variables. For each participant i, we estimate the conceptual model using seemingly unrelated regression (SUR) (Zellner 1962), with a system of six equations (see Table 2.3 and the equations below). Three of the equations include time, category, and location stability as dependent variables and one set of 10 regressors (i.e., three SDT variables and their three interactions and initial amount spent, age, gender, and employment as control variables); the other three equations have affective, cognitive, and behavioral engagement as dependent variables and a second set of 7 regressors (three habitual behaviors and the four control variables). This method is preferable to ordinary least squares (OLS) regression, because the error terms correlate across the six equations, as indicated by the Breusch-Pagan-Lagrange multiplier test for error independence $\left(\chi^{2}(15)=790.546 ; \quad p \leftarrow\right.$.001). Furthermore, the $\mathrm{R}^{2}$ for each individual equation is statistically significant at minimum $p<=.01$. Hence, we can conclude that using SUR is appropriate (Cameron and Trivedi 2009).

Table 2.3 - Overview of SUR Equations

\begin{tabular}{ccccc}
\hline Equation & $\begin{array}{c}\text { Number of } \\
\text { parameters }\end{array}$ & $\mathrm{R}^{2}$ & $\chi^{2}$ & $\mathrm{p}$ \\
\hline (1) & 10 & .032 & 23.110 & .010 \\
$(2)$ & 10 & .069 & 50.060 & .000 \\
$(3)$ & 10 & .077 & 57.200 & .000 \\
$(4)$ & 7 & .023 & 22.540 & .002 \\
$(5)$ & 7 & .131 & 102.350 & .000 \\
$(6)$ & 7 & .024 & 22.280 & .002 \\
\hline Notes: Sample size $=$ & 678. & Breusch-Pagan test of independence: $\chi^{2}(15)=790.546, p=$ \\
.000. &
\end{tabular}


(1) Time stability $_{i}$

$$
\begin{aligned}
& =\beta_{10}+\beta_{11} * \text { Autonomy }_{i}+\beta_{12} * \text { Competence }_{i}+\beta_{13} \\
& * \text { Relatedness }_{i}+\beta_{14} * \text { Autonomy }_{i} * \text { Competence }_{i}+\beta_{15} \\
& * \text { Relatedness }_{i} * \text { Competence }_{i}+\beta_{16} * \text { Autonomy }_{i} * \text { Relatedness }_{i} \\
& +\beta_{17} * \text { Initial amount spent }_{i}+\beta_{18} * \text { Age }_{i}+\beta_{19} * \text { Gender }_{i} \\
& +\beta_{110} * \text { Employment }_{i}+\delta_{1}
\end{aligned}
$$

(2) Category stability

$$
\begin{aligned}
& =\beta_{20}+\beta_{21} * \text { Autonomy }_{i}+\beta_{22} * \text { Competence }_{i}+\beta_{23} \\
& * \text { Relatedness }_{i}+\beta_{24} * \text { Autonomy }_{i} * \text { Competenc }_{i}+\beta_{25} \\
& * \text { Relatedness }_{i} * \text { Competence }_{i}+\beta_{26} * \text { Autonomy }_{i} * \text { Relatednes }_{i} \\
& +\beta_{27} * \text { Initial amount spent }_{i}+\beta_{28} * \text { Age }_{i}+\beta_{29} * \text { Gender }_{i} \\
& +\beta_{210} * \text { Employment }_{i}+\delta_{2}
\end{aligned}
$$

(3) Location stability

$$
\begin{aligned}
& =\beta_{30}+\beta_{31} * \text { Autonomy }_{i}+\beta_{32} * \text { Competence }_{i}+\beta_{33} \\
& * \text { Relatedness }_{i}+\beta_{34} * \text { Autonomy }_{i} * \text { Competence }_{i}+\beta_{35} \\
& * \text { Relatedness }_{i} * \text { Competence }_{i}+\beta_{36} * \text { Autonomy }_{i} * \text { Relatedness }_{i} \\
& +\beta_{37} * \text { Initial amount spent }_{i}+\beta_{38} * \text { Age }_{i}+\beta_{39} * \text { Gender }_{i} \\
& +\beta_{310} * \text { Employment }_{i}+\delta_{3}
\end{aligned}
$$

(4) Affective engagement ${ }_{i}$

$$
\begin{aligned}
& =\beta_{40}+\beta_{41} * \text { Time stability }_{i}+\beta_{42} * \text { Category stability } \text { Sim }_{i}+\beta_{43} \\
& * \text { Location stability }_{i}+\beta_{44} * \text { Initial amount spent }{ }_{i}+\beta_{45} * A g e_{i} \\
& +\beta_{46} * \text { Gender }_{i}+\beta_{47} * \text { Employment }_{i}+\delta_{4}
\end{aligned}
$$

(5) Cognitive engagement ${ }_{i}$

$$
\begin{aligned}
& =\beta_{50}+\beta_{51} * \text { Time stability }_{i}+\beta_{52} * \text { Category stability } i+\beta_{53} \\
& * \text { Location stability }_{i}+\beta_{54} * \text { Initial amount spent }_{i}+\beta_{55} * \text { Age }_{i} \\
& +\beta_{56} * \text { Gender }_{i}+\beta_{57} * \text { Employment }_{i}+\delta_{5}
\end{aligned}
$$

(6) Behavioral engagement ${ }_{i}$

$$
\begin{aligned}
& =\beta_{60}+\beta_{61} * \text { Time stability }_{i}+\beta_{62} * \text { Category stability } i+\beta_{63} \\
& * \text { Location stability }_{i}+\beta_{64} * \text { Initial amount spent }_{i}+\beta_{65} * \text { Age }_{i} \\
& +\beta_{66} * \text { Gender }_{i}+\beta_{67} * \text { Employment }_{i}+\delta_{6}
\end{aligned}
$$




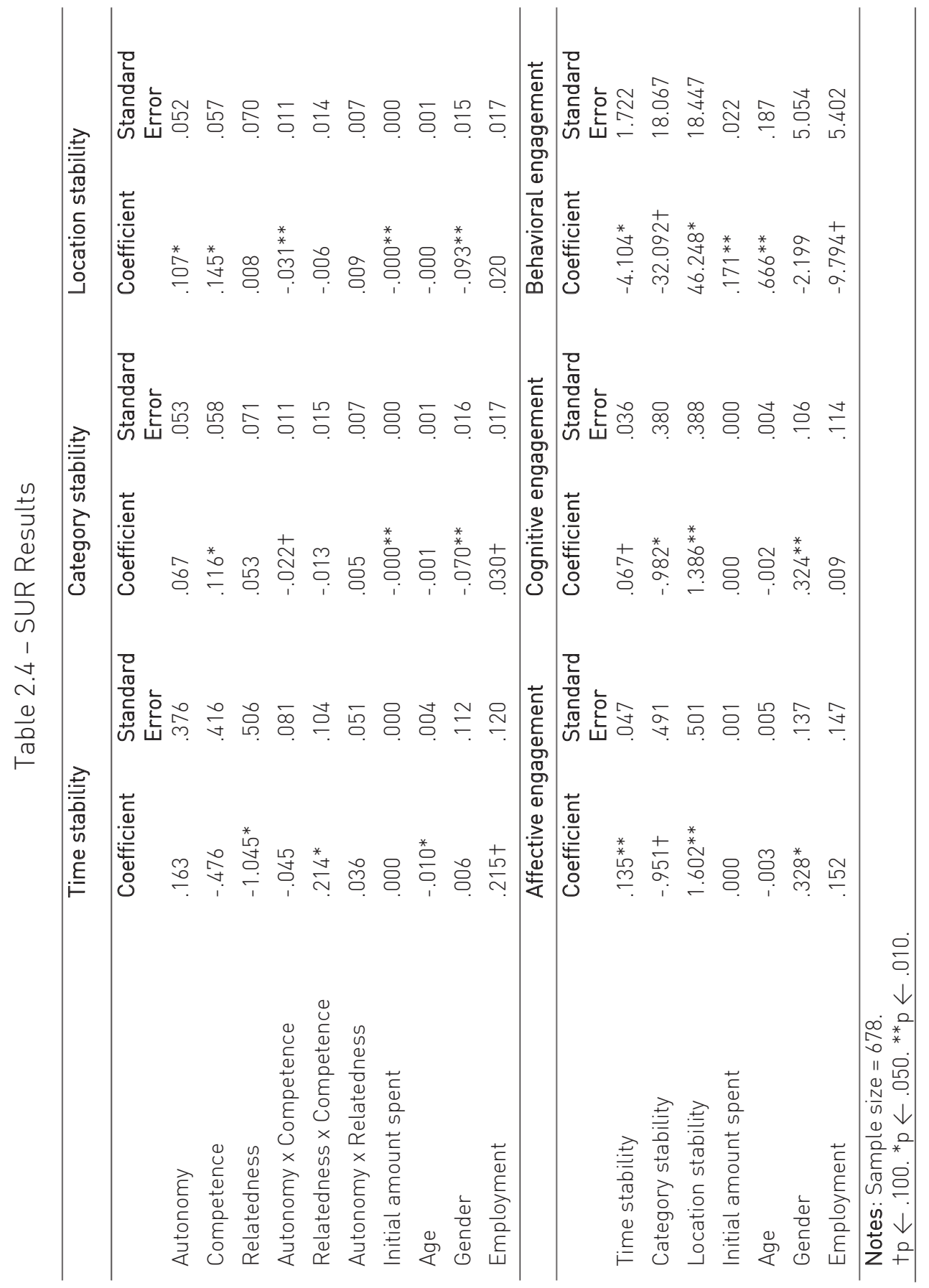


Results

The coefficients obtained with the SUR estimator ${ }^{2}$ (sureg command) in STATA 12.0 are in Table 2.4. Satisfying the psychological need for autonomy has a positive effect on location stability $(p \leftarrow$.05). The more participants think the stores supporting CMP are sufficient, the more dispersed their CMP usage becomes across the supporting stores during the focus period. Satisfying the psychological need for competence positively affects both category $(p<.05)$ and location $(p<.05)$ stability. The more participants believe they have the ability to use CMP, the more dispersed their CMP usage is across merchant categories and supporting stores during the focus period. Finally, satisfying the psychological need for relatedness negatively affects time stability $(p<.05)$, so the more participants believe it is important what others think about their CMP usage, the more fluctuation we find in their CMP usage during the focus period.

The results also indicate two significant interaction effects, related to the satisfaction of psychological needs, with consequences for the contextual stability of habitual behaviors. We explore these interactions by deriving Johnson-Neyman significance regions at the .05 level, based on OLS with asymptotic standard errors ${ }^{3}$ (Hayes and Matthes 2009), as depicted in Figure 2.3. First, competence interacts with relatedness, with a positive coefficient on time stability $(p \leftarrow .05$, Panel A, Figure 2.3). The Johnson-Neyman significance region, starting at competence levels of 4.997, indicates that the interaction effect is significant when participants have high perceptions of both competence and relatedness. Thus, participants who feel very competent with CMP exhibit fewer reversals in the amount spent via CMP when they also believe that others' perceptions of their CMP usage are important. Second, competence interacts with autonomy, with a negative coefficient on location stability $(p \leftarrow .01$; Panel B, Figure 2.3). The analysis yields two JohnsonNeyman points, at 3.093 and 4.851, which delineate two Johnson-Neyman significance regions. Participants who think they have low to medium CMP

2 If we estimate the system of equations with robust standard errors through bootstrapping and with 5000 repetitions, the significance levels persist.

3 The interaction coefficients in Figure 2.3 differ slightly from those in Table 2.4, because we used MODPROBE 2.0 (Hayes and Matthes 2009) to determine the JohnsonNeyman points for each separate effect, based on OLS regression. 
competence (3.093 or lower) thus exhibit more location-stable habitual behaviors when they perceive that enough stores support CMP. However, participants who regard themselves as very competent with CMP (4.851 or higher) show more dispersed spending across stores when they believe there are not enough stores supporting CMP.

Panel A: Dependent variable: Time stability. Moderator value defining nonsimultaneous Johnson-Neyman significance region 4.997; interaction coefficient. $220, p=.034$

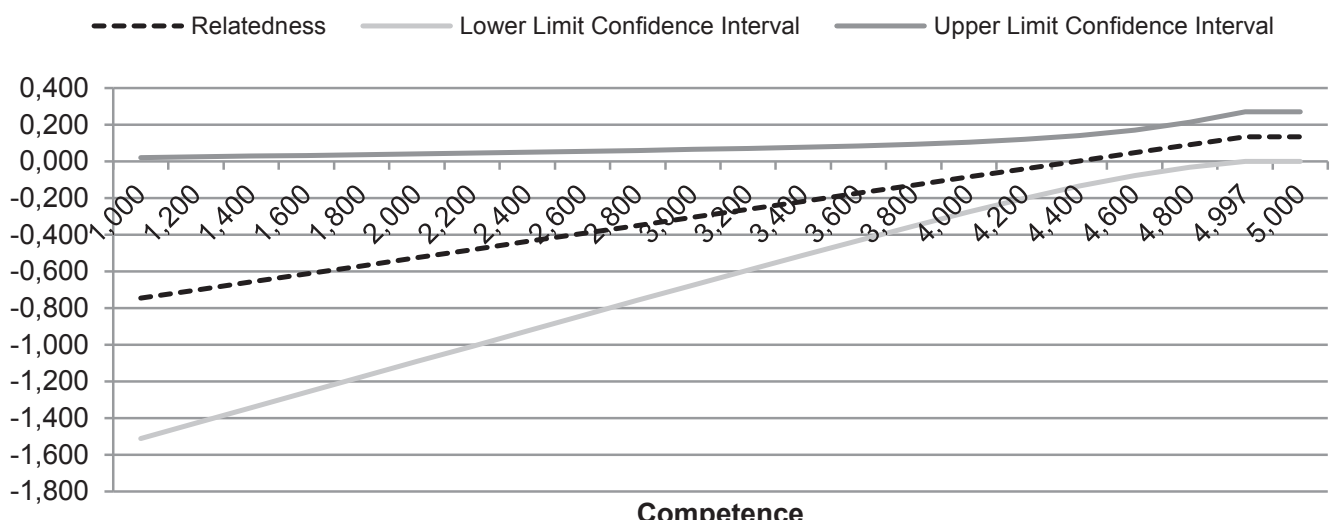

\section{Competence}

Panel B: Dependent variable: Location stability. Moderator values defining nonsimultaneous Johnson-Neyman significance regions 3.093 and 4.851; interaction coefficient $-.028, p=.008$.

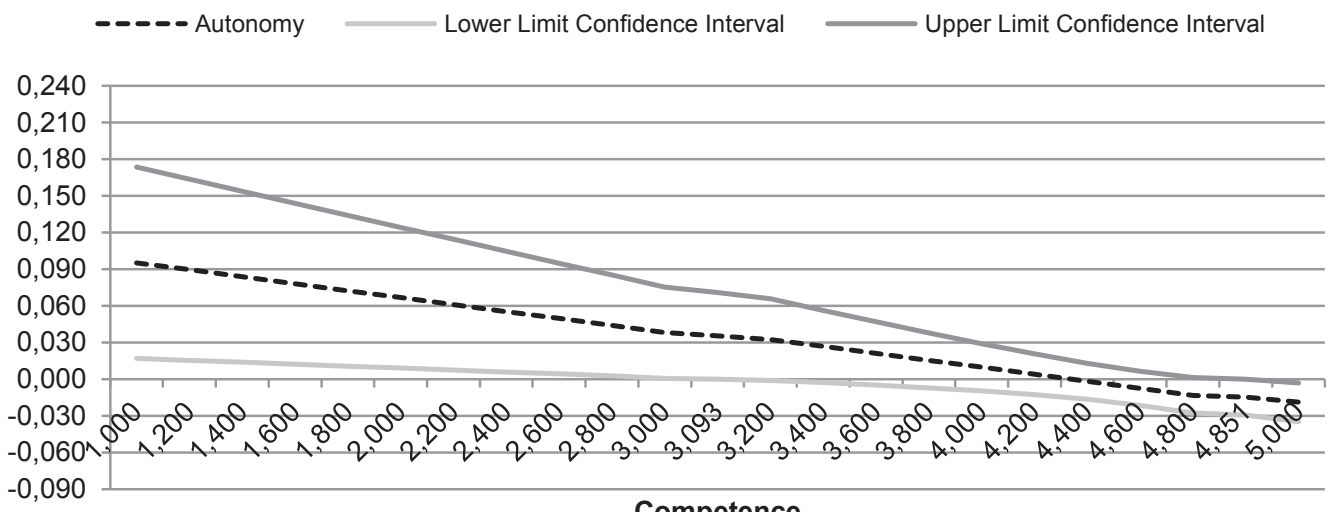

Competence

\footnotetext{
Notes: Each interaction effect is statistically significant in the Johnson-Neyman significance region obtained through OLS with asymptotic standard errors (i.e., where the confidence interval does not contain zero). The confidence intervals are wider when further from the moderator mean. The significance level is .05.
}

Figure 2.3 - Interaction Effects 


\section{DISCUSSION}

With this field study, we tested how different types of habitual behaviors develop with CMP usage, how satisfying the psychological needs required to fulfill CMP usage goals helps develop CMP habitual behaviors, and how the contextual stability of habitual behaviors stemming from complex interactions with the environment affects consumer engagement with the CMP service. We have focused on three habitual behaviors (related to time, merchant category, and location) that consumers develop with varying stability during a CMP roll-out.

Among the antecedents, we draw attention to the importance of considering not just the satisfaction of the psychological needs for autonomy, competence and relatedness but also their interplay in fulfilling CMP usage goals. Our results show that satisfying the psychological need for competence is pivotal for developing stable habitual behaviors. Competence has a positive effect on category and location stability, but it reveals more complex relationships in interaction with relatedness (positive on time stability) and autonomy (negative on location stabilityl. Therefore, feeling more competent leads to more dispersed CMP usage across merchant categories; feeling very competent and more socially connected with others leads to less fluctuation in CMP usage. Feeling very confident leads to more dispersed usage across supporting stores when accompanied by perceptions of low autonomy (cf. when feelings of limited or low competence are accompanied by perceptions of high autonomy).

Among the consequences, we emphasize that CMP engagement due to habitual behaviors is not just contingent on repeat usage, but on repeat usage in interaction with multiple actors in the service ecosystem. We find that the contextual stability of habitual behaviors in relation to location is pivotal for keeping consumers engaged with CMP. More dispersed uses of CMP across supporting stores have positive effects on affective, cognitive, and behavioral engagement. Although time stability positively influences affective engagement, it also has a negative effect on behavioral engagement. Therefore, though a lack of fluctuation in CMP usage determines whether consumers show positive affect about CMP, it does not encourage them to spend more. Finally, category stability negatively affects cognitive engagement, which implies that the more dispersed CMP usage is across different merchant categories, the more consumers' cognitive evaluation of the CMP experience suffers. 


\section{Theoretical Implications}

This study contributes in several ways to examinations of the role of habitual behaviors in IS continuance and the emerging fields of service research and consumer experiences in IS. First, by synthesizing literature on motivations and behavioral patterns, we derive a synergistic conceptualization of habit, as facilitated by goal fulfillment (satisfaction of psychological needs for autonomy, competence, and relatedness) and described by complex interactions with the environment (stability in time, merchant category, and location). By showcasing the interplay of goal fulfillment and the environment (Ortiz de Guinea and Markus 2009), our conceptualization also offers an in-depth understanding of habit as an unconscious (i.e., automatic) process that reconciles dominant IS views of habit as either a behavioral intention or a behavioral repetition.

Second, we empirically validate SDT for IS and emphasize the pivotal role of satisfying the psychological need for competence in the development of habitual behaviors with digital services. We furthermore enrich SDT literature by unveiling the interplay of psychological needs with both positive and negative consequences: Simultaneously satisfying needs for competence and relatedness can advance specific behaviors (i.e., habitually using CMP in time), but simultaneously satisfying psychological needs for competence and autonomy can be detrimental to other behaviors (i.e., habitually using CMP at supporting locations). Our results emphasize the importance of carefully considering the effects of satisfying each of the three psychological needs, as well as their interplay (Ryan and Deci 2000), rather than focusing on satisfying only one or two psychological needs.

Third, we illustrate how consumers use an interactive digital service in real life, by operationalizing habitual behaviors in relation to their time, category, and location stability using objective, longitudinal data. Our field study enables us to observe how consumers actually vary in their CMP usage across time, merchant categories, and supporting stores without prompting them to provide attitudes, such that we capture how their habitual behaviors develop unconsciously. Considering different types of habitual behaviors and how they influence consumer engagement with the CMP service leads to the main takeaway: Keeping consumers engaged with a digital service is contingent not just on them using the service more but also using it across more supporting locations in the service ecosystem. These findings stress the importance of 
developing a common perspective within the service ecosystem, to reduce cognitive distance among key actors and ensure the survival and further development of the whole ecosystem (Lusch and Nambisan 2015).

Fourth, for the first time, we establish a link between the contextual stability of habitual behaviors and consumer engagement with digital services. We go beyond actual usage (behavioral engagement) to examine attitudinal consequences of habitual behaviors too (affective and cognitive engagement). Although some habitual behaviors (i.e., location stability) positively influence all facets of CMP engagement, other types (i.e., time stability) can positively affect some but negatively affect other consumer engagement facets, and still others (i.e., merchant category stability) only have detrimental effects on certain consumer engagement facets. These findings emphasize the importance of a fine-grained perspective on habitual behaviors (Ortiz de Guinea and Markus 2009). It is clear that a consumer can develop different types of habitual behaviors while using a service, and each habitual behavior in turn can have different consequences for the consumer's engagement with the service.

Fifth and finally, our results provide insights into how to manage the consumer experience (Barrett et al. 2015). Trade-offs could be considered when rolling out digital services that might become habitual for consumers. For example, fostering time stability might be beneficial during the introduction phase, because it would lead to positive affect and potentially expand the end user base; fostering location stability instead could be beneficial in subsequent phases, because it leads to a positive consumer experience overall. This multifaceted perspective illustrates how consumer engagement can be generated, especially when more participation is required (Ostrom et al. 2015), and given that digital services usually are not focal objects of engagement (Brodie et al. 2011).

\section{Managerial Implications}

Our results have implications for different actors in the CMP service ecosystem. The insights into how satisfying the psychological needs for autonomy, competence, and relatedness affect the contextual stability of habitual behaviors provide guidance to both CMP enablers (e.g., terminal, smartphone or application providers) and CMP supporters (e.g., stores). Both types of actors might hope that consumers develop time-stable habitual behaviors, but CMP enablers likely are more interested in supporting category- and location-stable 
habitual behaviors, whereas CMP supporters might be more interested in consumers using CMP in their category and specifically in their stores.

Thus, CMP supporters should focus on building consumers' feelings of competence but also make sure that feelings of relatedness get fostered. For the former, they might rely on better communication at POS terminals (e.g., instore signage explaining how CMP works) and encourage in-store trails (e.g., CMP-only terminals, providing incentives for CMP use). For the latter, they also might use online communication le.g., sharing CMP usage on social media as a signal to friends and family). In addition, CMP enablers should focus on building feelings of autonomy by clearly communicating and encouraging usage at the multitude of locations where CMP is available, to ensure consumers' dispersed spending across supporting locations, especially when they do not regard themselves as able to use CMP. Satisfying the need for autonomy could be realized by integrating an interactive map of the stores supporting CMP and their location within the payment application. Most modern smartphones have global positioning system (GPS) trackers, so the payment application could send consumers push notifications once they enter a store supporting CMP. These implications may be bundled if the CMP enabler is the same entity as the CMP supporter. For example, in retailer consortia, the member companies operate in different categories, such as the U.S. Merchant Customer Exchange, which includes Walmart (supermarket), Best Buy (consumer electronics retailer), and CVS (pharmacy chain).

Moreover, CMP enablers should be aware of the consequences of consumers' habitual behaviors. Location stability is the only habitual behavior with positive effects on all three facets of consumer engagement, so enablers should first and foremost make sure consumers CMP spending is dispersed across supporting stores. To encourage such a spread, they might link CMP to a loyalty program that spans the supporting stores, as exemplified by Plenti, an initiative by American Express that offers cumulative points to consumers shopping at Macy's, Exxon Mobil, and AT\&T locations, among others. These loyalty programs could be integrated with the payment application, so every time they use CMP, consumers' loyalty points automatically get updated, eliminating the need to carry plastic loyalty cards. The payment application also could send consumers push notifications when they enter a CMP supporting store that participates in the loyalty program. 
Finally, our results provide insights for companies that are not part of a CMP ecosystem but are considering joining an existing initiative. The minimum requirement is to invest in a $\mathrm{CMP}$-compatible terminal, to allow consumers to use CMP, regardless of who the CMP enabler is le.g., consumer's bank, mobile operator, another companyl. Should these companies then want to ensure their consumers have a positive experience with CMP, they should join an existing ecosystem with multiple locations, all of which encourage CMP usage le.g., through a loyalty program). For bigger companies contemplating setting up their own CMP ecosystem, fostering time- lespecially during the introduction phase) and location-stable habitual behaviors, while mitigating the negative effects of category-stable habitual behaviors, would be beneficial. Nevertheless, habitual behaviors simply will not form if consumers do not use the digital service; given the nascent state of CMP, it probably would be most beneficial for a company to join an existing CMP ecosystem, where usage already is ongoing.

\section{Limitations and Further Research}

Several limitations of this study should be considered. First, we collected our data in a CMP roll-out with a finite duration. Further studies could consider digital service roll-outs with a wider time horizon, to assess consumers' longer-term engagement. Second, though representative of the general adult population, our participants agreed to participate in the field study to be the first to use CMP in their country. This could explain why most participants believed they had the skills to use CMP. Third, all participants used the same smartphone model during the field study, which was necessary to maintain a consistent CMP experience across all participants. However, some people naturally prefer specific smartphone brands or models. At the end of 2014, when Apple launched its first NFC compatible smartphone model bundled with a proprietary CMP service (Apple Pay), it brought CMP to the attention of a much broader audience; prior to this introduction, it had not been possible to use CMP on Apple devices. Additional research thus should consider how devices used for CMP affect the development of CMP habitual behaviors. This consideration should not be restricted to smartphones but should extend to other types of portable devices, such as smartwatches. Fourth, the behavioral data we employed were limited to CMP transactions; we could not observe participants' alternative payment behaviors at the supporting stores or within the merchant categories prior to or during the field study. Continued studies 
might compare the concomitant usage of different payment methods and control for the effect on the development of CMP habitual behaviors.

We have introduced a novel conceptualization of habit as an unconscious process and shown how the contextual stability of habitual behaviors can keep consumers engaged with an interactive digital service, using a combination of self-reported and objective data from a longitudinal field study. Our results provide insights for different actors in the CMP service ecosystem, related to recommendations for fostering habitual behaviors that will lead to the desired consumer engagement outcomes. 


\section{CHAPTER 3}

Engagement with a Sequential Digital Service Innovation

\section{The Effect of Users' Developmental Trajectory on Long-Term Engagement: A Dynamic Perspective}

“Ilsa: Play it, Sam. Play 'As Time Goes By.'” (Casablanca, 1942) 


\section{INTRODUCTION}

The digital services that are currently at the forefront of innovation (Barrett et al. 2015; Lusch and Nambisan 2015), such as video games, aim to deliver meaningful user experiences through information and communication technology (ICT)-enabled engagement platforms on which users actively take part in creating the experience (Nylén and Holmström 2015; Ramaswamy and Ozcan 2016). In digital realms, sequential iterations of existing service offerings and introductions of new versions of a service (Heath et al. 2015) can boost users' engagement (Ostrom et al. 2015), leverage existing user bases (Marchand 2016), and accelerate service lifecycles, such that digital service innovations enter markets with greater frequency (Heath et al. 2015). As some of the fastest growing and most innovative digital services (Marchand and Hennig-Thurau 2013), video games are iterative (Heath et al. 2015), interactive (Granic, Lobel, and Engels 2014), experiential (Marchand and Hennig-Thurau 2013) digital services that provide digitalized platforms for user engagement (Ramaswamy and Ozcan 2016). For example, the successful video game franchise Halo first was introduced by Microsoft on its Xbox gaming console in 2001; the most recent iteration (Halo 5: Guardians), introduced in 2015, generated more than $\$ 400$ million in global sales during its first week, and the franchise's lifetime revenue has surpassed $\$ 5$ billion (Microsoft 2015). According to Microsoft, users played nearly 7 million matches in a total of 9 million hours on the multiplayer mode of Halo 5: Guardians during the week after its introduction. Despite this impressive evidence of initial engagement though, these levels eventually decline as users lose interest in the service (Bauckhage et al. 2012), for reasons varying from boredom to the appeal of competitive offerings. As service lifecycles and user attention spans continue to diminish, digital service providers must identify the path of user engagement, after a new iteration has been introduced.

Customer or user engagement has received increasing attention from both academia (e.g., Calder, Malthouse and Schaedel 2009; Hollebeek, Glynn, and Brodie 2014) and practice (e.g., Accenture 2015; Forbes 2015). Engagement appears paramount in driving customer loyalty (EIU 2015) and even may be "everything" in terms of ensuring customer returns (Forbes 2015). Even as companies make considerable investments in digital service innovations to improve users' experiences though (Accenture 2015), they still struggle to maintain user engagement levels, especially for services that require 
participation (Ostrom et al. 2015), such as video games whose multiplayer mode requires users to play with and against other users online over time (Marchand 2016). Understanding how to maintain user engagement, as well as how user engagement and user experiences may reinforce each other, thus are central research priorities for marketing (e.g., MSI 2016), service (e.g., Ostrom et al. 2015), and information systems (e.g., Barrett et al. 2015).

User engagement with a video game, in the form of gameplay, represents a behavioral manifestation, is driven by user motivations, goes beyond purchases, and requires the investment of resources (e.g., time, effort) (Moeller et al. 2013; Van Doorn et al. 2010). Participation is voluntary, such that most users play video games for personal enjoyment and fun (Przybylski, Rigby, and Ryan 2010). With the purchase of a video game, users also unlock access to essentially infinite play in the multiplayer mode (Snow 2011). In turn, users often devote considerable amounts of time to game play; $63 \%$ of U.S. households include at least one person who plays video games for at least 3 hours each week, and the most frequent users spend an average of 6.5 hours weekly playing online with others (ESA 2016).

But their engagement also involves a dynamic, iterative process of interactive experiences (Brodie et al. 2011), and this dynamism has yet to be explored empirically (Hollebeek, Glynn, and Brodie 2014). This question seems important for at least three reasons. First, it is not clear how the diffusion of digital service innovation differs from that of analog innovation (Nylén and Holmström 2015; Yoo 2013). Digital innovation offers greater availability, due to ICT, and it also might facilitate faster user engagement during introduction phases. For example, users who preordered a digital copy of Halo 5: Guardians could download and install the game on their consoles and immediately start playing at moment of the official launch (Xbox 2015). Second, sequential forms of digital service innovation actively seek to leverage existing user bases, which already have experienced previous iterations (Heath et al. 2015; Marchand 2016) and thus might circumvent the need for early markets of users, because a late market already has been established (Chandrasekaran and Tellis 2011). Each time Microsoft introduces a new iteration of the Halo franchise, it benefits from the existing user base of players, familiar with the game content, as well as the entire existing user base of members on the Xbox Live platform who have ready digital access to the service. Third, different users likely exhibit varying magnitudes of engagement at any specific point in time le.g., some users could 
be highly engaged during the introduction week, but others might be more engaged only after the launch). To assess the dynamic nature of engagement, it therefore is necessary to determine the homogeneous trajectory of user engagement across all users while also accounting for variability among users over time.

With this study, we aim to capture the fundamentally dynamic nature of behavioral user engagement after the introduction of a new iteration of a digital service (i.e., video game). In so doing, we address several research questions: (1) When a new digital service is introduced, does user engagement follow a common developmental trajectory? (2) How does this trajectory influence subsequent user engagement? (3) How does this trajectory influence subsequent user experiences? The answers to these questions can help service providers detect early signs of the success or failure of a new digital service. To identify the developmental trajectory of behavioral user engagement across all users, we use trajectory growth factors (e.g., Palmatier et al. 2013), including the initial engagement level luser engagement during the first week after introduction) and the rate of change relative to that initial level (increase, stagnation, or decrease in engagement from the first until the fourth week after introduction). With telemetric longitudinal data (Bauckhage et al. 2012) related to users' behavioral engagement after the introduction of a new iteration of a multiplayer video game, we apply growth curve modeling (e.g., Bollen and Curran 2006) and thus make several contributions to marketing, service, and innovation research. In particular, for literature on user engagement le.g., Brodie et al. 2011), we provide an initial empirical test of the dynamic nature of engagement and show that after the introduction of a new digital service, users follow a common developmental trajectory, defined by the initial level and rate of change of engagement. For research into user experiences (De Keyser et al. 2015), we reveal empirically how user engagement reinforces user experiences, such that their homogenous engagement trajectory influences subsequent utilitarian, hedonic, and social user gratification. Finally, we contribute to literature on digital service innovation (Barrett et al. 2015) by emphasizing the importance of the introduction phase. In the context of ever decreasing service lifecycles, gratifying certain user needs may build user engagement, but service providers would be better off focusing on achieving positive user experience outcomes. 
In the next section, we introduce the conceptual background and formulate hypotheses that draw on digital service innovation, user experience and engagement, and uses-and-gratifications theory. After we describe our methodological approach, we present the results of our longitudinal analysis. We conclude with the implications of our findings for theory and practice.

\section{CONCEPTUAL BACKGROUND}

\section{Sequential, Digital Service Innovation}

The rapid development and introduction of ICT and smart devices constantly connected to the Internet has set the stage for unprecedented digital service innovations (Barrett et al. 2015). In this shift from analog to digital information, digital service innovation differs from traditional innovation with its focus on interactivity (i.e., users are interconnected and interact with other users and service providers and receive feedback in real timel and dynamic user experiences (i.e., users satisfy different needs by interacting with different features of a digital service across time) (Lusch and Nambisan 2015; Nylén and Holmström 2015). Digital services have established user bases and introduce innovations in sequences (i.e., existing offerings reiterated with shorter time intervals; Heath et al. 2015), which reduces their lifecycles and transforms the diffusion of these innovations (Marchand 2016). That is, a traditional, inverted Ushaped innovation adoption curve might not apply for each new iteration (Chandrasekaran and Tellis 2011; Van Doorn et al. 2010), especially because an established user base already exists. With the view that digital services constitute engagement platforms where users take part in creating the digital experience (Ramaswamy and Ozcan 2016), we examine how behavioral engagement develops over time after the introduction of new digital service iterations.

\section{User Experience and User Engagement}

User experience (De Keyser et al. 2015; Verhoef et al. 2009) and user engagement (Brodie et al 2011; Van Doorn et al. 2010) are interrelated, prominent research concepts (Barrett et al. 2015; MSI 2016; Ostrom et al. 2015). Debate persists about their conceptualization and operationalization (see De Keyser et al. 2015; Hollebeek, Glynn, and Brodie 2014), but consensus arises to indicate that the user experience is a source of user engagement (Calder, Malthouse, and Schaedel 2009; De Keyser et al. 2015) and that both constructs 
are highly relevant for digital service innovation (Barrett et al. 2015; Lusch and Nambisan 2015). We adopt a widespread view (e.g., Brodie et al. 2011; De Keyser et al. 2015; Nylén and Holmström 2015) and propose that user experience and user engagement reinforce each other in a digital environment (i.e., experience drives engagement, and engagement can drive subsequent experiences). We view users' behavioral engagement in terms of the investment of their resources (i.e., gameplay duration implies time), and user experience entails satisfying users' motivation (utilitarian, hedonic, and social gratification through gameplayl. This approach is supported by video game research in the fields of both human-computer interaction (Bauckhage et al. 2012; Boyle et al. 2012; Williams, Yee, and Caplan 2008) and social psychology (Barnett and Coulson 2010; Przybylski, Rigby, and Ryan 2010).

\section{Uses-and-gratifications Theory and the User Experience}

Uses-and-gratifications (U\&G) theory originated in communication research (Katz, Blumler and Gurevitch 1974) but has also been used in marketing (Nambisan and Baron 2007), information systems (Sutanto et al. 2013) and human-computer interaction ( $\mathrm{Li}$ et al. 2015) studies to explain the motives for using sequential, digital services, such as online music streaming le.g., Krause, North, and Heritage 2014). As a motivational paradigm, U\&G postulates that people are goal oriented and engage with specific digital services to gratify (i.e., satisfy) different psychological needs (Eisenbeiss et al. 2012; Nambisan and Baron 2007). In prior video games research, the U\&G approach reveals three broad categories of gratification (Boyle et al. 2012; Li et al. 2015; Williams, Yee, and Caplan 2008; Yee 2006): utilitarian (e.g., achievement or acquiring special items), hedonic (e.g., immersion by exploring the game environment and reconfiguring gameplay), and social (e.g., being part of a team and collaborating). We regard these three types of gratification as likely determinants of the user experience and drivers of user engagement. Therefore, we examine how the digital user experience drives user engagement, which in turn influences subsequent engagement and digital experience.

\section{HYPOTHESES DEVELOPMENT}

Behavioral user engagement ensues by virtue of interactive user experiences that occur in a dynamic, iterative process (Brodie et al. 2011). To capture the dynamism of this behavioral user engagement with a new video game iteration, 
we move beyond observed individual engagement levels at different points in time. Our goal is to determine if users exhibit a homogenous developmental trajectory in their behavioral engagement at different points in time, after the introduction of a new video game iteration (e.g., during the first month). A potential engagement trajectory might reveal high engagement in the initial phase, then declining engagement levels over time (van Doorn et al. 2010). If such a homogeneous trajectory exists, even with individual differences in how engaged users actually are, on average, they follow a common path le.g., positive growth, stagnation, or negative growth). If no such homogeneous trajectory appears, on average, behavioral engagement follows a random walk, and each user has a unique behavioral engagement trajectory (Palmatier et al. 2013). In its simplest form, a trajectory reflects two growth factors: a starting point (i.e., initial level) and the rate of change relative to that starting point (Bollen and Curran 2006). Therefore,

$\mathrm{H}_{1}$ : Behavioral user engagement after the introduction of a new iteration of a digital service follows a common developmental trajectory, defined by two growth factors: (a) an initial engagement level and (b) the rate of change in engagement.

Research on sequential, digital service innovations in general (e.g., Heath et al. 2015) and video games in particular (e.g., Bauckhage et al. 2012) leads us to expect that behavioral user engagement fades over time. Therefore, if we can establish a common behavioral engagement trajectory, the next step is to determine whether the growth factors describing this trajectory linitial level and rate of change) also influence outcome variables (engagement and experience). For example, individual behavioral engagement levels initially stem from the novelty of the digital service iteration (e.g., new video game environment with new characters and features, set in an identifiable storyline), but subsequent individual behavioral engagement (e.g., one year later) is contingent on other users (Lusch and Nambisan 2015; Ramaswamy and Ozcan 2016). In other words, users need their peers to stay engaged so that they can remain engaged. The more homogenous the behavioral engagement trajectory developed during the introduction period, the more positive its influence on subsequent behavioral engagement should be.

To assess subsequent user experience, we rely on the U\&G paradigm and hedonic, utilitarian, and social forms of gratification le.g., Li et al. 2015; 
Williams, Yee, and Caplan 2008). We follow a logic similar to the one we propose for subsequent behavioral user engagement: The more homogenous the behavioral engagement trajectory during the introduction period, the more opportunities users have to gratify their needs and enjoy more fulfilling user experiences later. If users play the game because they want a sense of achievement (utilitarian), seek to become immersed in the virtual environment (hedonic), or prefer to be part of a team effort (social), they should be better able to satisfy their needs if they share a common behavioral engagement trajectory with other users during the introduction period. We therefore expect that a higher, common, initial level of behavioral engagement following the introduction of a new iteration leads to more engaged users, such that they will be find their experience more fulfilling thereafter. Formally, we hypothesize:

$\mathrm{H}_{2}$ : Initial behavioral user engagement after the introduction of a new digital service iteration positively influences (a) subsequent behavioral user engagement and (b) subsequent user experience in terms of (i) utilitarian, (ii) hedonic, and (iii) social gratification.

Furthermore, a higher common rate of change in behavioral engagement during the introduction period should lead users to be more engaged and find the subsequent experience more fulfilling. A higher positive rate of change implies a more positive increase in behavioral user engagement (steeper positive change); a higher negative rate of change would imply a less negative increase in behavioral user engagement (less steep negative change). That is,

$\mathrm{H}_{3}$ : The rate of change in user engagement after the introduction of a new digital service iteration positively influences (a) subsequent user engagement and (b) subsequent user experience in terms of (i) utilitarian, (ii) hedonic, and (iii) social gratification. 


\section{RESEARCH METHODOLOGY}

The video game environment can be described in terms of the game content, platform ${ }^{4}$, and consumers (Marchand and Hennig-Thurau 2013). We investigate how game consumers (users) interact with the content (game characteristics) on a platform (gaming console).

\section{First-person Shooter Games as the Research Context}

In terms of content, we examine a first-person shooter (FPS) game, one of the most popular types of video games in terms of unit sales (ESA 2016): Call of Duty: Black Ops /// was the top selling video game of 2015, and five other FPS games were in the top 20 bestselling video games (ESA 2016). When playing FPS games, users enter simulated combat situations and make use of firearms and other weapons to defeat opponents. They experience the action through their characters' eyes, instead of seeing a 3D representation of their character, as tends to be the case for role-playing (RPG) games (Granic, Lobel, and Engels 2014). This perspective encourages FPS users to experience the game as deeply engaging; the U.S. military even uses FPS games for training purposes (Shaban 2013).

In terms of the platform, we focus on a FPS game accessible on a single type of console, not on personal computers or mobile devices, because console games remain the main source of revenue for video game developers (Marchand and Hennig-Thurau 2013). The effect of the hardware on the user experience thus remains relatively constant. We also consider a traditional business model, rather than a "freemium" or subscription-based game (Marchand and HennigThurau 2013). Each user purchases a copy of the game, pays the same price lapproximately \$60), and has unlimited time to play. This approach thus keeps the influence of price on the user experience constant.

${ }^{4}$ The gaming platform relates strictly to the type of hardware used to play le.g., gaming console such Xbox, mobile device such as an iPad), not the video game as a digitalized platform of engagement (Ramaswamy and Ozcan 2016). 


\section{FPS Multiplayer Mode as the Digital Engagement Platform}

Video game content is heterogeneous (Granic, Lobel, and Engels 2014), and FPS environments range from modern warfare (e.g., Call of Duty) to science fiction scenarios (Halo), yet they tend to have some common characteristics in multiplayer mode (Barnett and Coulson 2010). Within a specific multiplayer game, users cooperate and compete in matches of finite duration with clear objectives and clear outcomes against other players from all over the world, over the Internet (Marchand 2016). In other words, matches capture user engagement with the digital service (i.e., the video game). Thus, the extent to which users continue playing matches in multiplayer mode after a game's introduction indicates whether they are maintaining engagement with the game (Boyle et al. 2012; Przybylski, Rigby, and Ryan 2010). Furthermore, when playing with and against other users (cf. playing against artificial intelligence, as in single player mode), users take part in creating the experience (Ramaswamy and Ozcan 2016). This shared user experience in multiplayer mode may constitute the future of gaming (Stuart 2014).

\section{FPS Multiplayer Experience}

During each match, users are assigned to one of two competing factions and fight against members of the opposing faction in relatively confined virtual environments (Eisenbeiss et al. 2012). Matches can have specific, team-focused objectives (e.g., capture the other faction's flag), or non-team-focused objectives (i.e., eliminate as many members of the opposing faction as possible, while avoiding being eliminated). Irrespective of the focus, an FPS multiplayer experience is dynamic and interactive; players usually can be eliminated multiple times during the same match (Barnett and Coulson 2010). Each time they are eliminated, users may reconfigure their gameplay by selecting a new type of character, equipped with specific items (e.g., weapons) and abilities (e.g., sharpshooting skills). Therefore, unlike RPG games, in which users tend to invest in one specific character over time (Barnett and Coulson 2010), FPS users can change characters multiple times during the same match. Finally, as rewards for meritorious in-match performance le.g., eliminating many opponents, not being eliminated for a long period), users may receive temporary enhancements (e.g., increased damage imposed by their weapons). 


\section{Data and Variable operationalization}

Our sample consists of 879 users of a popular FPS game, part of an ongoing franchise. This iterated offering (Heath et al. 2015), first introduced in 2011, and has earned a Metacritic rating of universal acclaim, ${ }^{5}$ indicating very positive overall reviews from both industry critics and users. The study data were provided by the company that developed the game and comprises in-game usage behavior (or telemetry; Bauckhage et al. 2012). For privacy reasons, the game developer did not provide any data that could describe the users le.g., socio-demographics, geolocation) outside the telemetry. We thus can only observe individual players' actions during a match, such as collecting performance enhancers or changing characters, as well as the type of match they played (team- or non-team-focused) and match duration (in seconds). We focus on the period immediate after the introduction (i.e., first four weeks), which is the period of highest initial engagement (Van Doorn et al. 2010), whereas over time, most users' interest in playing the game naturally declines (Bauckhage et al. 2012).

Users were drawn randomly from the population of players who started playing the FPS on the first day of its introduction. The anonymous, telemetric data describe players solely in terms of their in-game usage. For each player, we computed average gameplay duration (in minutes), to reflect behavioral engagement (Bauckhage et al. 2012; Boyle et al. 2012; Przybylski, Rigby, and Ryan 2010), as well as their utilitarian (average achievement), hedonic (average immersion), and social (average social interaction) gratification during each of the first four weeks (Boyle et al. 2012; Williams, Yee, and Caplan 2008; Yee 2006). Next, we obtained measures of the same variables one year after the introduction of the game and until the game was no longer supported by the developer (i.e., 35 weeks). Table 3.1 details the variables operationalizations. We define five time periods: Times 1-4 refer to weeks 1-4 after the game's introduction, respectively, and then Time 5 refers to the 35 -week period one year after the game was introduced.

\footnotetext{
${ }^{5}$ http://www.metacritic.com/about-metascores
} 
Table 3.1 - Overview of variable operationalization

\begin{tabular}{|c|c|c|}
\hline Construct & Reference & Operationalization and description \\
\hline $\begin{array}{l}\text { User } \\
\text { engagement }\end{array}$ & $\begin{array}{l}\text { Boyle et } \\
\text { al. 2012; } \\
\text { Przybylski, } \\
\text { Rigby, and } \\
\text { Ryan } 2010\end{array}$ & $\begin{array}{l}\text { A match's gameplay duration refers to the number of minutes } \\
\text { of actual gameplay (time users spend playing the match). We } \\
\text { consider gameplay duration as a proxy for behavioral user } \\
\text { engagement with the game. The higher users' average } \\
\text { gameplay, the higher their behavioral engagement. }\end{array}$ \\
\hline $\begin{array}{l}\text { Utilitarian } \\
\text { gratification }\end{array}$ & $\begin{array}{l}\text { Li et al. } \\
2015 ; \\
\text { Williams, } \\
\text { Yee, and } \\
\text { Caplan } \\
2008\end{array}$ & $\begin{array}{l}\text { Total number of performance enhancers collected at Time } i \\
\text { Total number of matches played at Time } i \\
\text { During each match, every time users show noteworthy } \\
\text { behaviors (e.g., eliminating multiple opponents at the same } \\
\text { time, assisting teammates multiple times), they are rewarded } \\
\text { with limited-time performance enhancers (e.g., better aim, } \\
\text { higher damage). The specific behaviors necessary to receive a } \\
\text { performance enhancer are set by the game developer, are } \\
\text { finite, and do not change across matches. The more } \\
\text { performance enhancers users are rewarded with during a } \\
\text { match, the higher their achievement, because they receive } \\
\text { temporary advantages over opponents. A value of } 0 \text { indicates } \\
\text { the user was not rewarded with any performance enhancer. }\end{array}$ \\
\hline
\end{tabular}

\begin{tabular}{|c|c|c|}
\hline $\begin{array}{l}\text { Hedonic } \\
\text { gratification }\end{array}$ & $\begin{array}{l}\text { Li et al. } \\
\text { 2015; } \\
\text { Williams, } \\
\text { Yee, and } \\
\text { Caplan } \\
2008\end{array}$ & $\begin{array}{l}\frac{\text { Total number of character changes at Time } i}{\text { Total number of matches played at Time } i} \\
\text { During each match, every time users are eliminated, they can } \\
\text { choose to change their gameplay experience by opting for a } \\
\text { different type of character. Each character type has its unique } \\
\text { set of items and abilities (e.g., one character type uses long- } \\
\text { distance weapons, another focuses on camouflage). The } \\
\text { specific types of characters are set by the game developer, } \\
\text { are finite, and do not change across matches. The more users } \\
\text { change their character during a match, the higher their } \\
\text { immersion, because they can enhance their experience by } \\
\text { trying out different game features. A value of } 0 \text { indicates that } \\
\text { users did not make any character change (i.e., played the } \\
\text { whole match with the same type of character). }\end{array}$ \\
\hline
\end{tabular}


Table 3.1 - Overview of variable operationalization (cont.)

\begin{tabular}{|c|c|c|}
\hline $\begin{array}{l}\text { Social } \\
\text { gratification }\end{array}$ & $\begin{array}{l}\text { Li et al. 2015; } \\
\text { Williams, Yee, } \\
\text { and Caplan } \\
2008\end{array}$ & $\begin{array}{l}\text { Total number of team - focused matches at Time } i \\
\text { Total number of matches played at Time } i \\
\text { Users can choose between matches with or without a team } \\
\text { focus. When users play a team-focused match, they must } \\
\text { complete a series of objectives as part of a team le.g., } \\
\text { sabotaging the opponent, capturing opponents' } \\
\text { headquarters). The specific objectives are set by the game } \\
\text { developer, are finite, and do not change across matches. } \\
\text { The more team-focused matches users play, the higher } \\
\text { their social interaction, because the in-match objectives } \\
\text { cannot be completed without teamwork. A value of } 0 \\
\text { indicates the users did not play any team-focused matches } \\
\text { (i.e., only played matches where they had to eliminate } \\
\text { others while not getting eliminated). }\end{array}$ \\
\hline \multicolumn{3}{|c|}{$\begin{array}{l}\text { Notes: Time i refers to each of the following } 5 \text { periods of time; time } 1 \text { = first week after game } \\
\text { introduction; time } 2 \text { = second week after game introduction; time } 3=\text { third week after game } \\
\text { introduction; time } 4 \text { = fourth week after game introduction; time } 5=\text { one year after game introduction } \\
\text { until the game was discontinued (total of } 35 \text { weeks). }\end{array}$} \\
\hline
\end{tabular}

ANALYSIS AND RESULTS

\section{Growth Curve Models}

To test our hypotheses, we employ growth curve modeling (GCM), ${ }^{6}$ a statistical method for longitudinal data analyses that focuses on the latent trajectory of an outcome variable measured at different points in time across individuals (Bollen and Curran 2006). Other longitudinal data analysis techniques exist (e.g., hierarchical linear modeling), but GCM is the most appropriate method for testing our hypotheses, because it offers the possibilities of (1) estimating time scores for nonlinear growth trajectories, (2) testing for the influence of the latent growth variables (i.e., initial level and rate of change) on the outcome variables, and (3) controlling for the influences of time-varying covariates (TVC) on outcome variables in each growth period (Bollen and Curran 2006; Curran

6 This method also has been referred to as latent trajectory modeling (Curran and Hussong 2003) and latent growth modeling (Bollen and Curran 2006; Wang and Wang 2012). 
and Hussong 2003; Curran, Obeidat, and Losardo 2010). Previously, GCM mainly has been used to model trajectories over time in social psychology research (e.g., Steiger et al. 2014), but it also has been employed in recent marketing studies (e.g., Palmatier et al. 2013).

To capture unobserved, individual growth trajectories over time, GCM uses fixed (mean of the common developmental trajectory across all individuals) and random (variance of individual trajectories around the mean) effects (Curran, Obeidat, and Losardo 2010). Furthermore, GCM can assess several features of the growth trajectory, including its form (linear or nonlinear) and latent growth factors, such as the initial level of the outcome variable (or intercept) and rate of change in the outcome variable (or slope) (Bollen and Curran 2006; Wang and Wang 2012). Irrespective of the growth form, the fixed effects reflect estimates of the mean initial level of the outcome variable and the mean rate of change in the outcome variable, which commonly define the underlying trajectory of the entire sample. The random effects are estimates of the between-person variance in initial levels and rates of change (Curran and Hussong 2003).

\section{Analysis Overview}

Following GCM recommendations (e.g., Curran and Hussong 2003; Steiger et al. 2014), we perform a multistep analysis (see Table 3.2). The observed outcome variable, for which we expect a common developmental trajectory, is behavioral user engagement with the game in the first month after its introduction (i.e., Time 1-4, or the growth period). Figure 3.1 plots the individual growth trajectories of all 879 observed users observed during the growth trajectories. For the subsequent outcome variables, measured at Time 5, we test how they are influenced by the growth factors, but they are not part of the growth process.

We estimate two types of growth models: unconditional and conditional (Bollen and Curran 2006). Only in the latter do we control for the influence of covariates (user gratification) on behavioral user engagement at each growth period (see Figure 3.2 for the unconditional and Figure 3.3 for the conditional growth model). Table 3.3 contains an overview of the variable correlations across all five time points (Times 1-5) and their descriptive statistics. To estimate each model, we employ maximum likelihood estimation with robust standard errors (MLR) in Mplus Version 7 (Muthén and Muthén 1998-2015). 


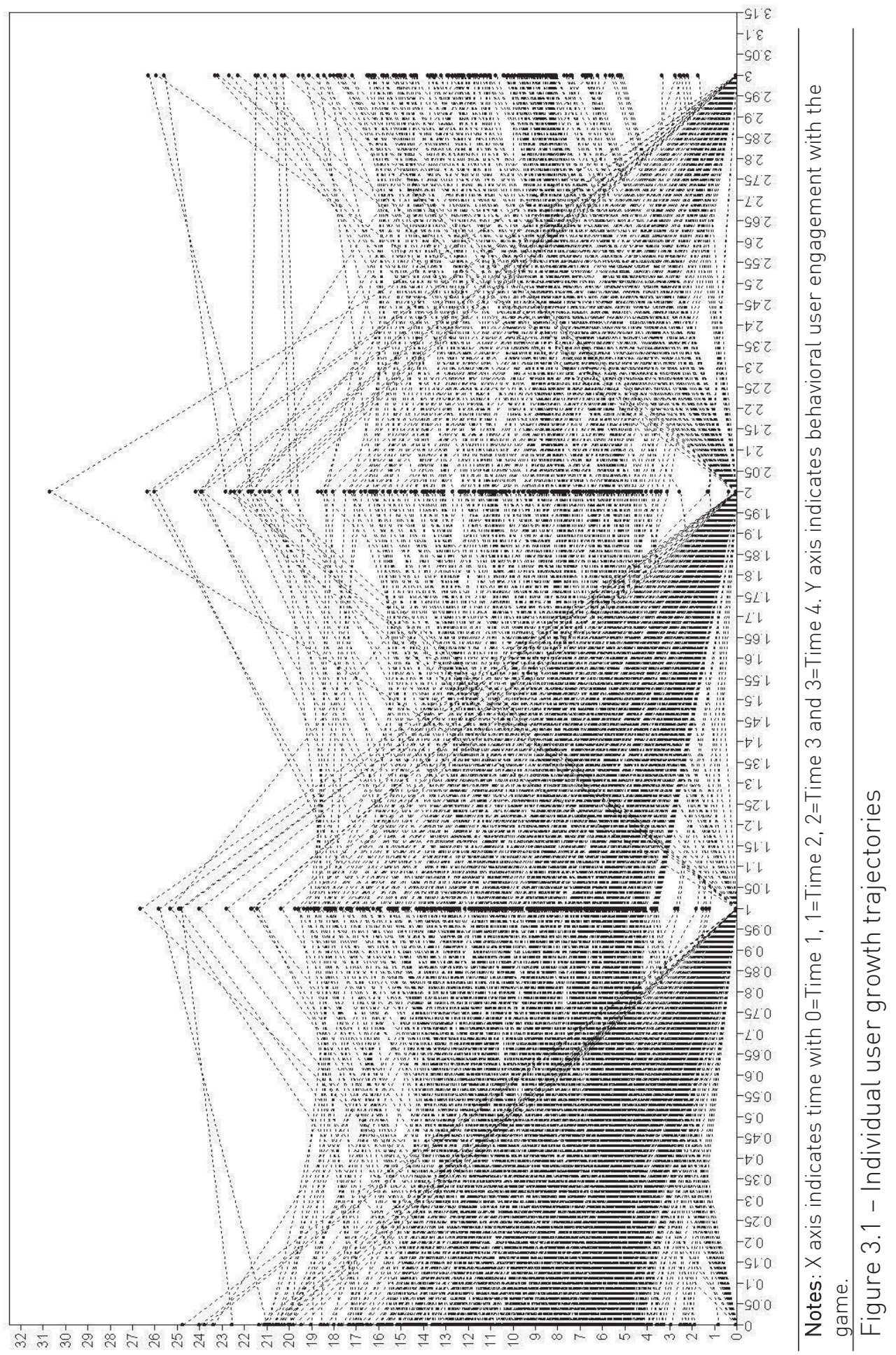




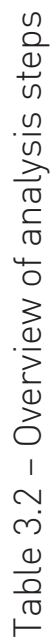

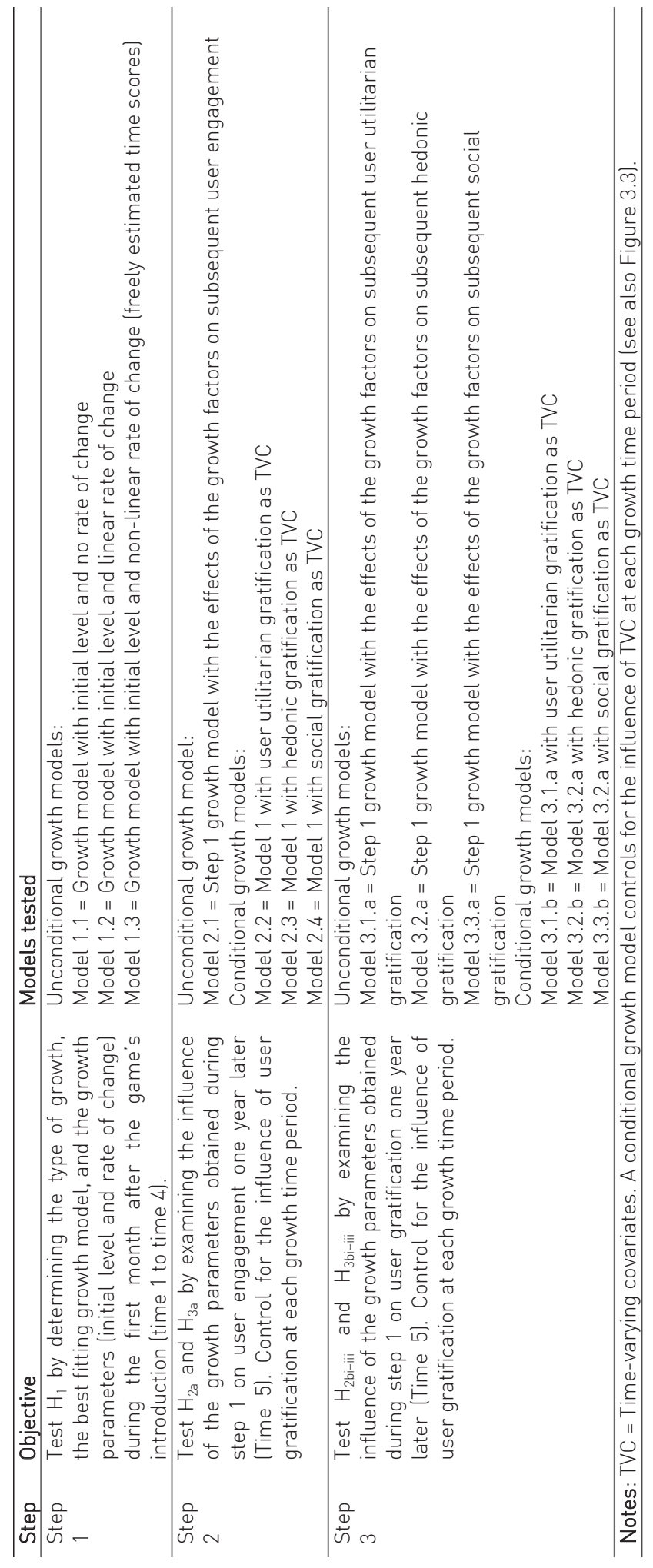




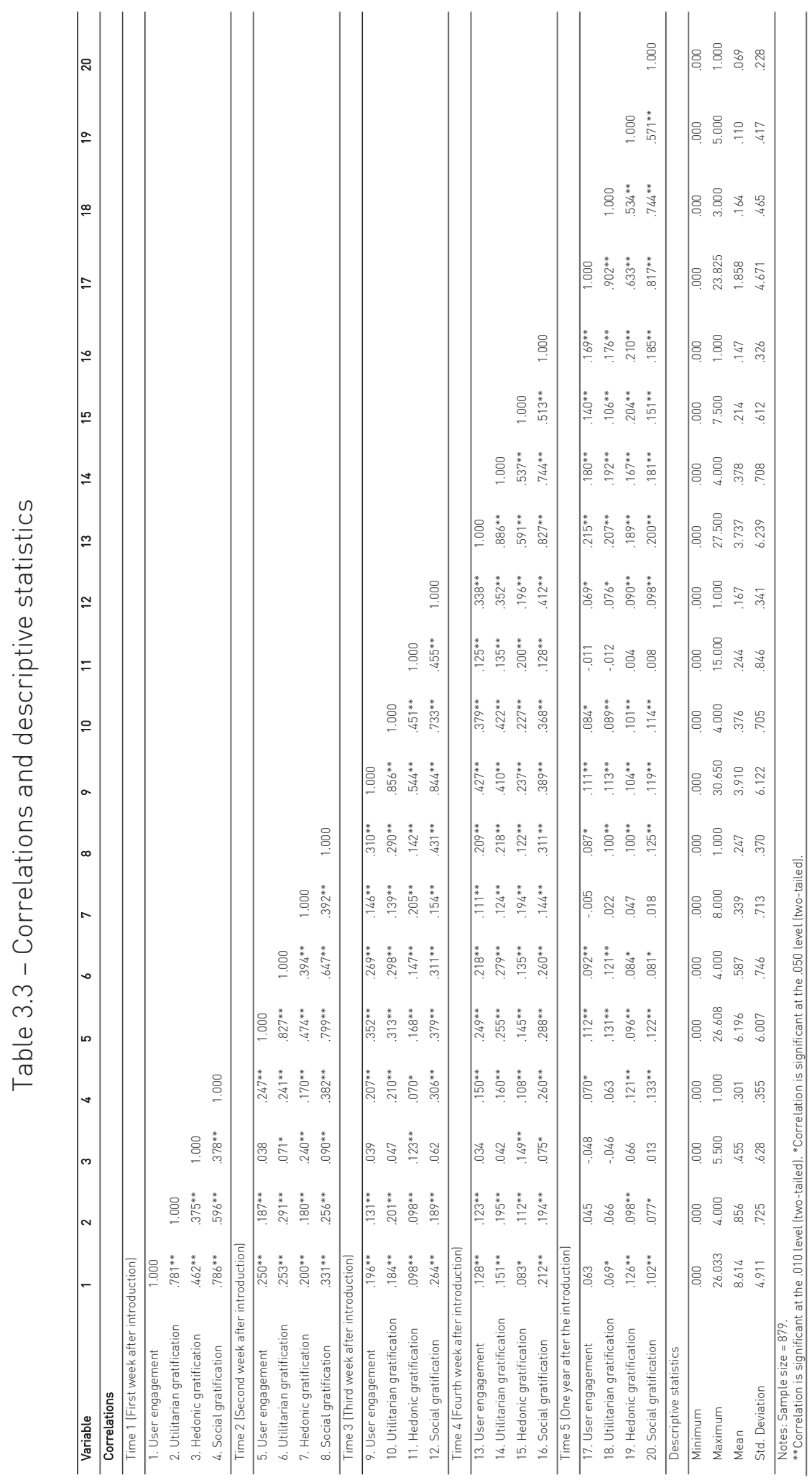




\section{Step 1 Growth Models}

We first estimate a model without the rate of change (only initial level) during the growth period, then estimate a second model with linear growth (initial growth and rate of change), and finally estimate a model with nonlinear growth (initial growth, rate of change, and freely estimated time scores) (Table 3.4). To estimate each model, we fix the factor loadings that relate the latent growth factors to the repeated outcome variable at each time period.

Fixing the factor loadings. Irrespective of the model, the factor loadings that relate the initial-level growth factor to the repeated outcome variables always must be fixed to values of 1 for each of the four observed time periods (Bollen and Curran 2016). The factor loadings that relate the rate of change factor to the repeated outcome variables are time scores and can be fixed differently for the four observed time periods, depending on the type of growth (i.e., linear or nonlinear) and desired interpretation (Wang and Wang 2012). In a linear model, the time scores can be set to values of, say, 0, 1, 2, and 3, implying that a 1-unit change in time indicates a 1-week time interval, because the repeated measures are separated by equal time intervals. A time score set to 0 indicates the starting point of the developmental trajectory and provides a baseline for the initial level growth factor. The estimated latent initial level growth factor therefore represents the level of the outcome variable at the beginning of the growth process (i.e., time 1, or the first week of observation). In a nonlinear model, two of the time scores must be fixed to values of 0 and 1 for model identification (i.e., specifying the measurement scale for the rate of change growth factor), but the other two scores can be freely estimated (Curran and Hussong 2003), ${ }^{7}$ which constitutes one of the advantages of GCM over other longitudinal data analysis techniques, because the free estimates allow the growth model to fit the data instead of following a fixed form (e.g., linear). ${ }^{8}$ Although fixing the time scores at different values does not change the model

${ }^{7}$ Freely estimating time scores requires at least four different measurements of the outcome variable for model identification (Bollen and Curran 2006).

8 To estimate nonlinear models, it is not always necessary to freely estimate time scores; the time scores can be fixed to reflect a quadratic or exponential growth function (Curran and Hussong 2003). We tested such models but found poor fit, so for simplicity, we do not discuss them further. 
fit indices, it affects their interpretation (Curran and Hussong 2003). We discuss this point in more detail in the next section.

Table 3.4 - Step 1 growth models: Fit indices and growth factors

\begin{tabular}{|c|c|c|c|}
\hline Step 1 models & Model 1.1. & Model 1.2 & Model 1.3 \\
\hline \multicolumn{4}{|l|}{ Fit indices } \\
\hline$\chi^{2}(d f)$ & $441.792(8)$ & $56.620(5)$ & 7.644 (3) \\
\hline $\mathrm{CFI}$ & .000 & .776 & .980 \\
\hline TLI & -.414 & .731 & .960 \\
\hline RMSEA & .248 & .108 & .042 \\
\hline SRMR & .301 & .066 & .024 \\
\hline \multicolumn{4}{|l|}{ Growth factors } \\
\hline Initial level mean & $5.691^{* * *}$ & $8.270^{* * *}$ & $8.622 * * *$ \\
\hline Initial level variance & $8.044^{* * *}$ & $9.926 * * *$ & $9.911^{* * *}$ \\
\hline Rate of change mean & NA & $-1.704^{* * *}$ & $-4.866^{* * *}$ \\
\hline Rate of change variance & NA & $2.303^{* * *}$ & $16.859^{* * *}$ \\
\hline \multicolumn{4}{|c|}{ 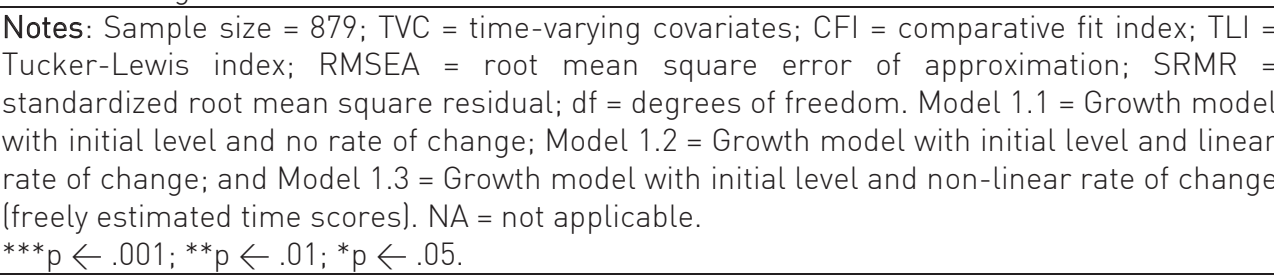 } \\
\hline
\end{tabular}

Determining the best fitting model. Average gameplay duration from Time 1 to Time 4 (Table 3) already reveals a negative trend luser engagement decreases from the first to fourth week), but the decrease is not linear or constant from one week to the next. We compare the three estimated models on several fit indices, including the comparative fit index (CFI) and Tucker-Lewis index (TLI) (cutoff values of .95 , values closer to 1 indicate better fit), root mean square error of approximation (RMSEA) (cutoff value of .08, values closer to 0 indicate better fit), and standardized root mean square residual (SRMR) (cutoff value of .06, values closer to 0 indicate better fit) (Bollen and Curran 2006). The model with freely estimated time scores offers the best fit (Model 1.3, Table 3.4). With a Satorra-Bentler scaled chi-square difference test (Bryant and Satorra 2012), we compute a scaling correction factor to account for non-normality, as is necessary when using the MLR estimator, and find $\chi^{2}(2)=42.657(p<.001)$, which confirms that Model 1.3, with fewer degrees of freedom, fits the data better than Model 1.2, with more degrees of freedom. We consider Model 1.3 the best fitting model and employ its estimated growth factors to test our hypotheses. Figure 3.2 provides its graphical representation. 


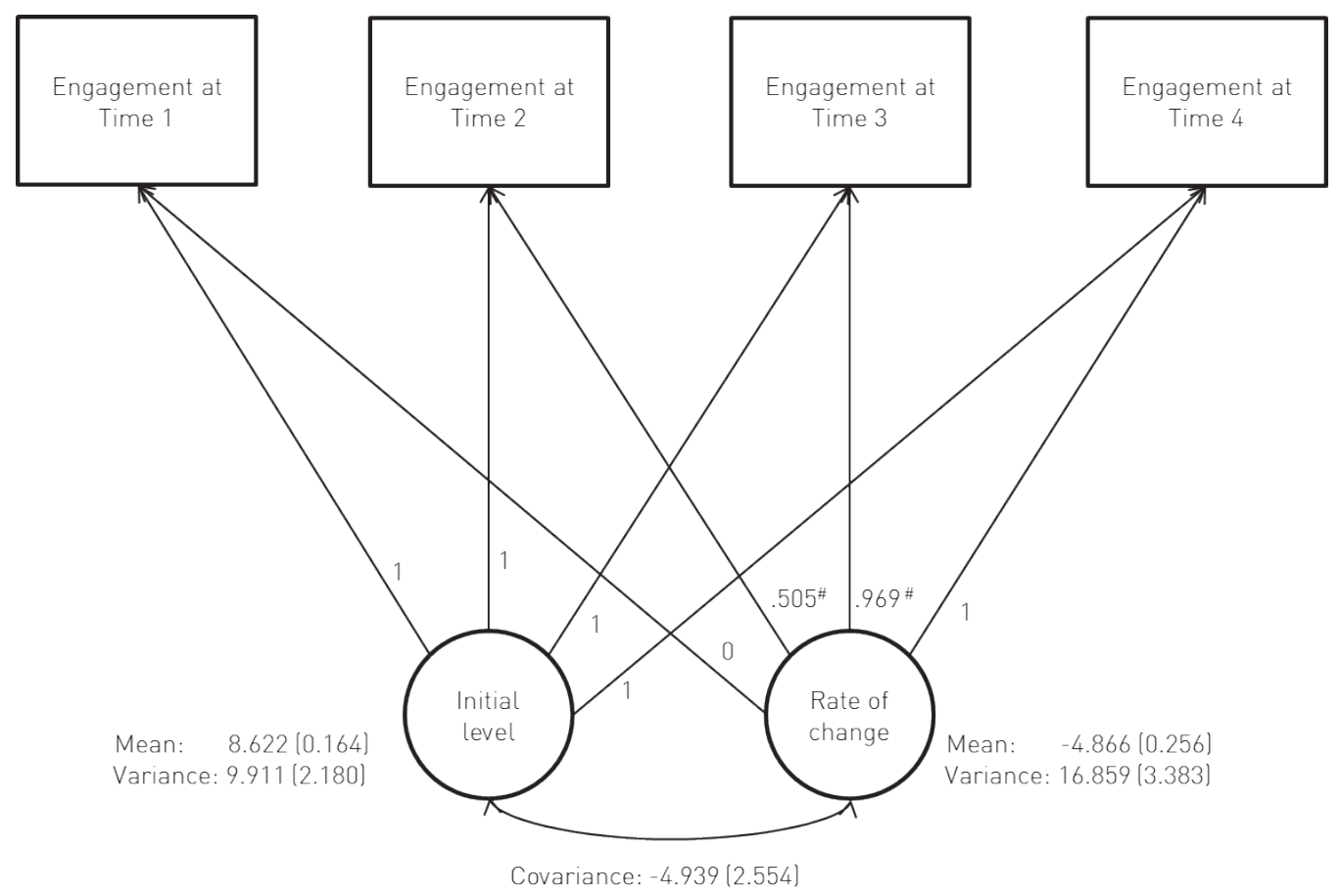

Notes: Numbers on the arrows from the growth factors to the outcome variables indicate factor loadings; \# indicates a freely estimated time score; numbers referring to the mean, variance, and covariance indicate estimates; numbers in parentheses indicate standard errors.

Figure 3.2 - Best fitting non-conditional growth model (Model 1.3) 
Interpreting growth factors. The significant means and variances of the two growth factors in Model 1.3 support our first hypothesis. However, interpreting these results is contingent on how we fixed the time scores for the model, in that we fixed the time score for time 1 at 0 and the time score for time 4 at 1 , whereas the scores for times 2 and 3 were freely estimated. ${ }^{9}$ For the initial engagement level growth factor, we find a significant mean $(8.622 ; p<.000)$ and variance $19.911 ; p<.000)$. The starting point of the developmental trajectory was set at time 1, so during the first week after the introduction of the game, users showed a common engagement level of about 9 minutes, but this level varied across users by about 10 minutes. In terms of the rate of change, we again find a significant mean $(-4.866 ; p<.000)$ and variance (16.859; $p \leftarrow .000$ ). From time 1 to time 4, the common change in user engagement diminished by about 5 minutes on average, and the rate of change varied between users by about 17 minutes. The model also estimates the covariance between the growth factors at $-4.939(p \leftarrow$.055), such that the rate of change in engagement depends on the initial engagement level, even if the significance is marginal.

The model also provides values for the freely estimated time scores. The estimated time score for time 2 was $.505(p<.000)$ (i.e., the rate of change during week 2 was .505 times the rate of change from week 1 to week 4), and the score for time 3 was $.969(p \leftarrow .000)$. Finally, the model provides R-square values for the variance explained lall significant at $p \leftarrow .000$ ) for the engagement outcome variables at each time period: .411 during week $1, .257$ during week 2, .445 during week 3, and .419 during week 4.

9 Thus, we observe the common change during the first month after the introduction (time 1 to time 4). Fixing the score for time 1 at 0 and the score for time 2 at 1, while freely estimating the scores for times 3 and 4, would have revealed the common change during the first week (time 1 to time 2). 


\section{Step 2 Growth Models}

In step 2, we use the best fitting growth model (Model 1.3) to test the effects of the growth factors on subsequent user engagement at Time 5, one year after the introduction. We therefore first estimate a new model that tests for the effects of the initial level and rate of change on subsequent user engagement by regressing subsequent user engagement on the two growth factors. The results (Model 2.1, Table 3.5) show significant, positive estimates for both the initial level $(.284 ; p<.010)$ and the rate of change $(.279 ; p<.001)$. The more engaged users are during the first week after the game's introduction, the more engaged they are one year later. The mean rate of change from week 1 to week 4 is negative, so the results imply that the less negative rate of change in engagement in the first month after the introduction leads to more engagement one year later. These results offer support for $\mathrm{H}_{2 \mathrm{a}}$ and $\mathrm{H}_{3 \mathrm{a}}$. 


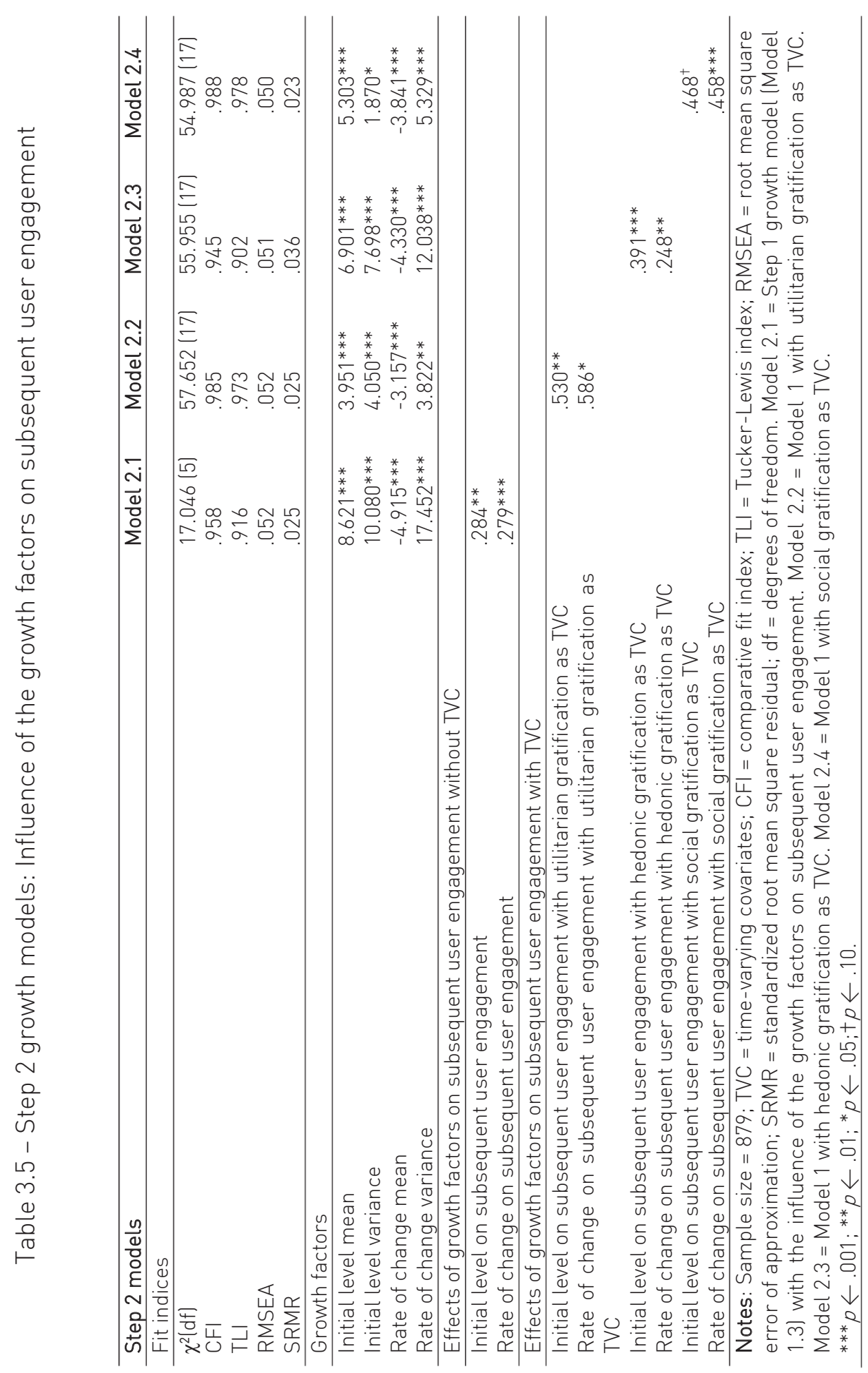


To test the robustness of these effects, we estimate three additional models in which we add a separate user gratification variable lutilitarian, hedonic, and social) as the TVC. In each model, the repeated outcome variables are functions of the growth factors and the repeated covariates (Bollen and Curran 2006). Moreover, in each model, we regress the subsequent user engagement outcome variable on the two growth factors and the four TVC variables lone TVC for each time period ${ }^{10}$ ). With these latter three models, we seek to control for the effects of user gratification on user engagement in each time period and examine whether the growth factors still influence engagement at Time 5. The results are in Table 3.5. With one exception, the initial engagement level and rate of change in engagement exert significant, positive influences on subsequent user engagement. Only when we control for social gratification do we find that the initial level has just a marginally significant influence on subsequent user engagement.

\section{Step 3 Growth Models}

In step 3, we use the best fitting growth model from step 1 (Model 1.3) to test the effects of the growth factors on subsequent user gratification (i.e., hedonic, utilitarian, and social at Time 5). For each subsequent outcome variable, we estimate two models: one in which we test for the influence of the user engagement growth factors on the subsequent outcome variable (Models 3.1.a, 3.2.a, and 3.3.a in Table 3.6) and one in which we also control for the repeated user gratification variables as TVC during the first month (Models 3.1.b, 3.2.b, and 3.3.b in Table 3.6). Similar to step 2, we test the first set of models by regressing the outcome variable on the growth factors, then test the second set of models by regressing each of the four repeated outcome variables, as well as the subsequent outcome variable, on the covariates during each time period. The graphical depiction of these tested models appears in Figure 3.3, and the results of the six models are in Table 3.6.

${ }^{10}$ In line with U\&G theory (e.g., Li et al. 2015; Williams, Yee, and Caplan 2008), each TVC variable had a significant, positive influence on user engagement in each time period (i.e., utilitarian, hedonic, and social gratifications during the first week each positively influenced user engagement during the first week, and so on for each time period). For simplicity we do not report these results. 


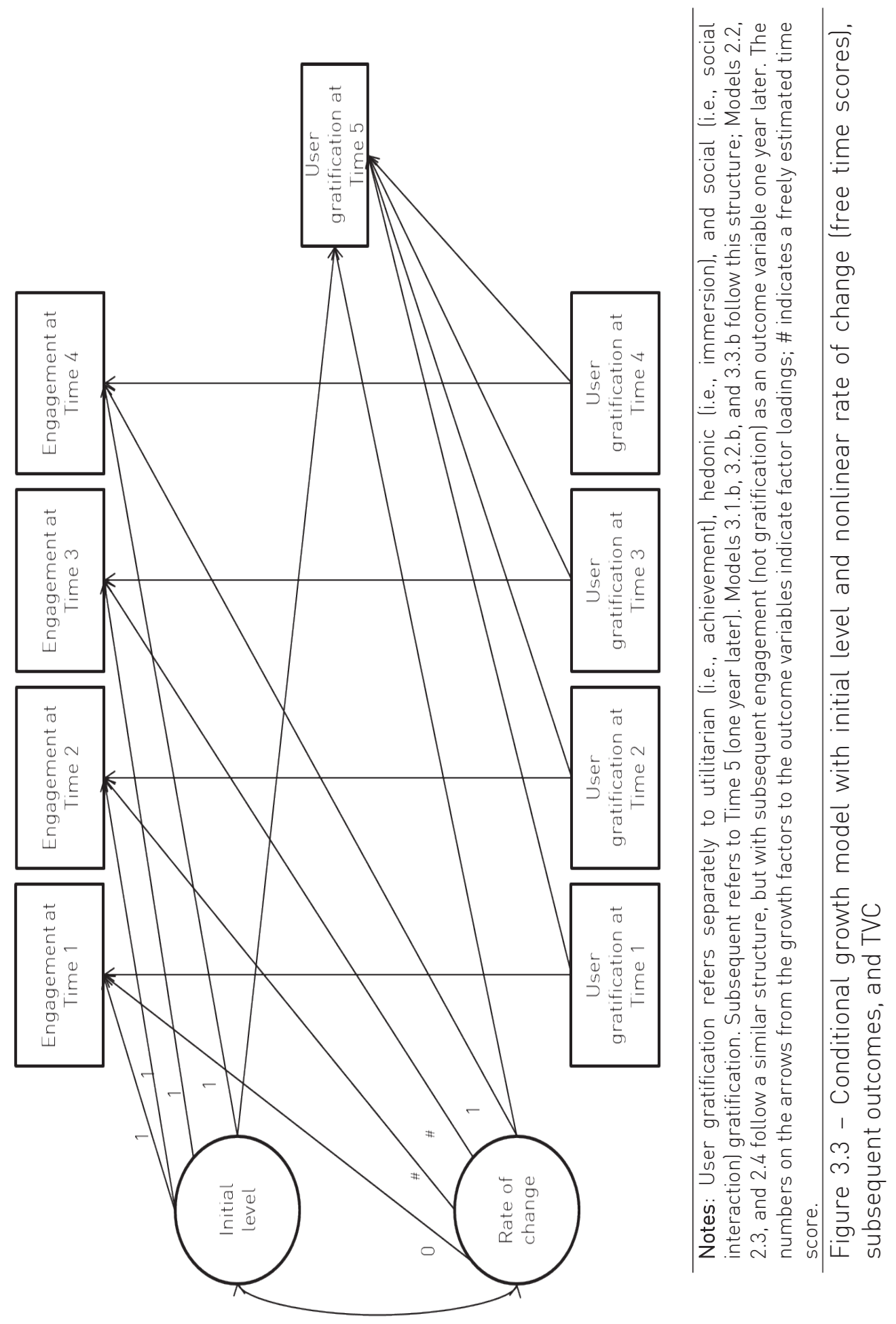




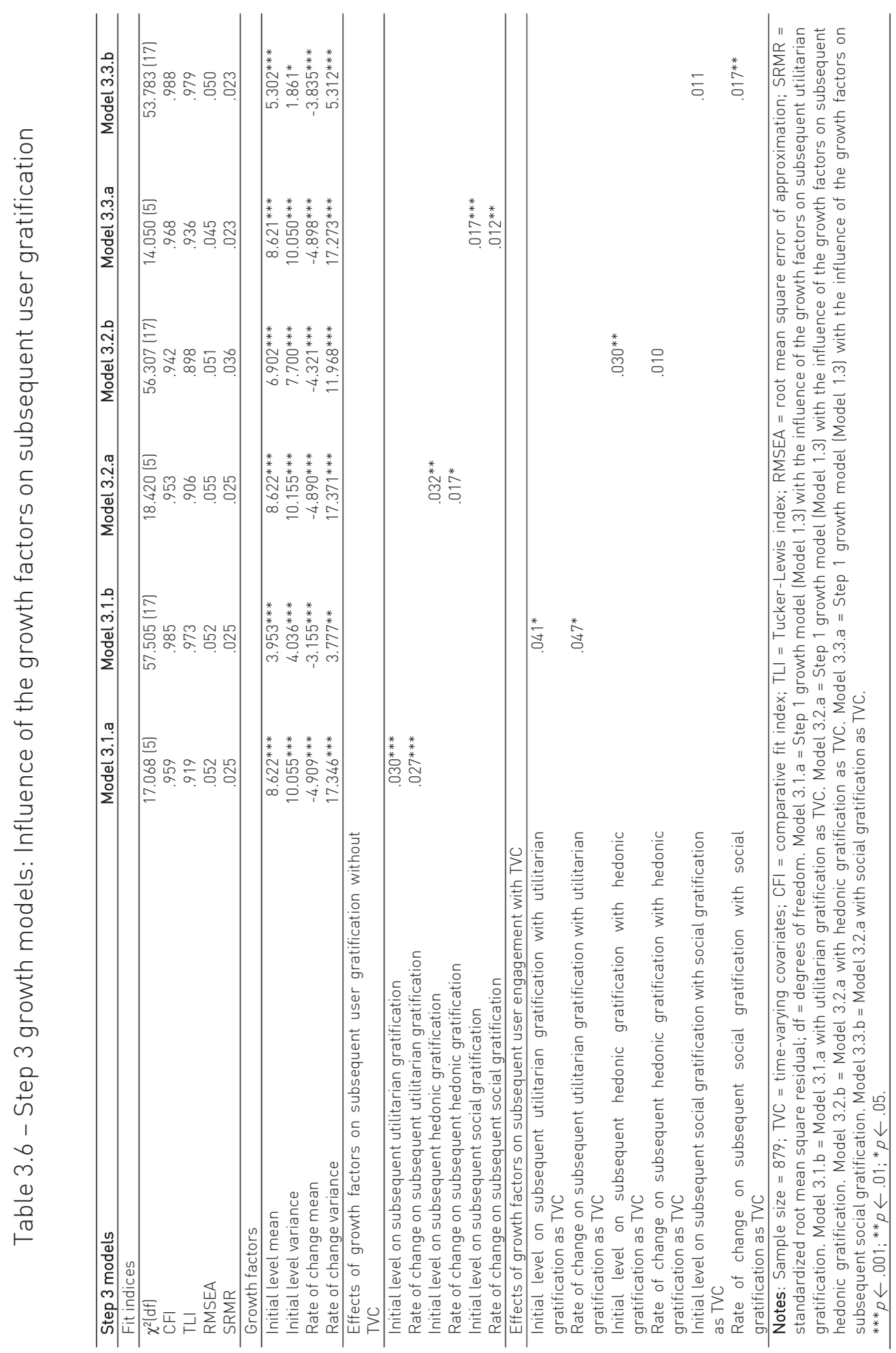


When we only account for the influence of the growth factors on each of the three user gratification variables, the initial engagement level and the rate of change in engagement both have significant, positive effects. However, when we control for the influence of the user gratification variables during the first four time periods, we determine that both growth factors have significant, positive influences on subsequent utilitarian gratification alone. The more engaged users are during the first week after the game introduction, and the less negative the rate of change in their engagement in the first month after the introduction, the more utilitarian gratification users experience one year later. These findings offer support for $\mathrm{H}_{2 \mathrm{bi}}$ and $\mathrm{H}_{3 \mathrm{~b}}$. For the influence of the growth factors on subsequent hedonic gratification while controlling for hedonic gratification during the first four time periods though, only the initial engagement level has a significant, positive influence. The more engaged users are during the first week after the game introduction, the more hedonic gratification they experience one year later. In this sense, we find support for $\mathrm{H}_{2 \mathrm{bii}}$ and partial support for $\mathrm{H}_{3 \mathrm{bii}}$. Finally, our investigation of the influence of the growth factors on subsequent social gratification, while controlling for social gratification during the first four time periods, reveals that only the rate of change in engagement has a significant, positive influence. The less negative the rate of change in engagement during the first month after the introduction, the more users interact socially one year later. We thus find support for $\mathrm{H}_{3 \text { biii }}$ but only partial support for $\mathrm{H}_{2 \text { biii. }}$.

\section{DISCUSSION}

In the introduction to this article, we formulated three research questions to address with our longitudinal empirical study. The results show that behavioral user engagement with a video game, assessed during the first month after the game's introduction, follows a common developmental trajectory across users that can be described by a positive initial engagement level but a negative rate of change in engagement. Users become less engaged with the video game from the first to the fourth week after its introduction. This homogeneous developmental trajectory has a positive influence on subsequent user engagement and user experience. Specifically, both the initial engagement level and the rate of change in engagement positively influence engagement and utilitarian gratification one year after the game introduction. Furthermore, the initial engagement level positively influences subsequent hedonic gratification, and the rate of change in engagement positively influences social gratification. 


\section{Theoretical Implications}

Our research makes several contributions to marketing research. We enrich literature on engagement in at least two ways (Brodie et al. 2011; Van Doorn et al. 2010). First, we provide an initial empirical examination of the dynamic nature of behavioral user engagement (Hollebeek, Glynn, and Brodie 2014). This examination accounts for inter-user variability in intra-user trajectories of engagement (Curran, Obeidat, and Losardo 2010). Individual users thus can have engagement trajectories of different magnitudes (i.e., steeper or less steep rates of change), but we capture the homogeneous development of engagement across users as a whole. Focusing solely on the level of engagement at a specific point in time provides a skewed perspective on user engagement, especially if some particularly engaged users tend to be active at that time (Libai 2011). Second, extant research mostly focuses on brands as focal objects of engagement (e.g., Hollebeek, Glynn, and Brodie 2014), whereas we consider sequential service offerings (Heath et al. 2015). This perspective is important, because such offerings tend to have shorter lifespans, so achieving high user engagement with each current iteration is of paramount importance for future iterations.

Our research also advances literature on the user experience (e.g., De Keyser et al. 2015; Verhoef et al. 2009) by providing an empirical examination of how behavioral user engagement and the user experience reinforce each other. In line with the U\&G approach, we show that satisfying utilitarian, hedonic, and social psychological needs keeps users motivated to engage with a service offering (e.g., Li et al. 2015; Williams, Yee, and Caplan 2008). Moreover, the growth factors that determine the homogenous engagement trajectory, developed across users, positively influence subsequent gratification. Although engagement naturally decreases over time (Van Doorn et al. 2010), smoothing its negative rate of change can lead to a fulfilling user experience, in terms of user achievement and social interaction, long after the service offering has been introduced.

Finally, we contribute to literature on digital service innovation (Lusch and Nambisan 2015; Ostrom et al. 2015) by emphasizing the importance of user engagement trajectories for iterated service offerings (Heath et al. 2015). A common behavioral engagement trajectory, developed across users during the period immediately after the introduction of a new service iteration, can drive 
subsequent engagement. Contrary to traditional innovation diffusion models that count on early markets (Chandrasekaran and Tellis 2011), iterated service offerings should strive to maximize engagement among the late market of users as soon as a new iteration is introduced.

\section{Managerial Implications}

Our results have implications for managers introducing new iterations in digital services. First, we emphasize the importance of the period immediately following the introduction of the new iteration in terms of developing behavioral user engagement. Service providers should ensure that they maximize gameplay across all users when they introduce a new iteration; they might encourage preorders by bundling a game download with unique in-game content (e.g., special map, limited edition item) or offering to double the number of points users can earn if they play during a specific period, namely, the launch day.

Second, the behavioral user engagement trajectory developed during the introduction period is critical for maintaining subsequent behavioral engagement. Both of the growth factors that determine the trajectory can enhance engagement one year later. Even if the rate of change is negative, a less steep drop in engagement during the first month still leads to greater engagement later. Thus, service providers can predict the potential success of a newly introduced iteration by monitoring user engagement during the first weeks and introduce engagement boosters if they observe any steep drops. For example, introducing additional game content that makes incremental changes to the game environment and provides users with new opportunities could help gratify them. Additional downloadable content might come in the form of expansion packages with new maps, items, or gameplay modes.

Third, we emphasize the importance of the behavioral user engagement trajectory that develops during the introduction period in leading to a fulfilling user experience later. Both growth factors positively influence utilitarian gratification one year later; the initial level positively influences utilitarian gratification, and the rate of change positively influences social gratification. Service providers thus should invest in building utilitarian and hedonic gratification in the first week, perhaps by publishing user and team achievements in traditional (e.g., rankings) or more innovative le.g., live broadcasts of gameplay, connections to social medial forms. 


\section{Limitations and Further Research}

Some limitations of this research should be considered as research opportunities. First, we focus on behavioral engagement, but engagement is a multifaceted construct (Brodie et al. 2011). Further studies thus might consider affective and cognitive facets of engagement le.g., Hollebeek, Glynn, and Brodie 2014), such as growth or subsequent outcomes. Second, our data are purely behavioral and telemetric; we cannot describe users' non-behavioral variables (e.g., attitudes toward the game, socio-demographics or geo-location). Additional research might find ways to combine behavioral and attitudinal data le.g., take survey measures at different points in time and use them as TVC in growth curve models) to achieve a deeper understanding of how users perceive their experience at different times and the varying influences on their engagement. Alternatively, GCM can add time-invariant covariates, to uncover determinants of the growth factors that are constant across time (Bollen and Curran 2006). In this sense, researchers might include behavioral (e.g., engagement with previous iterations in the franchise or competing offerings) or attitudinal variables measured before the introduction of a digital service as time-invariant covariates. Third, our research zooms in on a single, very successful video game. Observing user engagement with multiple games with different types of gameplay (e.g., RPG, adventure, sports), using GCM, researchers might estimate parallel growth trajectories (Curran and Hussong 2003), which would be useful for clarifying user engagement with multiple video games. Fourth, we focus on a rather hedonic digital service. Further research could benefit from determining user engagement trajectories for more utilitarian services (e.g., mobile payment). 


\section{CHAPTER 4}

\section{Engagement with a Gradual Digital Service Innovation}

\section{Coping with Innovation in Digital Services: Consequences for the User Experience}

"HAL: Look Dave, I can see you're really upset about this. I honestly think you ought to sit down calmly, take a stress pill, and think things over." (2001: A Space Odyssey, 1968) 


\section{INTRODUCTION}

Digital (or technology-based) services such as Facebook, Netflix, Skype, and Uber constitute a rapidly developing business sector with the potential to enhance user experiences and disrupt traditional markets and business models (Ostrom et al. 2015). In these increasingly complex, demanding environments, service innovation becomes a key competitive strategy for ensuring a company's survival (Snyder et al. 2016) but also requires consideration of how to manage disruptive service innovations (Biemans and Langerak 2015). Relatively little research attention centers on ways to manage innovation in existing digital services, despite it being a top priority for managers (Storey et al. 2015). In digital services settings, product life cycles also are growing more dynamic and difficult to control, such that providers of existing services must introduce innovations at a quicker pace (Nylén and Holmström 2015). Successful innovations in existing digital services are fundamental to enabling service providers to stay competitive; for example, $25 \%$ of participants in an annual global survey on the state of innovation predict that extensions of existing services will have the greatest impact on their industry in the near future (BCG 2015).

Yet despite this managerial relevance, we know relatively little about users' perspective on innovations newly introduced to existing services, especially in terms of how they affect the user experience (Bettencourt, Brown, and Sirianni 2013). Addressing this gap is crucial, because it may hold the key to understanding why so many digital services fail to keep their users engaged (Ostrom et al. 2015). Therefore, identifying the consequences of innovating existing digital services on users' experience is a top research priority (Barrett et al. 2015; MSI 2016), and to address it, we investigate innovation in an existing digital service that adds new features that alter how the user interacts with the service-thus changing the user experience. The more new features the innovation entails, the more its complexity increases (Patel et al. 2014). Regardless of the number of new features introduced though, the core offering of the digital service does not change fundamentally, which implies a form of incremental innovation (Snyder et al. 2016). For example, an updated Skype 
version that adds a new toolbar with icons for file and photo sharing is an innovation in an existing digital service with relatively low complexity. ${ }^{11}$

The change in the user experience is subjective: Some users will assess it as positive (something to pursue), but others will see it negatively (something to avoid). Regardless of their assessment, the change in the user experience may tax or exceed their resources (Nylén and Holmström 2015). For providers that want users to continue using their digital services, after the innovation is introduced, it therefore is crucial to understand how users manage this newly required resource investment, incurred by the change in their experience. We accordingly formulate four research questions: (1) How do users perceive changes in their experience due to innovation in existing digital services? (2) How do users manage these changes? (3) What effect do the strategies that users employ to manage the changes have on their relationship with the service provider? and (4) What role does innovation complexity play in this process?

To answer these research questions, we adopt appraisal and coping theory (Lazarus and Folkman 1984), a well-established, social-psychology theoretical lens that explains how people manage perceived change. Thus, we conceptualize incremental service innovation as a stressor that affects the user experience and advance a conceptual model of how users deal with innovation in an existing digital service. We empirically test our model in a field study, then expand it with an experimental study. Accordingly, we investigate (1) whether users consider the stressor something to be pursued (i.e., appraisal as a challenge) or something to be avoided (i.e., appraisal as a threat); (2) how users manage the stressor, depending on the coping resources they possess (i.e., self-efficacyl and the coping strategies they can deploy (i.e., problem-focused, emotion-focused, or social support coping); (3) what outcomes result for the user from managing the stressors, in relation to the innovated service (passion) and the innovation (usefulness); and (4) innovation complexity as a boundary

${ }^{11}$ A new Skype version that introduces general fixes but does not add new features, in contrast, would not affect how the user interacts with the service and thus is not considered an innovation in an existing service (https://support.skype.com/en/faq/FA34509/what-s-new-in-skype-for-windowsdesktop). 
condition on how users appraise and cope with the changes brought about by digital service innovations.

This approach produces several contributions for innovation literature. First, we focus on users of digital services, as opposed to employees in organizations (e.g., Ayyagari, Grover, and Purvis 2011), to explicate how users perceive innovation (Mahr, Lievens, and Blazevic 2014). Second, we contribute to incremental service innovation literature (e.g., Snyder et al. 2016) by conceptualizing an incremental service innovation as a stressor in the relationship with a digital service provider that also affects the user's experience. Third, with our use of appraisal and coping theory, we introduce and empirically test a conceptual model of how users manage changes in their experience, stemming from incremental service innovation (Snyder et al. 2016). In so doing, we draw attention to how innovation affects digital users' experience (Barrett et al. 2015). Fourth, we advance innovation outcomes literature (e.g., Li, Zhang, and Wang 2014) by establishing user coping strategies as drivers of both affective (i.e., passion) and cognitive (i.e., usefulness) outcomes. Fifth, we establish innovation complexity as a boundary condition in relation to how users manage innovation in existing digital services (Martinsuo and Poskela 2011). The interplay of appraisal, coping, and innovation complexity bridges innovation and consumer psychology research (Duhachek 2005). Consequently, our findings can help managers understand how to facilitate positive user experiences when introducing incremental service innovations and thus keep their users engaged with their digital services.

The remainder of this article is structured as follows: First, drawing on digital service innovation and appraisal and coping literature, we elaborate why incremental service innovation can be regarded as a stressor affecting the user experience. Second, we formulate hypotheses and present a conceptual model of how users deal with innovation stressors. Third, we describe the procedure and analysis and discuss the results of our field and then our experimental study. Fourth, we conclude by discussing the implications of our findings for theory and practice. 


\section{CONCEPTUAL BACKGROUND}

\section{Innovation in Existing Digital Services}

Service innovation continues to be a research priority in multiple fields, including innovation management (Biemans and Langerak 2015), service (Ostrom et al. 2015), marketing (MSI 2016), and information systems (Barrett et al. 2015). Most innovation research focuses on new-to-the-market services (e.g., Evanschitzky et al. 2015) or radical service innovations (e.g., Perks, Gruber and Edvardsson 2012), but relatively less attention focuses on innovation in existing digital services. Such attention is warranted though, because innovating existing digital services remains a top priority for managers, and most innovation in existing services is incremental (Storey et al. 2015). Digitalization also facilitates incremental service innovation, because digital technologies are malleable and support a faster pace of introduction (Nylén and Holmström 2015). But digitalization makes incremental service innovation more difficult to control, because users face more frequent changes to their experience with the digital services (Barrett et al. 2015). These changes often stem from aesthetic or usability modifications, brought about by new features that affect how users interact with the digital service (Berry et al. 2010; Snyder et al. 2016). Moreover, the changes usually are external to users (Ayyagari, Grover, and Purvis 2011), who rarely have a choice about adopting the incremental innovations and instead must devote efforts to managing the changes if they want to continue using the service. The proliferation of digital technology, reduction of product life cycles, and advancement of user expectations in combination suggest that introducing innovation in existing digital services potentially either enhances or diminishes the user experience (Nylén and Holmström 2015). Ensuring superior user experiences following each innovation in existing digital services thus is a priority for providers, because improved customer experiences are instrumental for generating user engagement (MSI 2016; Ostrom et al. 2015).

\section{Appraisal and Coping with Digital Service Innovation}

Perceived change in the user experience is central to understanding the consequences of innovating existing digital services. The service provider intends the innovation to have positive consequences (i.e., enhance the user experience), but from the user's perspective, it also might have unintended, negative consequences (i.e., diminish the user experience). Research in 
organizational settings (Ayyagari, Grover, and Purvis 2011; Tarafdar, Pullins, and Ragu-Nathan 2015) indicates that introducing a new technology in the workplace can become a stressor for employees, with positive and negative consequences on their job performance. We follow a similar logic but focus on users in the marketplace rather than employees in an organization. Thus, we conceive of innovation in an existing digital service as a stressor that can affect the user-service provider relationship because it brings changes to the user experience.

\section{Digital service innovation as a stressor}

The stressor concept is rooted in appraisal and coping theory (Lazarus and Folkman 1984), which helps explain how people manage change (Moschis 2007). Specifically, appraisal and coping theory posits that stress is a subjective state that occurs because of the discrepancies between people's interpretations of external conditions (e.g., innovation by a digital service provider) and their internal characteristics (e.g., experience with the digital service) (Lazarus and Folkman 1984). Stress refers to a person's internal arousal; a stressor is the external circumstance that creates that perceived discrepancy (Aneshensel 1992). We focus on discrete or acute stressors, which are objective, external occurrences of sufficient magnitude to change the activities of most persons and which have clear origins in time (Aneshensel 1992; Moschis 2007). Because innovation in an existing digital service usually is external to the user, we consider it a discrete stressor, subjectively evaluated by the user. When faced with a stressor stemming from innovation in an existing digital service, users first must determine the extent to which it changes their experience with the service (i.e., appraisal).

\section{Appraisal}

In the appraisal process, people evaluate if an encounter with the environment is significant for their well-being and, if so, whether that encounter is primarily threatening or challenging (Lazarus and Folkman 1984). Threat appraisal usually is presented negatively, because it arises in response to changes that produce excessive or undesirable constraints or demands (i.e., losses). Challenge appraisal instead is usually regarded as positive, in that it results from changes that provide people with opportunities to attain something they desire (i.e., gain) (Bhagat et al. 1985). When confronting a stressor stemming from innovation in an existing digital service, users might primarily appraise the 
change in their experience as a challenge, because it promises to improve how they interact with the service, or as a threat, because it might harm this interaction. The fundamental step that follows after appraisal is determining how the change in the user experience can be managed (i.e., coping).

\section{Coping}

Coping reflects constant cognitive or behavioral efforts to manage a change brought about by a stressor that has been appraised as taxing or exceeding available resources (Lazarus and Folkman 1984; Moschis 2007). In line with recent extensions of appraisal and coping theory in consumer behavior contexts (e.g., Duhachek 2005; Duhachek and lacobucci 2005), we focus on coping strategies, which we define as contextual mechanisms that can be employed to manage specific, appraised stressors, such as problem-focused, emotionfocused, and social support coping, and coping resources, which are the preexisting characteristics people may call on to address a stressor, such as self-efficacy (Aneshensel 1992; DeLongis and Holtzman 2005). The various types of coping outcomes considered in social-psychology research usually focus on individual psychological or physiological well-being (DeLongis and Holtzman 2005). Knowledge about coping with innovation, especially beyond organizational contexts, instead remains in the early phases of development (Ayyagari, Grover, and Purvis 2011).

\section{HYPOTHESES DEVELOPMENT}

\section{Appraisal and Coping Strategies}

When an innovation is introduced in existing digital services, users anticipate changes in how they interact with the service, which changes their user experience (Berry et al. 2010; Nylén and Holmström 2015). They evaluate the anticipated change according to how it affects their resource investment, or the extent to which it taxes or exceeds their adaptive resources (Barrett et al. 2015). If this appraisal indicates a threat, it likely does not warrant the resource investment, whereas if it is a challenge, it justifies that investment (Lazarus and Folkman 1984). Yet regardless of their actual appraisal, users must find a way to cope with the anticipated change if they want to continue using the digital service (Evanschitzky et al. 2015). Specifically, users must invest conscious cognitive and behavioral efforts to manage the adaptational demands prompted by the perceived change in their experience (Lazarus and Folkman 1984). It is 
not possible for users to adapt to innovation in existing digital services without employing coping strategies that provide situational means to manage the taxed or exceeded resources (Moschis 2007).

Three general types of coping strategies have been established in appraisal and coping literature (DeLongis and Holtzman 2005; Duhachek and lacobucci 2005; Moschis 2007). Problem-focused coping consists of efforts meant to address the change brought about by the innovation directly le.g., trying the new feature). Emotion-focused coping entails efforts meant to manage the emotions resulting from the change le.g., venting on the service provider's social media page). Finally, social support coping involves eliciting help from peers to manage the change, whether in a problem-focused le.g., asking friends for assistance) or emotion-focused (e.g., asking friends for comfort) way. When users' appraisals are stronger (threat or challenge), their coping efforts should be stronger as well. Therefore,

H1: Users' threat appraisal of innovation in an existing digital service has a positive influence on their use of (a) problem-focused, (b) emotion-focused, and (c) social support coping strategies.

H2: Users' challenge appraisal of innovation in an existing digital service has a positive influence on their use of (a) problem-focused, (b) emotion-focused, and (c) social support coping strategies.

Coping Resources and Coping Strategies

Service providers increasingly must introduce innovations to existing digital services, which suggests that users who want to continue using the services become more accustomed to changes to their experience (Barrett et al. 2015; Nylén and Holmström 2015). Through learning processes, these users likely develop coping resources over time, including a greater sense of their own efficacy in dealing with digital service innovations (Bandura 1977; Lazarus and Folkman 1984). These developed coping resources reduce the effort required, because they diminish the resource investments necessary to manage changes (Moschis 2007). Whereas coping strategies are situational responses to an appraisal, coping resources are relatively stable characteristics that each person can call on after appraising a stressor (Aneshensel 1992; DeLongis and Holtzman 2005).

Self-efficacy is a person's conviction that she or he can successfully execute the behavior required to produce an outcome (Bandura 1977); it offers an 82 
effective coping resource (Aneshensel 1992; Aspinwall and Taylor 1992) and has been proposed as an antecedent of coping strategies (Duhachek 2005; Gist and Mitchell 1992). Self-efficacy with digital services in particular (Van Beuningen et al. 2009) may have a buffering role in managing stressors in an organizational context (e.g., Ayyagari, Grover, and Purvis 2011; Tarafdar, Pullins, and RaguNathan 2015). We expect self-efficacy as a coping resource to act in parallel with appraisal to influence the use of coping strategies, to the extent that the more self-efficacy users develop, the less coping efforts they must incur. We hypothesize:

H3: Users' possession of self-efficacy has a negative influence on their use of (a) problem-focused, (b) emotion-focused, and (c) social support coping strategies.

\section{Affective and Cognitive Outcomes of Employing Coping Strategies}

In response to an innovation introduced in an existing digital service, users make efforts to manage the situational demands created by the change (Moschis 2007). Whether their initial coping strategies are successful or not, the more effort users put into coping, the more they interact with the innovated service. With our focus on strategies that can enhance user experiences, we consider two outcomes of coping with an innovation in an existing digital service: affective (i.e., becoming passionate about the innovated service) and cognitive (i.e., finding the innovation useful). When users devote more effort to employing coping strategies, they likely develop more positive affective and cognitive outcomes.

On the affective side, the more effort users put into coping, the more they interact with the innovated service, which can build feelings of attachment and increased desire to use the service (Batra, Ahuvia, and Bagozzi 2012). Developing such feelings is characteristic of becoming passionate, a recently introduced potential driver of customer-firm affection that helps explain users' emotional connection to service providers (Batra, Ahuvia, and Bagozzi 2012; Yim, Tse, and Chan 2008). Passion is an important outcome of coping with innovation in an existing digital service, because it translates into intense lalbeit short-term) feelings toward the innovated service (Yim, Tse, and Chan 2008). We therefore hypothesize: 
H4: Employing (a) problem-focused, (b) emotion-focused, and (c) social support coping strategies makes users more passionate about the innovated service.

On the cognitive side, the more effort users put into coping, and the more they interact with the innovated service, the better they should realize that it is meant to improve their digital service usage performance, which is a perception analogous to the well-established concept of usefulness from the technology acceptance model (Venkatesh and Davis 2000). Usefulness is an important outcome of dealing with innovation in an existing digital service, because it drives higher usage intentions (Schepers and Wetzels 2007). If users perceive the service innovation as useful, it also is likely to be more successful (Li, Zhang, and Wang 2014). We hypothesize:

H5: Employing (a) problem-focused, (b) emotion-focused, and (c) social support coping strategies makes users perceive the innovation as more useful.

Our proposed conceptual model of how users manage innovation in an existing digital service is in Figure 4.1.

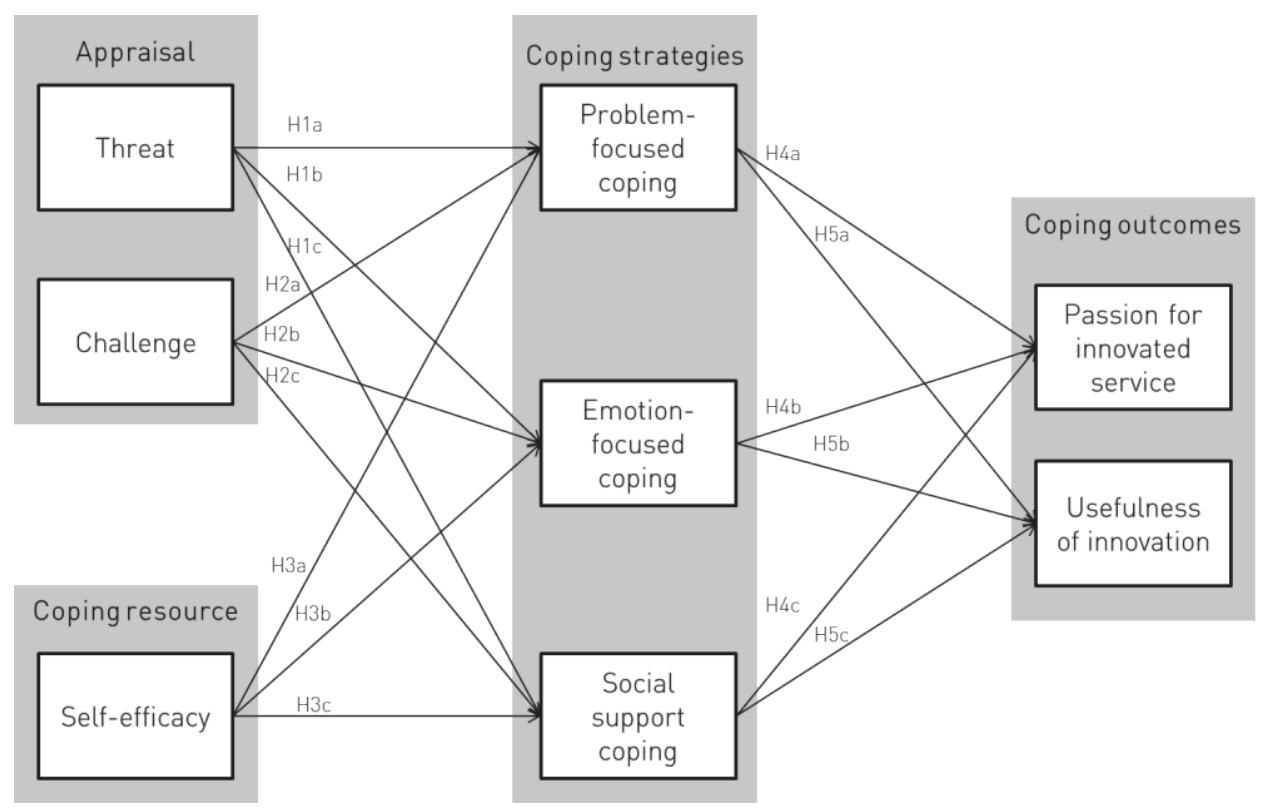

Figure 4.1 - Conceptual model of how users manage innovation in existing digital services 


\section{METHODOLOGY}

\section{Field Study}

The purpose of this first study is to test the conceptual model of how users manage innovation in an existing digital service in a real-life context. We focus on the digital socialization service Facebook, a popular online service used daily by more than 1 billion people worldwide in 2015. ${ }^{12}$ Facebook offers continuous service innovation; in 2015 alone, it introduced dozens of innovations, including the Messenger application (app) platform, Instant Articles, Moments, and 360 Videos. For our field study, we focused on a specific innovation by Facebook, introduced globally in 2012: the Timeline, which changed the type of user profile information depicted on the platform in the form of new features such as cover photos and activity logs. This innovation explicitly sought to change users' experience with Facebook, and it became the default soon after its rollout: Continuing to use Facebook was contingent on using the Timeline.

\section{Participants}

One hundred fifty Facebook users were recruited from a West European university, after the introduction of the Timeline, to take part in the field study. While convenience sampling was employed, the participants' demographics and usage statistics reflected the typical profile of the majority of Facebook users during that time period (Pew Research Center 2015). However, 10 participants were removed due to their lack of familiarity with the Timeline innovation. The remaining 140 users had an average age of 20.82 years (SD $=1.50$ ), and $51 \%$ were women. Using Facebook was relevant for their day-to-day activities, such that on average, they spent 86.01 minutes daily using the service (SD $=67.79$ ) and logged in to the service 7.97 times daily $(S D=8.81$ ).

${ }^{12}$ See http://newsroom.fb.com/company-info/ 


\section{Procedure}

Participants completed an online survey, shortly after the introduction of the Timeline, which asked them to describe briefly what they thought and felt when the innovation was introduced, using a textbox. Participants then answered questions related to their appraisal of the innovation, the coping resources they possessed, the coping strategies they used to manage the innovation, and the outcomes of their coping (i.e., how passionate they were toward the innovated service and how useful they found it). All the constructs, illustrative quotes from the respondents' open-ended answers, the scales used to measure them, and their reliability are available in Appendix A. Confirmatory factory analysis (with Principal Axis Factoring as an extraction method and Promax with Kaiser Normalization as a rotation method) was employed to assess unidimensionality and validity with all requirements being met (DeVellis 2003). Table 4.1 provides an overview of the descriptive statistics and correlations across variables.

\section{Analysis}

We first estimate the conceptual model using seemingly unrelated regression (SUR) with a system of five linear equations (see Panel $A$ in Table 4.2 for an overview of the dependent variables and regressors in each equation). The SUR method is based on generalized least squares and is more efficient than ordinary least squares regression when the regressors differ across a set of equations, because it accounts for correlated errors (Zellner 1962). The significant Breusch-Pagan-Lagrange multiplier test for error independence $\left(\chi^{2}(10)=60.872, p \leftarrow .001\right)$ shows that the errors in the five equations are correlated, and the R-square for each individual equation is statistically significant at a minimum of $p<.05$, so use of SUR is recommended (Cameron and Trivedi 2009). 
ENGAGEMENT WITH A GRADUAL DIGITAL SERVICE INNOVATION

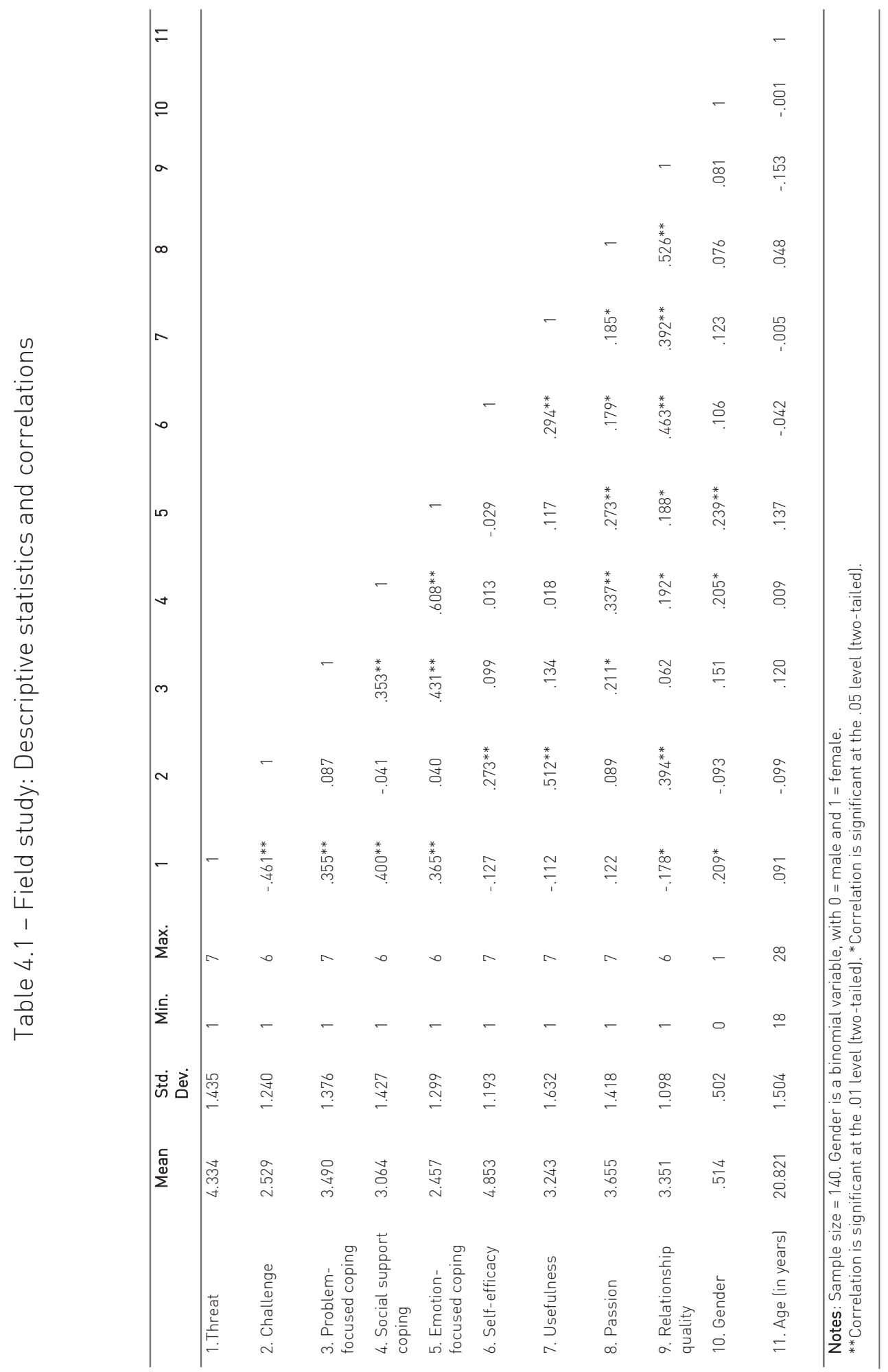


Because our data came from single informants, we test for common method variance bias (Lindell and Whitney 2001). We include learning goal orientation (Mun and Hwang 2003) as a marker variable with very low, non-significant correlations with the two main outcome variables (passion $=.02$, usefulness = .05), as well as low correlations with all other measured variables (Mahr, Lievens, and Blazevic 2014). Controlling for learning goal orientation in the correlations in Table 4.1 does not affect the significance of the initial correlations or their magnitude. Furthermore, adding learning goal orientation as a covariate in all SUR equations does not change the significance of the results in Table 4.2. Therefore, bias due to common method variance does not pose a threat to this study's findings (Lindell and Whitney 2001).

\section{Results}

The coefficients and their standard errors, obtained from the SUR estimator (sureg command) in STATA 12.0 SE, are in Table 4.2. Users' appraisal of the introduction of innovation in an existing digital service positively influences their use of coping strategies, in support of $\mathrm{H} 1$ and $\mathrm{H} 2$. Whether they appraise the innovation as a threat or a challenge, users employ problem-focused, emotionfocused, and social support coping strategies $(p<.01)$. However, possessing coping resources, in the form of self-efficacy, does not have a significant effect on the use of any of the three coping strategies, so we cannot confirm H3. Employing a social support coping strategy influences users, making them more passionate about the innovated service $(p<.05)$; a problem-focused coping strategy instead leads them to perceive the innovation as more useful I $p$ $\leftarrow$.05). Therefore, we find support for $\mathrm{H} 4 \mathrm{C}$ and $\mathrm{H} 5 \mathrm{a}$. 
Table 4.2 - Field study: SUR results

Panel A: Conceptual Model Results

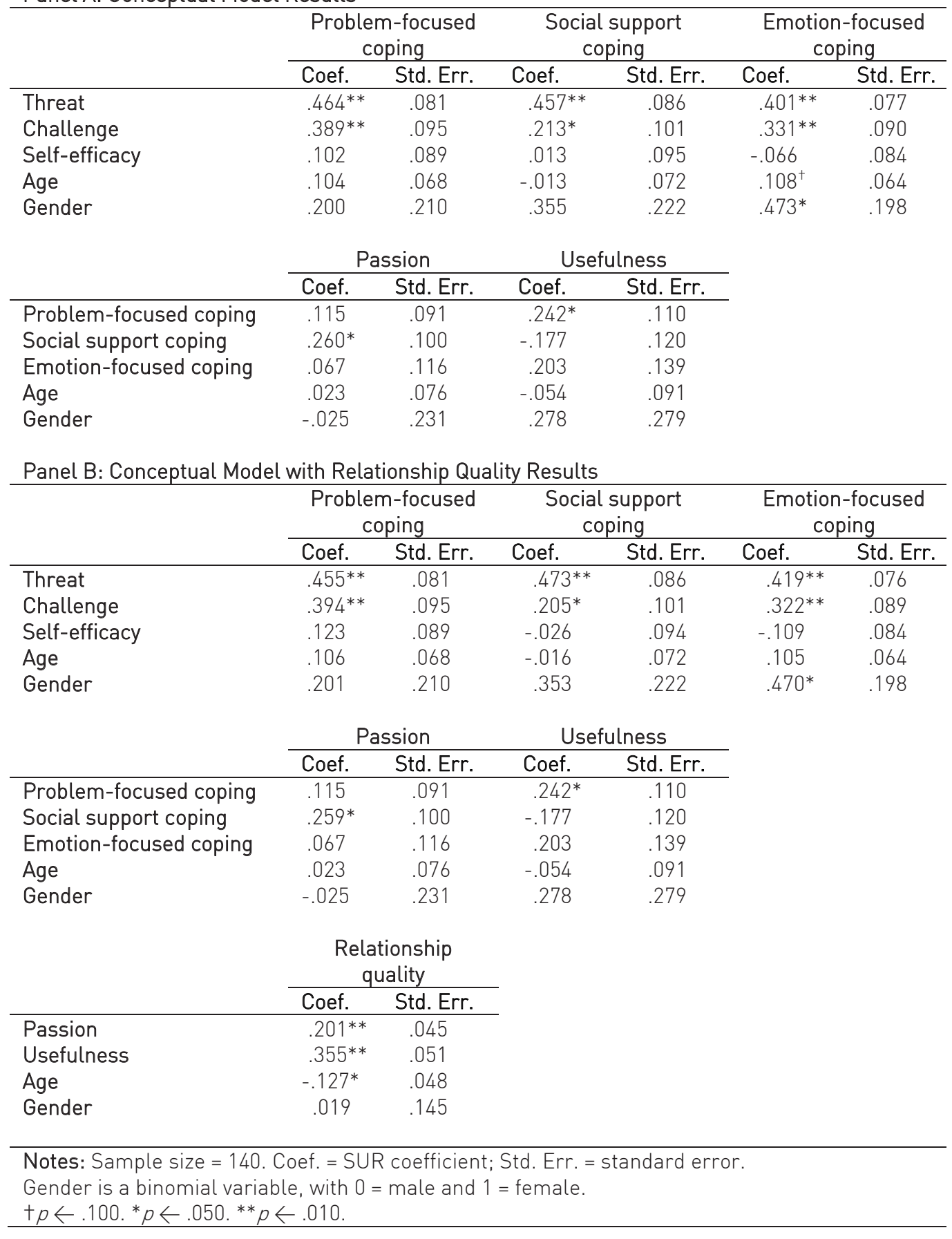




\section{Additional analysis}

To enhance the managerial validity of our findings, we test for the influence of passion and usefulness on relationship quality, measured as an aggregate of satisfaction with, trust in, and commitment to the service (De Wulf, OdekerkenSchröder, and lacobucci 2001). We ask the participants to assess the quality of their relationship with the service, after the introduction of the innovation, such that we add a sixth equation to the SUR system (Breusch-Pagan test of independence: $\left.\chi^{2}(15)=65.896, p \leftarrow .001\right)$. The results in Panel $\mathrm{B}$ in Table 4.2 show that both affective (passion) and cognitive (usefulness) outcomes of dealing with the innovation have positive, significant effects on the quality of the relationship with the service in general $(p \leftarrow .01)$.

To check for robustness, we test the two systems of SUR equations (without and with relationship quality as a final outcome), using the same measurements, procedure, and methodology but focusing on a different existing digital service, namely, the digital learning service Blackboard. We asked 147 Blackboard users (20.9 years old on average [SD $=1.33$ ], 52\% women) how they dealt with the introduction of version 9 of Blackboard. Similar to the Facebook Timeline, this innovation imposed new features, meant to change the users' experience with Blackboard. An independent samples t-test $(p \leftarrow .001)$ shows that compared with Facebook, Blackboard was perceived as less hedonic. ${ }^{13}$ The significant results and directions obtained in the Facebook study were replicated in the Blackboard study, with one exception: Problemfocused coping $(p \leftarrow$.05) rather than social support coping positively affects passion in relation to Blackboard. This result might reflect Blackboard's less hedonic character, or it could stem from the relatively limited opportunities for asking and providing social support that it offers compared with Facebook. That is, as an online socialization service, Facebook inherently provides ample opportunities to interact with other users.

13 In both the Facebook and Blackboard studies, the extent to which the service was perceived as hedonic was measured using five items, anchored by "not fun/fun," "dull/exciting," "not delightful/delightful," "not thrilling/thrilling," and "enjoyable/unenjoyable" (Gill 2008), such that the results indicated $M_{\text {Facebook }}=4.57$ (SD = 1.05 ) and $M_{\text {Blackboard }}=3.34$ (SD = 1.09). 


\section{Experimental Study}

The purpose of the experimental study is twofold: to decontextualize the findings of the field study and to uncover a potential boundary condition (i.e., innovation complexityl in our conceptual model that could explain why we did not find any influence of self-efficacy on the use of coping strategies. Therefore, we attempt to avoid any associations that users might have with the new features of an innovation in an existing digital service, because in the field study, participants had to engage with a real-life innovation they experienced firsthand. Furthermore, innovation complexity offers a likely boundary condition for several reasons. First, consumer research acknowledges that new product complexity can overwhelm users and make them dissatisfied, especially prior to usage (Thompson, Hamilton, and Rust 2005). We therefore expect that innovation complexity moderates the way in which users appraise and cope with the change brought about by innovation in existing digital services: The more complex the innovation, the stronger the influence of appraisal on coping. Innovation complexity also might activate the negative influence of self-efficacy on employing coping strategies, because task complexity constitutes an external determinant of self-efficacy (Gist and Mitchell 1992). Second, new product development research has explored the contingent role of innovation complexity in determining the market success (Talke and Hultink 2010) or future business potential (Martinsuo and Poskela 201) of innovations. Thus, we expect innovation complexity to interact with the coping strategies employed by users and influence how passionate they are about the innovated service, as well as how useful they find the innovation.

\section{Procedure}

Users perceive innovation complexity in terms of the number of new features introduced by that innovation; more new features indicate greater complexity (Patel et al. 2014; Thompson, Hamilton, and Rust 2005). In our experimental study, we therefore tell participants that Facebook has innovated its service by adding new features meant to change its users' experience, then manipulate innovation complexity as the number of new features introduced without actually specifying what those features are (see Appendix B). We pretested the complexity manipulation with 71 graduate students who participated for partial course credit laverage age 23.50 years [SD = 1.98]; 68\% women). These participants were randomly split into two groups and exposed to a hypothetical 
Facebook innovation containing either one new feature or nine new features. As a manipulation check, we asked if they believe that the innovation introduces several new features, with two seven-point scales anchored by "not at all complex/very complex" and "do not agree at all/agree very much" (Martinsuo and Poskela 2011). The independent sample t-tests reveal statistically significant mean differences on both manipulation checks, with at least $p<$ .05. Therefore, we use the manipulation in which one new feature depicts low complexity and nine new features indicate high complexity.

\section{Participants}

One hundred nine Facebook users, with an average age of 34.06 years (SD = 10.46; 52\% women) were recruited from Amazon Mechanical Turk, an established data collection platform for the social sciences. All participants were familiar with Facebook and had a personal Facebook profile, for 7.81 years on average (SD = 2.39). Participants were randomly assigned to either the low (Facebook introduces an innovation with one new feature) or high (Facebook introduces an innovation with nine new features) complexity condition. The independent sample t-tests show that participants perceive that the Facebook innovation with nine new features includes many more new features $\left(p \leftarrow .01 ; M_{\text {Low }}=3.85, S D=2.02 ; M_{\text {High }}=6.00, S D=1.23\right)$ and is more complex $\left(p<.05 ; M_{\text {Low }}=3.09, \mathrm{SD}=1.76 ; M_{\text {High }}=3.98, \mathrm{SD}=1.38\right)$ than the Facebook innovation with one new feature (Martinsuo and Poskela 2011). On average, participants consider the situation presented realistic $(M=5.96, S D=$ 1.19), and they largely pass the attention tests that checked whether they believe the Facebook innovation was meant to change what they could do when using Facebook ( $M=5.11, S D=1.56)$. These items used seven-point scales, anchored by "strongly disagree/strongly agree." The constructs and scale items were the same as those in the field study (see Appendix A). The descriptive statistics and correlations are in Table 4.3.

\section{Analysis}

Similar to the procedure for the field study, we first estimate the conceptual model using SUR with a system of five linear equations (see Panel A in Table 4.4 for an overview). Each equation contains an additional regressor though: innovation complexity, a binomial variable for which 0 indicates low complexity (Facebook innovation with one new feature) and 1 is high complexity (Facebook innovation with nine new features). We add the interaction effects of each 
regressor with innovation complexity to each of the five equations (Panel $B$, Table 4.4). In both sets of equations, the Breusch-Pagan-Lagrange multiplier test for error independence is significant $(p \leftarrow .001)$, such that the errors across equations are correlated, while the R-square for each individual equation is statistically significant at $p \leftarrow .001$; using SUR thus is recommended (Cameron and Trivedi 2009). 


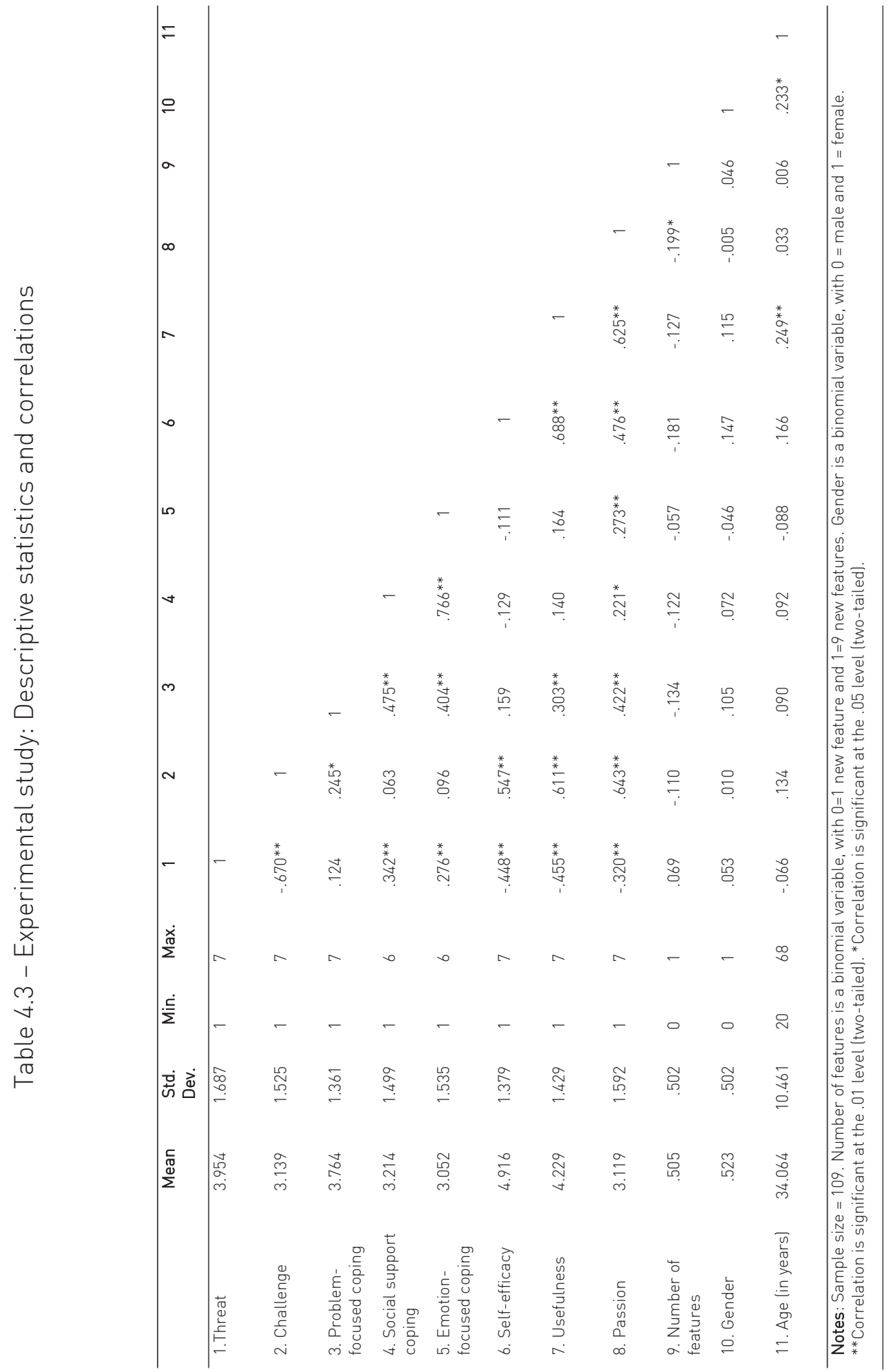


Table 4.4 - Experimental study: SUR results

Panel A: Equations without Interaction Effects

\begin{tabular}{|c|c|c|c|c|c|c|}
\hline & \multicolumn{2}{|c|}{ Problem-focused coping } & \multicolumn{2}{|c|}{ Social support coping } & \multicolumn{2}{|c|}{ Emotion-focused coping } \\
\hline & Coef. & Std. Err. & Coef. & Std. Err. & Coef. & Std. Err. \\
\hline Threat & $.419 * *$ & .092 & $.604^{* *}$ & .095 & $.562 * *$ & .102 \\
\hline Challenge & $.539 * *$ & .108 & $.582^{* *}$ & .111 & $.615^{* *}$ & .120 \\
\hline Self-efficacy & .081 & .102 & $-.301 * *$ & .105 & $-.226^{*}$ & .113 \\
\hline Number of features & -.248 & .232 & $-.468^{+}$ & .241 & -.206 & .258 \\
\hline Age & .002 & .011 & .013 & .012 & -.013 & .013 \\
\hline \multirow[t]{3}{*}{ Gender } & .161 & .239 & .167 & .248 & -.098 & .265 \\
\hline & \multicolumn{2}{|c|}{ Passion } & \multicolumn{2}{|c|}{ Usefulness } & & \\
\hline & Coef. & Std. Err. & Coef. & Std. Err. & & \\
\hline Problem-focused coping & $.622^{* *}$ & .112 & $.433^{* *}$ & .103 & & \\
\hline Social support coping & $-.321^{*}$ & .148 & $-.416^{* *}$ & .136 & & \\
\hline Emotion-focused coping & $.322^{*}$ & .140 & $.258^{*}$ & .129 & & \\
\hline Number of features & $-.464^{\dagger}$ & .272 & -.323 & .252 & & \\
\hline Age & .007 & .014 & $.036^{*}$ & .013 & & \\
\hline Gender & -.094 & .279 & .171 & .258 & & \\
\hline \multicolumn{7}{|c|}{ Panel B: Equations with Interaction Effects } \\
\hline & \multicolumn{2}{|c|}{ Problem-focused coping } & \multicolumn{2}{|c|}{ Social support coping } & \multicolumn{2}{|c|}{ Emotion-focused coping } \\
\hline & Coef. & Std. Err. & Coef. & Std. Err. & Coef. & Std. Err. \\
\hline Threat & $.292^{*}$ & .115 & $.593^{* *}$ & .120 & $.531^{* *}$ & .129 \\
\hline Challenge & $.654^{* *}$ & .134 & $.743^{* *}$ & .140 & $.748^{* *}$ & .150 \\
\hline Self-efficacy & -.179 & .159 & $-.527 * *$ & .166 & $-.554^{* *}$ & .178 \\
\hline Number of features & $-2.994^{+}$ & 1.531 & -1.146 & 1.599 & -2.143 & 1.716 \\
\hline Threat $x$ & .255 & .187 & -.035 & .195 & .031 & .210 \\
\hline Number of features & & & & & & \\
\hline $\begin{array}{l}\text { Challenge } x \\
\text { Number of features }\end{array}$ & -.214 & .218 & -.393 & .228 & $-.325^{+}$ & .244 \\
\hline Self-efficacy $x$ & $.489 *$ & .201 & $.414^{*}$ & .210 & $.572^{*}$ & .225 \\
\hline Number of features & & & & & & \\
\hline Age & .000 & .011 & .013 & .012 & -.012 & .012 \\
\hline \multirow[t]{3}{*}{ Gender } & .185 & .231 & .154 & .242 & -.103 & .258 \\
\hline & \multicolumn{2}{|c|}{ Passion } & \multicolumn{2}{|c|}{ Usefulness } & & \\
\hline & Coef. & Std. Err. & Coef. & Std. Err. & & \\
\hline Problem-focused coping & $.350^{+}$ & .194 & $.355^{*}$ & .178 & & \\
\hline Social support coping & -.331 & .212 & -.054 & .194 & & \\
\hline Emotion-focused coping & $.621^{* *}$ & .199 & .025 & .182 & & \\
\hline Number of features & -.271 & .829 & .069 & .763 & & \\
\hline $\begin{array}{l}\text { Problem-focused coping } \times \\
\text { Number of features }\end{array}$ & .337 & .236 & .103 & .217 & & \\
\hline $\begin{array}{l}\text { Social support coping } \times \\
\text { Number of features }\end{array}$ & .079 & .298 & $-.714^{* *}$ & .273 & & \\
\hline Emotion-focused coping $x$ & $-.570^{*}$ & .277 & $.497 *$ & .254 & & \\
\hline Number of features & & & & & & \\
\hline Age & .016 & .014 & $.030^{*}$ & .013 & & \\
\hline Gender & -.114 & .277 & .040 & .256 & & \\
\hline \multicolumn{7}{|c|}{$\begin{array}{l}\text { Notes: Sample size }=109 . \text { Coef. }=\text { SUR coefficient; Std. Err. }=\text { standard error. } \\
\text { Gender is a binomial variable with } 0=\text { male and } 1=\text { female. } \\
+p<.100 .{ }^{*} p \leftarrow .050 .{ }^{* *} p<.010 \text {. }\end{array}$} \\
\hline
\end{tabular}


Interaction 1: Self-Efficacy $\times$ Number of Features Dependent variable: Problem-focused coping

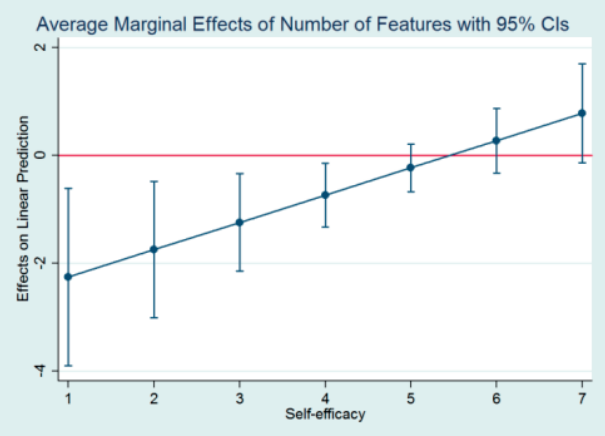

Interaction 3: Self-Efficacy $\times$ Number of Features Dependent variable: Emotion-focused coping

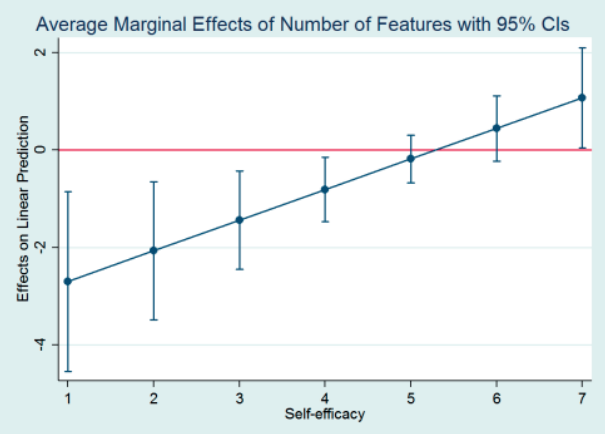

Interaction 5: Social Support Coping $\times$ Number of Features Dependent variable: Usefulness

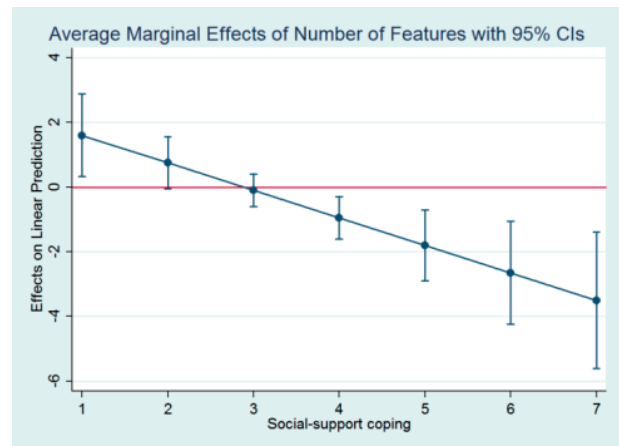

Interaction 2: Self-Efficacy $\times$ Number of Features Dependent variable: Social support coping

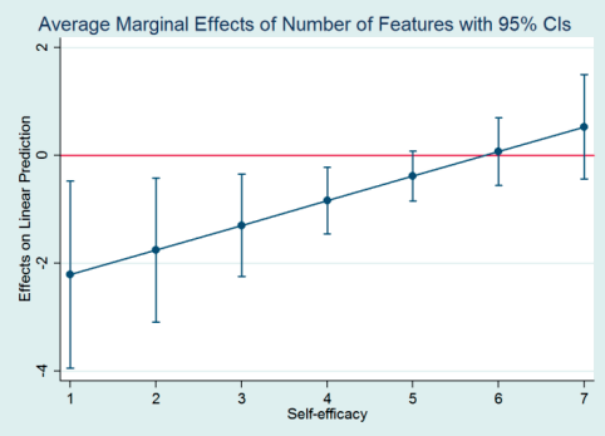

Interaction 4: Emotion-Focused Coping $\times$ Number of Features Dependent variable: Passion

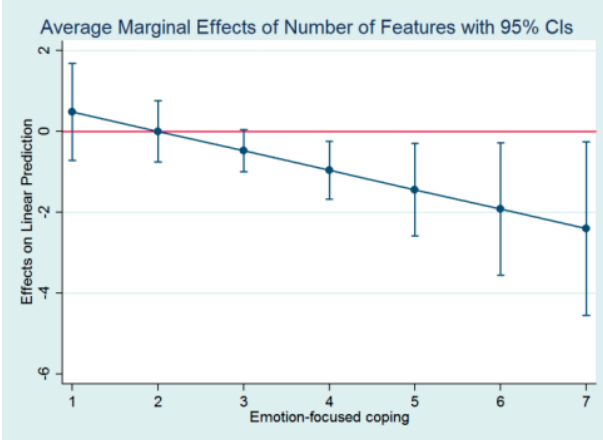

Interaction 6: Emotion-Focused Coping $\times$ Number of Features Dependent variable: Usefulness

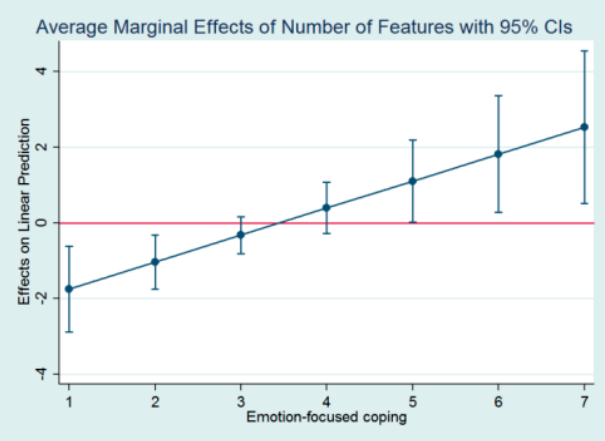

Figure 4.2 - Experimental study: Significant interaction effects 


\section{Results}

The coefficients and their standard errors, obtained with the SUR estimator (sureg command) in STATA 12.0 SE, are in Table 4.4. In line with the field study, the influence of appraisal, as threat or challenge, on the three coping strategies is significant and positive $(p \leftarrow$.01). In line with $\mathrm{H} 3$, self-efficacy also has significant negative effects on the use of an emotion-focused coping strategy ( $p$ $\leftarrow .05)$ and a social support coping strategy $(p<.01)$. Self-efficacy interacts with innovation complexity, with positive coefficients for each coping strategy ( $p$ $\leftarrow$.05) (Panel B, Table 4.4). In Figure 4.2, we present the difference between high and low innovation complexity at different levels of self-efficacy (i.e., average marginal effects) for each significant interaction (Williams 2012). To illustrate the interaction effects, we focus on the significant, positive interaction effect of self-efficacy and innovation complexity on emotion-focused coping (Interaction 3, Figure 4.2). When self-efficacy is lower than or equal to 4 or else equal to 7 (i.e., the confidence interval does not contain 0), the average marginal effects of innovation complexity on emotion-focused coping are significant. That is, self-efficacy negatively influences emotion-focused coping when self-efficacy is low to moderate and innovation complexity is low lor selfefficacy is very high and innovation complexity is also high).

In terms of coping outcomes, we find that similar to the field study, problemfocused coping has a positive influence on the perceived usefulness of the innovation $(p<.05)$, and emotion-focused coping has a positive influence on passion $(p<.01)$. Social support and emotion-focused coping both interact with innovation complexity, but with negative $(p<.01)$ and positive $(p<.05)$ coefficients, respectively, on perceived usefulness. Finally, emotion-focused coping interacts with innovation complexity with a negative coefficient on passion (Panel B, Table 4.4). We also illustrate the significant, negative interaction between social support coping and innovation complexity on perceived usefulness (Interaction 5, Figure 4.2). As this graphical depiction shows, when social support coping is equal to 1 or 4 or higher (i.e., confidence interval does not contain 0), the average marginal effects of innovation complexity on usefulness are significant. Employing a social support coping strategy positively influences perceived usefulness when social support coping is very low and innovation complexity is high lor social support coping is moderate to high and innovation complexity is (ow). 


\section{DISCUSSION}

We began this article with four research questions (RQ), which we have examined in two empirical studies. The results across both studies show that users perceive changes in their user experience, due to innovations in existing digital services, as primarily threatening or challenging (RQ1). In both studies, the change brought about by an innovation in the existing service was perceived primarily as a threat (Table 4.1, Table 4.3). These results might reflect the environment; along with other, well-known digital service providers, Facebook often has been the subject of media attention regarding concerns over user rights, such as data privacy. ${ }^{14}$ Perhaps Facebook users are especially suspicious of any changes the service provider introduces, a theme often cited in the open-ended answers from the field study participants.

Users manage the changes to their experience by expending coping resources that they possess (self-efficacy) and employing coping strategies (problemfocused, social support, emotion-focused) (RQ2). In both studies, appraising the change as a threat or as a challenge positively influences users' employment of coping strategies. However, we only find support for a negative direct influence of self-efficacy on social support and emotion-focused coping in our experimental study. We posit that we failed to find such an influence in the field study because the participants took a retrospective perspective; they already had dealt with the innovation. In the experimental study, with a hypothetical innovation whose complexity was made salient, users instead activated their self-efficacy as a coping resource.

The coping strategies adopted also influence how passionate users are toward the innovated service and how useful they find it (RQ3). In both studies, users tend to employ problem-focused coping strategies most, followed by social support and then emotion-focused coping strategies (Table 4.1, Table 4.3). Moreover, a problem-focused coping strategy positively influences how useful people find the innovation to be. When users try to tackle the innovation directly (e.g., exploring its new features), they find it more useful. However, to make

14 See http://www.theguardian.com/technology/2015/nov/03/data-protection-failuregoogle-facebook-ranking-digital-rights 
users more passionate about the innovated service, employing a social support coping strategy has a positive influence in the field study, and employing an emotion-focused coping strategy has a positive influence in the experimental study. The field study refers to an actual innovation that participants had experienced, and in this case, users may have noticed the innovation in their friends' profiles, so reaching out to them for support had affective consequences. The experimental study did not specify what the innovation entailed but made its complexity salient, so users trying to regulate emotions related to the innovation may have felt stronger affective consequences.

Finally, innovation complexity interacts with self-efficacy to affect the use of coping strategies; it also interacts with the coping strategies to influence affective and cognitive outcomes (RQ4). When the complexity of the innovation is made salient, there is an interplay with the coping resource that users possess, which thereby influences the employment of each of the three coping strategies. Specifically, when users possess little self-efficacy and the innovation is less complex, they employ fewer coping strategies. In terms of outcomes, we find an interesting result related to the use of an emotionfocused coping strategy: Users perceive the innovation as more useful when they try hard to regulate their emotions related to the stressor and the innovation has high complexity. However, if users rely on a lot of emotionfocused coping, they become more passionate for the innovated service only if the innovation is less complex.

\section{Theoretical Implications}

Our research contributes to service innovation literature in several ways. First, we focus on users' perspectives on service innovation (Bettencourt, Brown, and Sirianni 2013), by investigating users of digital services who deal with innovation rather than employees in organizations (Ayyagari, Grover, and Purvis 2011). This distinction is important: Employees must use the innovations their employers introduce, but users can decide to disengage from the service providers if an innovation overwhelms them. Yet service providers still need to introduce innovations at an increasing pace (Nylén and Holmström 2015).

Second, we contribute to literature on incremental service innovation (Snyder et al. 2016) by conceptualizing incremental service innovation as a stressor that affects the user experience. Our focus on innovation in existing digital services reflects the concern that though most digital innovation is incremental in 
nature, it remains underrepresented in research (Storey et al. 2015). Conceptualizing incremental innovation also addresses recent calls for insights into how digital service innovation affects the user experience (Ostrom et al. 2015). Specifically, providers introduce innovations in digital services to enhance the user experience, but users can perceive them as taxing or exceeding their resources. Thus, we highlight how innovation in existing digital services can have unfavorable consequences for users.

Third, we introduce a conceptual model based on appraisal and coping (Lazarus and Folkman 1984) that provides a new perspective on how users evaluate and manage innovation as a stressor. Users can evaluate the change brought about by innovation in existing digital services as negative (threat) or positive (challenge). Even if users see innovation primarily as a threat, they still employ coping strategies to manage the change. For highly interactive digital services, coping even offers a means to enhance the user experience lOstrom et al. 2015).

Fourth, we advance innovation outcomes research (Li, Zhang, and Wang 2014) by establishing how coping promotes users' interactions with innovations in digital services, leading to different affective and cognitive outcomes. When users exert coping efforts to deal with the change brought about by innovation, they find the innovation more useful; we thus introduce a novel driver of innovation acceptance (Venkatesh and Davis 2000). When users devote coping efforts to regulate the emotions they feel due to the change or ask for support from their peers, they become more passionate about the innovation. Passion is a particularly important affective innovation outcome, because it ensures shortterm attachment to the service and keeps users engaged, at least until the next innovation is introduced.

Fifth, we enrich literature on innovation complexity (Martinsuo and Poskela 2011) by establishing innovation complexity lobjective characteristic of the innovation) as a boundary condition on how users manage innovation in existing digital services. Complexity interacts with subjective individual characteristics (self-efficacy) to influence the strategies that users employ to cope with changes due to innovation. Innovation complexity also interacts with individual and situational characteristics (emotion-focused coping) to influence the affective and cognitive outcomes in various ways. 


\section{Managerial Implications}

On average, users appraise the change brought about by innovation as a threat rather than a challenge. Yet even if they see the innovation primarily as something negative, users still employ different coping strategies. Service providers should strive to facilitate more positive appraisals among users, leading them to feel more eager about pursuing the innovation. Providers could offer interactive tutorials with each innovation, to explain why the change was necessary and how it can improve the user experience. For example, each time it introduces a new feature, Gmail captures users' attention by digitally highlighting what has changed and asking them to acknowledge the changes by clicking a "got it" button.

Service providers also should encourage users to employ coping strategies. Irrespective of the complexity, they should inspire users to adopt problemfocused coping and give them chances to interact with new features once they have been introduced. If users try the innovation, they may be more likely to find it more useful, which would drive their usage. Dropbox relies on gamification elements and rewards users with additional cloud storage space if they employ problem-focused coping le.g., trying a new image viewing feature by completing relatively simple usage tasks, such as uploading photographs).

When introducing more complex innovations, service providers also should be aware of the interplay with emotion-focused coping strategies. If the objective is to generate positive word of mouth, providers should encourage users to employ emotion-focused coping to deal with less complex innovations, because this combination should increase passion for the innovated service. If the providers instead seek to drive actual usage, they should encourage emotionfocused coping to deal with more complex innovations, which increases the perceived usefulness of the innovation. When Facebook recently introduced Reactions, it offered users increased possibilities for expressing a wide set of emotions, ranging from happiness to anger, which may help them regulate their emotions more easily.

Finally, service providers can inspire users to rely on social support by reminding them that their friends and family are already using the innovation or encouraging them to ask for help from peers. However, the outcomes of employing this type of coping strategy are mixed. Especially when introducing a low complexity innovation, providers should not encourage social support 
coping, because it could limit how useful users perceive the innovation to be. The provider might direct users to company-endorsed, digital sources of support, instead of other users, when innovation complexity is low. Along with its privacy check-up feature, Facebook introduced the Privacy Dinosaur for example, which offers advice to users on how to manage their privacy settings.

\section{Limitations and Further Research}

Some limitations of this research provide research opportunities as well. First, our two studies complement each other-the experiment decontextualizes the field study and explains the lack of support for some of the hypotheses-but each study takes a cross-sectional perspective on innovation in existing digital services. Additional research could benefit from a longitudinal perspective that considers multiple innovations in an existing service and monitors changes in the user experience over time. Second, we note a specific boundary condition that influences how users manage innovation in existing digital services. Innovation complexity has an important role, but further research could explore other potential boundary conditions le.g., time between consecutive innovations, whether the innovation is available for all users at the same time). Third, with our focus on the innovated digital service, it is beyond our research scope to account for the type of technology users employ to experience the service. Research that investigates the effects of different types of digital technology (e.g., smartphones, tablets, wearables) in determining how users cope with innovation in existing digital services could provide additional insights. Fourth, the popular digital service we research is mainly hedonic. A robustness check confirms that our results apply to less hedonic digital services, but additional research might test the conceptual model in more varied contexts (e.g., paid services, professional services). 


\section{CHAPTER 5 \\ Conclusions}

“Vincent Hanna: I don't know how to do anything else.

Neil McCauley: Neither do I.

Vincent Hanna: I don't much want to either.

Neil McCauley: Neither do I."

(Heat, 1995) 
My aim with this dissertation is to achieve a better understanding of why and how users interact with digital service innovation and what elements of the resulting service experience affect their engagement with the service. In the previous three chapters, I presented a series of empirical studies each examining a different type of digital service innovation and different facets of user engagement. In this chapter I discuss how my results address the initial research questions and consequently what contributions I bring to service and innovation research (see Table 5.1).

Table 5.1 - Overview of dissertation conclusions

\begin{tabular}{|c|c|c|c|}
\hline & Chapter 2 & Chapter 3 & Chapter 4 \\
\hline \multicolumn{4}{|l|}{ Background } \\
\hline Context & $\begin{array}{l}\text { Contactless mobile } \\
\text { payment (CMP) }\end{array}$ & Multiplayer video gaming & Online socialization \\
\hline $\begin{array}{l}\text { Degree of change brought to user } \\
\text { experience }\end{array}$ & $\begin{array}{l}\text { New-to-the-market } \\
\text { service }\end{array}$ & $\begin{array}{l}\text { Sequential (new version } \\
\text { of an existing service) }\end{array}$ & $\begin{array}{l}\text { Gradual (new features in } \\
\text { an existing service) }\end{array}$ \\
\hline Type of engagement examined & $\begin{array}{l}\text { Affective, cognitive and } \\
\text { behavioral }\end{array}$ & Behavioral & Affective and cognitive \\
\hline \multicolumn{4}{|l|}{ Research questions } \\
\hline $\begin{array}{l}\text { Why do users interact with digital service } \\
\text { innovation? }\end{array}$ & $\begin{array}{l}\text { Users satisfy the } \\
\text { psychological needs for } \\
\text { autonomy, competence } \\
\text { and relatedness. There is } \\
\text { interplay between } \\
\text { satisfying these needs. }\end{array}$ & $\begin{array}{l}\text { Users satisfy the } \\
\text { psychological needs for } \\
\text { utilitarian, hedonic and } \\
\text { social gratification. }\end{array}$ & $\begin{array}{l}\text { Users appraise } \\
\text { innovation as primarily } \\
\text { threatening or } \\
\text { challenging. Innovation } \\
\text { complexity activates user } \\
\text { self-efficacy with negative } \\
\text { influences on coping. }\end{array}$ \\
\hline $\begin{array}{l}\text { How do users interact with digital service } \\
\text { innovation? }\end{array}$ & $\begin{array}{l}\text { Over time, users develop } \\
\text { habitual usage behaviors } \\
\text { of varying stability in } \\
\text { time, location and } \\
\text { merchant category. }\end{array}$ & $\begin{array}{l}\text { During the first month } \\
\text { after introduction users } \\
\text { exhibit a common } \\
\text { behavioral engagement } \\
\text { trajectory defined by an } \\
\text { initial level and a rate of } \\
\text { change. }\end{array}$ & $\begin{array}{l}\text { Irrespective of their initial } \\
\text { appraisal, users can } \\
\text { apply problem-focused, } \\
\text { emotion-focused or } \\
\text { social support coping } \\
\text { strategies to deal with the } \\
\text { changes brought by } \\
\text { innovation. }\end{array}$ \\
\hline $\begin{array}{l}\text { What elements of the service experience } \\
\text { affect engagement with digital service } \\
\text { innovation? }\end{array}$ & $\begin{array}{l}\text { Habitual behavior in } \\
\text { terms of location has a } \\
\text { positive influence on all } \\
\text { facets of engagement } \\
\text { with a new-to-the- } \\
\text { market service. The } \\
\text { stabilities in terms of } \\
\text { time and merchant } \\
\text { category have mixed } \\
\text { results on the different } \\
\text { engagement facets. }\end{array}$ & $\begin{array}{l}\text { The growth factors (i.e., } \\
\text { initial level and the rate } \\
\text { of change) developed } \\
\text { after the introduction of a } \\
\text { digital innovation } \\
\text { positively influence } \\
\text { behavioral engagement } \\
\text { and also have some } \\
\text { positive influence on the } \\
\text { user experience one year } \\
\text { later. }\end{array}$ & $\begin{array}{l}\text { Employing problem- } \\
\text { focused coping has a } \\
\text { positive influence on } \\
\text { cognitive engagement } \\
\text { irrespective of innovation } \\
\text { complexity being made } \\
\text { salient or not. The other } \\
\text { coping strategies have a } \\
\text { mixed influence on the } \\
\text { two engagement facets } \\
\text { contingent on complexity } \\
\text { being made salient. }\end{array}$ \\
\hline \multicolumn{4}{|l|}{ Key contributions } \\
\hline Service research & $\begin{array}{l}\text { Establishing the stability } \\
\text { of habitual behaviors as a } \\
\text { driver of user } \\
\text { engagement with a new- } \\
\text { to-the-market digital } \\
\text { service. }\end{array}$ & $\begin{array}{l}\text { Providing a dynamic } \\
\text { perspective on behavioral } \\
\text { user engagement; } \\
\text { Illustrating the interplay } \\
\text { between the user } \\
\text { experience and user } \\
\text { engagement. }\end{array}$ & $\begin{array}{l}\text { Establishing coping } \\
\text { strategies as drivers of } \\
\text { user engagement. }\end{array}$ \\
\hline Innovation research & $\begin{array}{l}\text { Demonstrating the } \\
\text { importance of developing } \\
\text { a common perspective } \\
\text { for developing user } \\
\text { engagement between } \\
\text { actors in a new digital } \\
\text { service ecosystem. }\end{array}$ & $\begin{array}{l}\text { Demonstrating the } \\
\text { importance of the } \\
\text { introduction period for } \\
\text { driving engagement with } \\
\text { sequential digital service } \\
\text { innovation. }\end{array}$ & $\begin{array}{l}\text { Conceptualizing gradual } \\
\text { digital service innovation } \\
\text { as a stressor. } \\
\text { Highlighting potential } \\
\text { unfavorable } \\
\text { consequences of gradual } \\
\text { digital service innovation. }\end{array}$ \\
\hline
\end{tabular}




\section{WHY USERS INTERACT WITH DIGITAL SERVICE INNOVATION}

Inspired by motivational theories from social-psychology (i.e., selfdetermination; Deci and Ryan 2000) and media consumption (i.e., uses and gratifications; Katz, Blumler and Gurevitch 1974) I demonstrate that satisfying users' psychological needs plays an important role in driving user interaction with a new-to-the-market digital service (Chapter 2) and with a sequential digital service innovation (Chapter 3). The results in Chapter 2 illustrate that satisfying users' psychological need for competence (i.e., their sense of efficacyl leads to more dispersed contactless mobile payment (CMP) spending across merchant categories (e.g., supermarkets, restaurants or clothing outlets) and locations (i.e., CMP supporting stores). Furthermore, I elaborate on more complex interplays existing between satisfying users' need for competence and satisfying their need for autonomy (i.e., sense of volition and personal agencyl and relatedness (i.e. sense of social connectedness) respectively (Deci and Ryan 2000).

Users' perceived competence reemerges in Chapter 4 where I show that selfefficacy can have a negative influence on how users cope with digital service innovation in an online socialization context especially when innovation complexity (e.g., Martinsuo and Poskela 2011) is made salient. While the digital service innovation examined in Chapter 2 is new-to-the-market, the one examined in Chapter 4 is a gradual innovation in an existing service (Heath et al. 2015). Hence, I can conclude that satisfying the psychological need for competence is pivotal in driving user interaction with new-to-the market digital services, but can be detrimental for coping with more complex gradual digital service innovations.

The results in Chapter 3 illustrate that satisfying utilitarian (i.e., achievement), hedonic (i.e., immersion) and social (i.e., social interaction) psychological needs (e.g., Boyle et al. 2012; Williams, Yee, and Caplan 2008) when faced with a sequential digital service innovation positively influences users' behavioral engagement with a multiplayer video game. While in Chapters 2 and 4 competence is based on users' self-assessment, in Chapter 2 competence li.e., achievement) is based on their actual in-game behavior. Thus, it should be noted that for more hedonic, sequential digital service innovations actual (not perceived) competence during the first month after introduction can prolong user interaction with a new digital service iteration. 


\section{HOW USERS INTERACT WITH DIGITAL SERVICE INNOVATION}

Each of the empirical studies presented in this dissertation provides a different facet of how users interact with digital service innovation. In Chapter 2, I demonstrate that when interacting with a new-to-the-market digital service users can develop habitual usage behaviors (related to time, merchant category and location) of varying stability (e.g., ranging from very unstable to very stable). For service ecosystems (Lusch and Nambisan 2015) such as CMP developing habitual behaviors with high stability related to location (i.e., more dispersed CMP usage across supporting stores) is most beneficial as it positively influences the different facets of user engagement with CMP (i.e., affective, cognitive and behavioral; Brodie et al. 2011). This chapter specifically contributes to research on service ecosystems (e.g., Lusch and Nambisan 2015; Ostrom et al. 2015) by presenting how different actors can achieve a common, user engagement-building perspective: encouraging more dispersed usage of a new digital service across all supporting locations is beneficial for the ecosystem as a whole in terms of driving user engagement.

In Chapter 3, I reveal that when interacting with sequential digital service innovation, users develop a common engagement developmental trajectory during the first month after introduction described by a positive initial level and a negative rate of change. Hence, while different users have different levels of behavioral engagement with the video game (see Figure 3.1), on the whole they show a homogenous decrease in behavioral engagement from the first to the fourth week after the digital service innovation was introduced, even after controlling for the satisfaction of their utilitarian, hedonic and social psychological needs (e.g., Li et al. 2015; Williams, Yee, and Caplan 2008). This chapter specifically enriches literature on how users engage with video games (e.g., Boyle et al. 2012; Marchand and Hennig-Thurau 2013) by providing a dynamic perspective of user engagement based on analysis of telemetry (Bauckhage et al. 2012).

Finally, in Chapter $4 \mathrm{I}$ show that when users are faced with gradual digital service innovation, they can apply different coping strategies (Duhachek 2005) to deal with the change brought by the innovation. Applying problem-focused coping (i.e., taking action to directly deal with the change such as by trying out new features) is beneficial for driving cognitive engagement with the service in both the field as well as the experimental study. Applying social support coping 
(i.e., asking others for help in dealing with the change) is beneficial for driving affective engagement with the service in the field study, whereas applying emotion-focused coping (i.e., attempting to manage the emotions resulting from the changel is beneficial for driving affective engagement with the service in the experimental study (where innovation complexity was made salient). This chapter specifically addresses the call for research on how service innovation affects the user experience (Ostrom et al. 2015) by conceptualizing digital service innovation as a stressor that users have to cope with.

To summarize, developing stable habitual usage behaviors is important for new-to-the-market digital service innovations, smoothing the negative rate of change in engagement (i.e., making it less steep) is important for sequential digital service innovations and supporting users' coping is important for gradual digital service innovation. In their entirety, these results address recent calls for research on how to manage digital service innovation contingent on positive user experiences and increased user participation in increasingly complex service ecosystems (e.g., MSI 2016; O'Cass and Wetzels 2016; Ostrom et al. 2015).

\section{WHAT ELEMENTS OF THE SERVICE EXPERIENCE AFFECT ENGAGEMENT WITH}

\section{DIGITAL SERVICE INNOVATION}

Each chapter in this dissertation takes a different, but reinforced perspective on user engagement with digital service innovation, employing different measurements and operationalizations with the aim of broadening and deepening or understanding of this phenomenon. Thus, my results enrich the developing research stream on user engagement with digital services (e.g., Hollebeek, Glynn, and Brodie 2014).

In Chapter 2 I focus on all three facets of engagement (i.e., affective, cognitive and behavioral; Brodie et al. 2011), while in Chapter 3 I only focus on the behavioral facet and in Chapter 4 on the affective and cognitive facets. Behavioral engagement is operationalized as actual usage behavior relevant to the examined digital service innovation lamount spent via CMP in Chapter 2 and gameplay duration in Chapter 3). Similarly, affective and cognitive engagement are operationalized in terms of their relevance to the type of digital service innovation examined: in Chapter 2 the focus is on the degree of positive affect and the evaluation of the complete CMP experience (both relevant to a new-to- 
the-market service), while in Chapter 3 the focus is on how passionate users become and how useful they find the gradual digital service innovation (both relevant to a service introducing gradual innovation).

With Chapters 2 and 4, I contribute to literature on how the service experience with a digital service innovation can drive user engagement (e.g., Lusch and Nambisan 2015; Nylén and Holmström 2015). My results identify the stability of habitual behaviors developed after the introduction of a new-to-the-market service and respectively the coping strategies employed after the introduction of a gradual digital innovation as drivers of multiple facets of engagement. Additionally, in Chapter 4 I demonstrate that innovation complexity lin terms of the number of new features introduced) interacts with the coping strategies employed to the extent that the more complex users perceive the innovation (in terms of the number of features introduced), the weaker the influence of the coping strategies.

In Chapter 3 I show how a common engagement trajectory developed during the first four weeks after the introduction can positively influence both user engagement, as well as the user experience lin terms of utilitarian, hedonic and social gratification) with a video game one year later. Importantly, the common engagement developmental trajectory is derived while controlling for the user experience during the first four weeks. This chapter specifically addresses recent calls for research on the dynamic nature of engagement le.g., Hollebeek, Glynn, and Brodie 2014), as well as on the interplay between the user experience and user engagement (e.g. De Keyser et al. 2015).

Hence, across the chapters in this dissertation I have demonstrated that users' experience with digital service innovation introducing varying degrees of change can influence their engagement with the digital service; the developed user engagement in turn can influence the subsequent user experience. 


\section{FINAL THOUGHTS}

Supported by unprecedented ICT developments, digitalization is currently at the forefront of service innovation. Although enthusiastic about the potential of digital service innovation, managers face challenges in keeping users engaged with the new-to-the-market, sequential or gradual digital service innovations they introduce. This dissertation builds on rich contexts, data and analysis methods and paves the way towards achieving a better understanding of why and how users interact with digital service innovation and how the resulting user experience influences (long-term) user engagement. Exciting times lay ahead of us in terms of user engagement with digital service innovation. In the words of Captain Jean-Luc Picard: "Let's see what's out there. Engage!". 
APPENDICES 


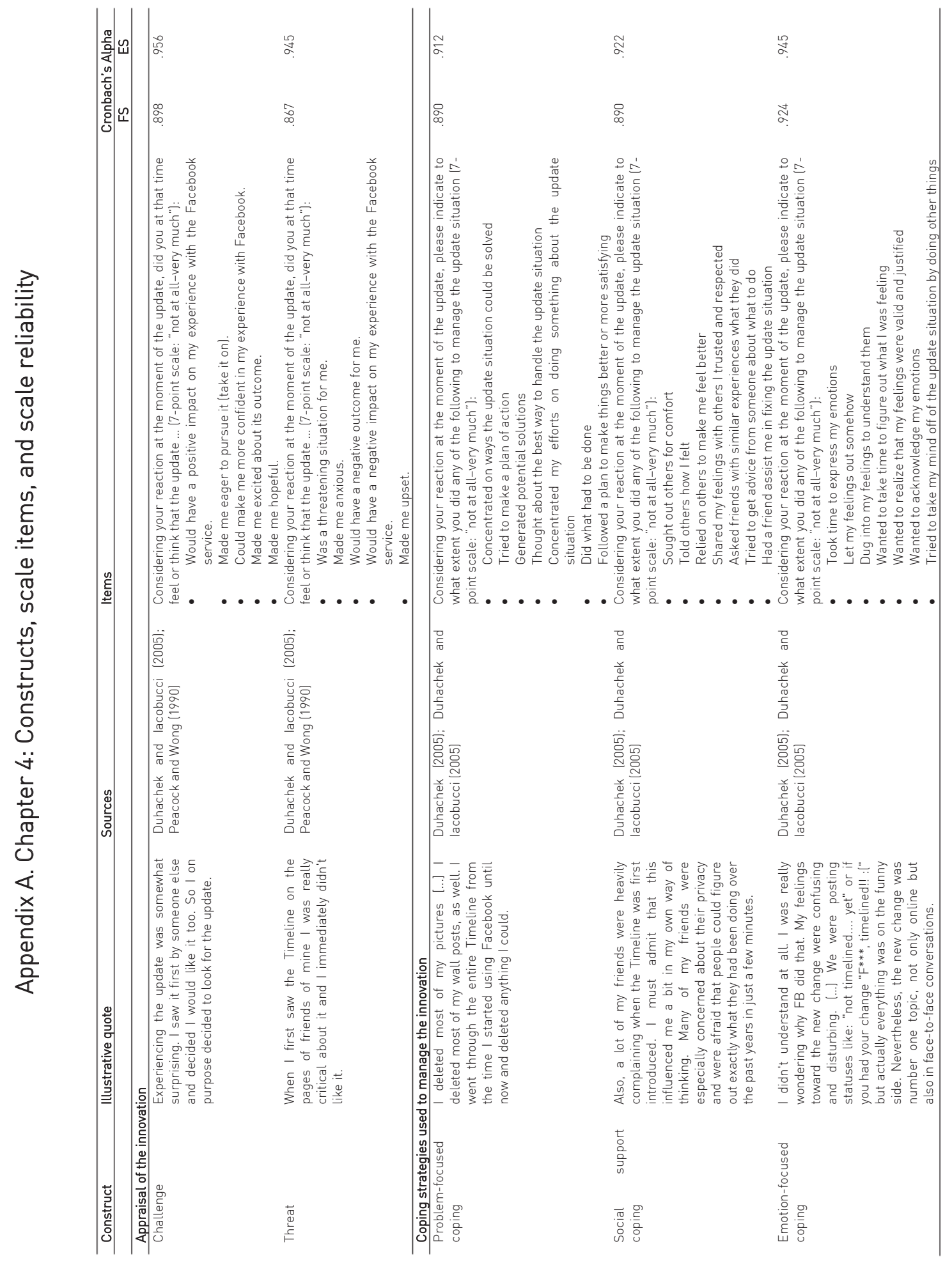




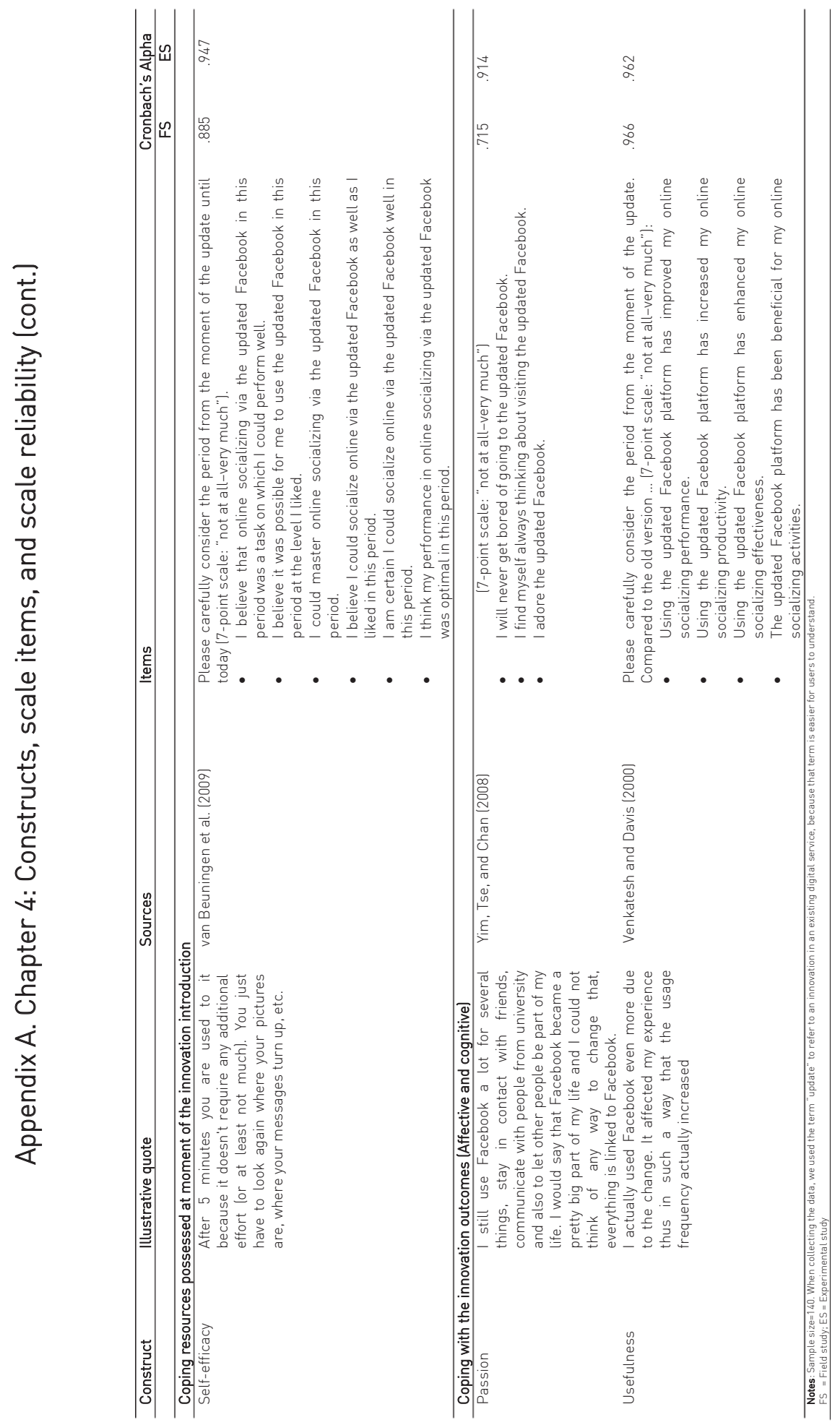




\section{Appendix B. Chapter 4: Experimental study manipulations}

Throughout this study we use the term "online socialization service" to refer to a service for which you have to register on the Internet and then create a user profile and add other users as "friends". Once you have created a profile, online socialization involves, among others, exchanging messages, posting status updates and photos, sharing videos and receiving notifications when others update their profiles.

From this point onward we will be referring specifically to the Facebook online socialization service.

\section{1 new feature condition}

Please take the time to carefully read the following description and try as best as you can to imagine yourself in the situation presented.

During its history Facebook underwent multiple updates by introducing new features. Each new feature is meant to change the way the service looks like and also to change what you can do when you are using Facebook. Examples of new features introduced over the years to update the Facebook service include the newsfeed, the chat, the timeline and the save feature. These changes are part of Facebook's effort to innovate and update its service to improve users' experience.

Now imagine the following situation:

You log into your Facebook and see an announcement that Facebook has been updated with one new feature.

\section{9 new features condition}

Please take the time to carefully read the following description and try as best as you can to imagine yourself in the situation presented.

During its history Facebook underwent multiple updates by introducing new features. Each new feature is meant to change the way the service looks like and also to change what you can do when you are using Facebook. Examples of new features introduced over the years to update the Facebook service include the newsfeed, the chat, the timeline and the save feature. These changes are part of Facebook's effort to innovate and update its service to improve users' experience.

Now imagine the following situation:

You log into your Facebook and see an announcement that Facebook has been updated with nine new features. 


\section{REFERENCES}

"Steve Rogers: Let's start with that stick of his. It may be magical, but it works an awful lot like a Hydra weapon.

Nick Fury: I don't know about that, but it is powered by the cube. And I'd like to know how Loki used it to turn two of the sharpest men I know into his personal flying monkeys.

Thor: Monkeys? I do not understand.

Steve Rogers: I do!

[Stark rolls his eyes, while Captain America looks proud of himself]

Steve Rogers: I understood that reference."

(The Avengers, 2012) 


\section{A}

Aarts, H., and Dijksterhuis, A. 2000. Habits as knowledge structures: automaticity in goal-directed behavior. Journal of Personality and Social Psychology 78(1): 53 - 63.

Accenture 2015. Digital disconnect in customer engagement. Available at: https://www.accenture.com/t20160324T010518_w_/usen/_acnmedia/PDF-10/Accenture-Strategy-GCPR-DigitalDisconnect.pdf\#zoom=50.

--- 2016. Accenture Technology Vision 2016 People First: The Primacy of People in a Digital Age. Available at: https://www.accenture.com/t20160314T114937_w_/usen/_acnmedia/Accenture/Omobono/TechnologyVision/pdf/TechnologyTrends-Technology-Vision-2016.PDF.

Aneshensel, C. S. 1992. Social stress: Theory and research. Annual Review of Sociology 18: 15-38.

Aspinwall, L.G. and Taylor, S.E. 1992. Modeling cognitive adaptation: A longitudinal investigation of the impact of individual differences and coping on college adjustment and performance. Journal of Personality and Social Psychology 63 (6): 989-1003.

Ayyagari, R., Grover, V., and Purvis, R. 2011. Technostress: Technological antecedents and implications. MIS Quarterly35(4): 831-858.

B

Bandura, A. 1977. Self-efficacy: Toward a unifying theory of behavioral change. Psychological Review 84 (2): 191-215.

Barnett, J., and Coulson, M. 2010. Virtually real: A psychological perspective on massively multiplayer online games. Review of General Psychology 14(2): 167-179.

Barrett, M., Davidson, E., Prabhu, J., and Vargo, S. L. 2015. Service innovation in the digital age: Key contributions and future directions. MIS Quarterly39 (1): 135-154.

Batra, R., Ahuvia, A., and Bagozzi, R. P. 2012. Brand love. Journal of Marketing 76(2): 1-16. 
Bauckhage, C., Kersting, K., Sifa, R., Thurau, C., Drachen, A., and Canossa, A. 2012. How players lose interest in playing a game: an empirical study based on distributions of total playing times. 2012 IEEE Conference on Computational Intelligence and Games (C/G): 139-146.

BCG 2015. The most innovative companies 2015. Available at: https://www.bcgperspectives.com/Images/BCG-Most-InnovativeCompanies-2015-Dec-2015_tcm80-203388.pdf

Berry, L. L., Bolton, R. N., Bridges, C. H., Meyer, J., Parasuraman, A., and Seiders, K. 2010. Opportunities for innovation in the delivery of interactive retail services. Journal of Interactive Marketing 24 (2): 155-167.

Bettencourt, L. A., Brown, S. W., and Sirianni, N. J. 2013. The secret to true service innovation. Business Horizons 56(1): 13-22.

Bhagat, R.S., McQuaid, S.J., Lindholm, H. and Segovis, J. 1985. Total life stress: A multimethod validation of the construct and its effects on organizationally valued outcomes and withdrawal behaviors. Journal of Applied Psychology 70 (1): 202-214.

Biemans, W., and Langerak, F. 2015. More research priorities. Journal of Product Innovation Management 32(1): 2-3.

Bollen, K. A., and Curran, P. J. 2006. Latent curve models: a structural equation perspective (Vol. 467). John Wiley \& Sons, Hoboken, NJ.

Bolton, R., and Saxena-lyer, S. 2009. Interactive services: A framework, synthesis and research directions. Journal of Interactive Marketing 23(1): $91-104$.

Boyle, E. A., Connolly, T. M., Hainey, T., and Boyle, J. M. 2012. Engagement in digital entertainment games: A systematic review. Computers in Human Behavior 28(3): 771-780.

Brodie, R. J., Hollebeek, L. D., Juric, B., and Ilic, A. 2011. Customer engagement: conceptual domain, fundamental propositions, and implications for research. Journal of Service Research 14(3): 252-271.

Bryant, F. B., and Satorra, A. 2012. Principles and practice of scaled difference chi-square testing. Structural Equation Modeling: A Multidisciplinary Journal 19(3), 372-398. 
Burton, K. D., Lydon, J. E., D'Alessandro, D. U., and Koestner, R. 2006. The differential effects of intrinsic and identified motivation on well-being and performance: Prospective, experimental, and implicit approaches to selfdetermination theory. Journal of Personality and Social Psychology 91(4): $750-762$.

\section{C}

Calder, B. J., Malthouse, E. C., and Schaedel, U. 2009. An experimental study of the relationship between online engagement and advertising effectiveness. Journal of Interactive Marketing 23(4): 321-331.

Cameron, A. C., and Trivedi, P. K. 2009. Microeconomics using Stata. College Station, TX: Stata Press Publications.

Chandrasekaran, D., and Tellis, G. J. 2011. Getting a grip on the saddle: Chasms or cycles? Journal of Marketing 75(4): 21 - 34.

Conroy, D. E., Maher, J. P., Elavsky, S., Hyde, A. L., and Doerksen, S. E. 2013. Sedentary behavior as a daily process regulated by habits and intentions. Health Psychology32(11): 1149 - 1157.

Curran, P. J., and Hussong, A. M. 2003. The use of latent trajectory models in psychopathology research. Journal of Abnormal Psychology 112(4): 526.

---, Obeidat, K., and Losardo, D. 2010. Twelve frequently asked questions about growth curve modeling. Journal of Cognition and Development 11(2): 121-136.

D

D'Emidio, T., Dorton, D., and Duncan, E. 2015. Service innovation in a digital world. McKinsey Quarterly. Available at http://thg.hfnelson.com/wpcontent/uploads/2015/02/\%E2\%88\%9A.-Service-innovation-in-a-digitalworld.pdf.

Dahl, D. W., and Moreau, C. P. 2007. Thinking inside the box: why consumers enjoy constrained creative experiences. Journal of Marketing Research 44(3): $357-369$.

Deci, E. L., Koestner, R., and Ryan, R. M. 1999. A meta-analytic review of experiments examining the effects of extrinsic rewards on intrinsic motivation. Psychological Bulletin 125(6): 627 - 668. 
---, and Ryan, R. M. 2000. The 'What' and 'Why' of goal pursuits: Human needs and the self-determination of behavior. Psychological Inquiry 11(4): $227-268$.

De Keyser, A., Lemon, K.N., Klaus, P. and Keiningham, T.L. 2015. A framework for understanding and managing the customer experience. Marketing Science Institute Working Paper Series 2015, Report No. 15-121.

DeKinder, J. S., and Kohli, A. K. 2008. Flow signals: how patterns over time affect the acceptance of start-up firms. Journal of Marketing 72(5): 84 97.

DeVellis, R.F., 2003. Scale Development: Theory and Applications Second Edition (Applied Social Research Methods). Sage Publications, Thousand Oaks, CA.

De Wulf, K., Odekerken-Schröder, G., and lacobucci, D. 2001. Investments in consumer relationships: a cross-country and cross-industry exploration. Journal of Marketing 65(4): 33-50.

Deloitte 2015. Contactless mobile payments (finally) gain momentum. Available at: http://www2.deloitte.com/global/en/pages/technology-media-andtelecommunications/articles/tmt-pred-contactless-mobilepayments.html.

DeLongis, A., and Holtzman, S. 2005. Coping in context: The role of stress, social support, and personality in coping. Journal of Personality 73(6): 1633-1656.

Dotzel, T., Shankar, V., and Berry, L. L. 2013. Service innovativeness and firm value. Journal of Marketing Research 50(2): 259-276.

Duhachek, A. 2005. Coping: A multidimensional, hierarchical framework of responses to stressful consumption episodes. Journal of Consumer Research 32(1): 41-53.

- - - and D. lacobucci. 2005. Consumer personality and coping: Testing rival theories of process. Journal of Consumer Psychology 15 (1): 52-63.

$E$

Eisenbeiss, M., Blechschmidt, B., Backhaus, K., and Freund, P. A. 2012. “The (real) world is not enough:" Motivational drivers and user behavior in virtual worlds. Journal of Interactive Marketing 26(1): 4-20. 
EIU [Economist Intelligence Unit] 2015. The rise of the marketer: driving engagement, experience and revenue. Available at http://futureofmarketing.eiu.com/briefing/EIU_MARKETO_Marketer_WEB .pdf.

ESA [Entertainment Software Association] 2016. Essential facts about the computer and video game industry. Available at:

http://essentialfacts.theesa.com/Essential-Facts-2016.pdf.

Evanschitzky, H., lyer, G. R., Pillai, K. G., Kenning, P., and Schütte, R. 2015.

Consumer trial, continuous use, and economic benefits of a retail service innovation: The case of the personal shopping assistant. Journal of Product Innovation Management 32(3): 459-475.

Euromonitor International 2015. Consumer payments 2015: trends, developments and prospects. Available at: http://www.euromonitor.com/consumer-payments-2015-trendsdevelopments-and-prospects/report.

Eyal, N. 2014. Hooked: How to build habit-forming products. Penguin Canada.

$\mathrm{F}$

Forbes 2015. Customer engagement: best of the best. Available at http://www.forbes.com/forbesinsights/sap_customer_engagement/index. html.

G

Gardner, B., and Lally, P. 2013. Does intrinsic motivation strengthen physical activity habit? Modeling relationships between self-determination, past behaviour, and habit strength. Journal of Behavioral Medicine 36(5): 488 497.

Gill, T. 2008. Convergent products: What functionalities add more value to the base? Journal of Marketing 72(2): 46-62.

Gist, M. E., and Mitchell, T. R. 1992. Self-efficacy: A theoretical analysis of its determinants and malleability. Academy of Management Review 17(2): 183-211.

Google 2015. Mobile app marketing insights: How consumers really find and use your apps. Available at: 
https://think.storage.googleapis.com/docs/mobile-app-marketinginsights.pdf.

Granic, I., Lobel, A., and Engels, R. C. 2014. The benefits of playing video games. American Psychologist 69(1): 66-78.

$\mathrm{H}$

Harrison, D. A., and Klein, K. J. 2007. What's the difference? Diversity constructs as separation, variety, or disparity in organizations. Academy of Management Review 32(4): 1199 - 1228.

Hayes, A. F., and Matthes, J. 2009. Computational procedures for probing interactions in OLS and logistic regression: SPSS and SAS implementations. Behavior Research Methods 41(3): 924 - 936.

Heath, T. B., Chatterjee, S., Basuroy, S., Hennig-Thurau, T., and Kocher, B. 2015. Innovation sequences over iterated offerings: A relative innovation, comfort, and stimulation framework of consumer responses. Journal of Marketing 79(6): 71-93.

Hollebeek, L. D., Glynn, M. S., and Brodie, R. J. 2014. Consumer brand engagement in social media: Conceptualization, scale development and validation. Journal of Interactive Marketing 28(2): 149-165.

J

Jaruzelski, B., Schwartz, K., and Staack, V. 2015. Innovation's new world order. strategy+business 81:1-16. Available at: http://www.strategybusiness.com/media/file/00370_Innovations_New_World_Order.pdf.

K

Katz, E., Blumler, J.G., and Gurevitch, M. 1974. Utilization of mass communication by the individual. In: The uses of mass communications: Current perspectives on gratifications research, ed. J.G. Blumler, and E. Katz. Beverly Hills, California: Sage, 19-32.

Kim, S. S. 2009. The integrative framework of technology use: An extension and test. MIS Quarterly33(3): 513 - 537.

---, and Malhotra, N. K. 2005. A longitudinal model of continued IS use: an integrative view of four mechanisms underlying postadoption phenomena. Management Science 51(5): 741 - 755. 
-- - - - - and Narasimhan, S. 2005. Research note-two competing perspectives on automatic use: A theoretical and empirical comparison. Information Systems Research 16(4): 418 - 432.

Krause, A. E., North, A. C., and Heritage, B. 2014. The uses and gratifications of using Facebook music listening applications. Computers in Human Behavior 39: 71-77.

Kumar, V., Aksoy, L., Donkers, B., Venkatesan, R., Wiesel, T., \& Tillmanns, S. 2010. Undervalued or overvalued customers: capturing total customer engagement value. Journal of Service Research 13(3): 297-310.

L

Lazarus, R. S. and Folkman, S. 1984. Stress, appraisal, and coping. Springer Publishing Company, New York.

Li, G., Zhang, R., and Wang, C. 2015. The role of product originality, usefulness and motivated consumer innovativeness in new product adoption intentions. Journal of Product Innovation Management 32(2): 214-223

Li, H., Liu, Y., Xu, X., Heikkilä, J., and Van Der Heijden, H. 2015. Modeling hedonic is continuance through the uses and gratifications theory: an empirical study in online games. Computers in Human Behavior 48: 261 272.

Libai, B. 2011. Comment: the perils of focusing on highly engaged customers. Journal of Service Research 14(3): 275-276.

Limayem, M., Hirt, S. G., and Cheung, C. M. K. 2007. How habit limits the predictive power of intention: The case of information systems continuance. MIS Quarterly31(4): 705 - 737.

Lindell, M. K. and Whitney, D. J. 2001. Accounting for common method variance in cross-sectional research designs. Journal of Applied Psychology 86(1): 114-121.

Liu-Thompkins, Y., and Tam, L. 2013. Not all repeat customers are the same: designing effective cross-selling promotion on the basis of attitudinal loyalty and habit. Journal of Marketing 77(5): 21 - 36.

Ludwig, S., de Ruyter, K., Mahr, D., Wetzels, M., Bruggen, E., and De Ruyck, T. 2014. Take their word for it: The symbolic role of linguistic style matches in user communities. MIS Quarterly38(4): 1201 - 1217. 
Lusch, R. F., and Nambisan, S. 2015. Service innovation: a service-dominant logic perspective. MIS Quarterly39(1): 155-175.

Lynch, J. G. 1999. Theory and external validity. Journal of the Academy of Marketing Science 27(3): 367-376.

M

Mahr, D., Lievens, A., and Blazevic, V. 2014. The value of customer cocreated knowledge during the innovation process. Journal of Product Innovation Management 31(3): 599-615.

Marchand, A. 2016. The power of an installed base to combat lifecycle decline: The case of video games. International Journal of Research in Marketing 33 (1): 140-154.

Marchand, A., and Hennig-Thurau, T. 2013. Value creation in the video game industry: Industry economics, consumer benefits, and research opportunities. Journal of Interactive Marketing 27(3): 141-157.

Martin, K. D., and Hill, R. P. 2012. Life satisfaction, self-determination, and consumption adequacy at the bottom of the pyramid. Journal of Consumer Research 38(6): 1155 - 1168.

Martinsuo, M., and Poskela, J. 2011. Use of evaluation criteria and innovation performance in the front end of innovation. Journal of Product Innovation Management 28(6): 896-914.

McKinsey \& Company 2015. Cracking the digital code: McKinsey global survey results. Available at: http://www.mckinsey.com/businessfunctions/business-technology/our-insights/cracking-the-digital-code.

Microsoft 2015. Halo 5: Guardians Smashes Record with Biggest Halo Launch in History. Available at: https://news.xbox.com/2015/11/04/halo-5guardians-biggest-halo-launch-in-history/.

Moeller, S., Ciuchita, R., Mahr, D., Odekerken-Schröder, G., \& Fassnacht, M. 2013. Uncovering collaborative value creation patterns and establishing corresponding customer roles. Journal of Service Research 16(4): 471487.

Moschis, G.P. 2007. Stress and consumer behavior. Journal of the Academy of Marketing Science 35(3): 430-444. 
MSI [Marketing Science Institute] 2016. Research Priorities 2016-2018. Available at: http://www.msi.org/uploads/articles/MSI_RP16-18.pdf.

Mun, Y. Y., and Hwang, Y. 2003. Predicting the use of web-based information systems: Self-efficacy, enjoyment, learning goal orientation, and the technology acceptance model. International Journal of Human-Computer Studies 59(4): 431-449.

Muthén, L.K. and Muthén, B.O. 1998-2015. Mplus User's Guide. Seventh Edition. Los Angeles, CA: Muthén \& Muthén.

$\mathrm{N}$

Nambisan, S., and Baron, R. A. 2007. Interactions in virtual customer environments: implications for product support and customer relationship management. Journal of Interactive Marketing 21(2): 42-62.

Neal, D. T., Wood, W., and Drolet, A. 2013. How do people adhere to goals when willpower is low? The profits (and pitfalls) of strong habits. Journal of Personality and Social Psychology 104(6): 959 - 975.

Nylén, D., and Holmström, J. 2015. Digital innovation strategy: A framework for diagnosing and improving digital product and service innovation. Business Horizons 58(1): 57-67.

0

O'Cass, A., and Wetzels, M. 2016. Contemporary issues and critical challenges on innovation in services. Journal of Product Innovation Management. Call for papers. Available at:

http://onlinelibrary.wiley.com/store/10.1111/(ISSN)15405885/asset/homepages/JPIM_CFP_-

Contemporary_Issues_and_Critical_Challenges_on_Innovation_in_Servi ces.pdf? $=1 \& s=f 561 f 322533110 d 375 e b d 7 d 928 a 1 d 90 d d 77 e 4 f 17$.

Ortiz de Guinea, A., and Markus, M. L. 2009. Why break the habit of a lifetime? Rethinking the roles of intention, habit, and emotion on continuing information technology use. MIS Quarterly33(3): 433 - 444.

Ostrom, A. L., Parasuraman, A., Bowen, D. E., Patrício, L., Voss, C. A., and Lemon, K. 2015. Service research priorities in a rapidly changing context. Journal of Service Research 18(2): 127-159. 
Palmatier, R. W., Houston, M. B., Dant, R. P., and Grewal, D. 2013. Relationship velocity: Toward a theory of relationship dynamics. Journal of Marketing 77(1): 13-30.

Patel, P. C., Fernhaber, S. A., McDougall-Covin, P. P., and van der Have, R. P. 2014. Beating competitors to international markets: The value of geographically balanced networks for innovation. Strategic Management Journal35(5): 691-711.

Peacock, E. J., and Wong, P. T. 1990. The stress appraisal measure (SAM): A multidimensional approach to cognitive appraisal. Stress Medicine 6(3): 227-236.

Perks, H., Gruber, T., and Edvardsson, B. 2012. Co-creation in radical service innovation: A systematic analysis of microlevel processes. Journal of Product Innovation Management 29(6): 935-951.

Pew Research Center 2015. Mobile messaging and social media 2015. Available at http://www.pewinternet.org/files/2015/08/Social-Media-Update-2015FINAL2.pdf.

Polites, G. L., and Karahanna, E. 2012. Shackled to the status quo: The inhibiting effects of incumbent system habit, switching costs, and inertia on new system acceptance. MIS Quarterly36(1): 21 - 42.

Przybylski, A. K., Rigby, C. S., and Ryan, R. M. 2010. A motivational model of video game engagement. Review of General Psychology 14(2): 154-166.

$\mathrm{R}$

Ramaswamy, V., and Ozcan, K. 2016. Brand value co-creation in a digitalized world: an integrative framework and research implications. International Journal of Research in Marketing 33(1): 93-106.

Rogowsky M. 2014. Card carrying: Can your smartphone at last render the plastic in your wallet obsolete? Available at:

http://www.forbes.com/sites/markrogowsky/2014/05/25/for-the-mobilewallet-and-especially-apple-finally-an-opening/.

Rust, R. T., and Huang, M. H. 2014. The service revolution and the transformation of marketing science. Marketing Science 33(2): 206-221. 
Ryan, R. M., and Deci, E. L. 2000. Self-determination theory and the facilitation of intrinsic motivation, social development, and well-being. American Psychologist 55(1): $68-78$.

\section{S}

Schepers, J., and Wetzels, M. 2007. A meta-analysis of the technology acceptance model: Investigating subjective norm and moderation effects. Information \& Management 44(1): 90-103.

Shaban, H. 2013. Playing war: how the military uses video games. Available at: http://www.theatlantic.com/technology/archive/2013/10/playing-warhow-the-military-uses-video-games/280486/.

Shah, D., Kumar, V., and Kim, K.H. 2014. Managing customer profits: The power of habits. Journal of Marketing Research 51(6): 726 - 741.

- - - - - - Qu, Y. and Chen, S. 2012. Unprofitable cross-buying: Evidence from consumer and business markets. Journal of Marketing 76(3): 78 95.

Sheeran, P., Aarts, H., Custers, R., Rivis, A., Webb, T. L., and Cooke, R. 2005. The goal-dependent automaticity of drinking habits. British Journal of Social Psychology 44(1): $47-63$.

Snow, B. 2011. Why most people don't finish video games. Available at: http://edition.cnn.com/2011/TECH/gaming.gadgets/08/17/finishing.videog ames.snow/.

Snyder, H., Witell, L., Gustafsson, A., Fombelle, P., and Kristensson, P. 2016. Identifying categories of service innovation: A review and synthesis of the literature. Journal of Business Research, DOl: 10.1016/j.jbusres.2016.01.009.

Statista 2016. Revenue from e-book sales in the United States from 2008 to 2018 (in billion U.S. dollars). Available at:

http://www.statista.com/statistics/190800/ebook-sales-revenue-forecastfor-the-us-market/.

Steiger, A. E., Allemand, M., Robins, R. W., and Fend, H. A. 2014. Low and decreasing self-esteem during adolescence predict adult depression two decades later. Journal of Personality and Social Psychology 106(2): $325-$ 338. 
Storey, C., Cankurtaran, P., Papastathopoulou, P., and Hultink, E. J. (2016). Success factors for service innovation: A meta-analysis. Journal of Product Innovation Management, DOI: 10.1111/jpim.12307.

Stuart, K. 2014. Player one: The gamers who only want to play with themselves. Available at: https://www.theguardian.com/technology/2014/jul/14/singleplayer-gamers-destiny-solo-activision-grand-theft-forza.

Sutanto, J., Palme, E., Tan, C. H., and Phang, C. W. 2013. Addressing the personalization-privacy paradox: An empirical assessment from a field experiment on smartphone users. MIS Quarterly37(4): 1141-1164.

\section{$\mathrm{T}$}

Talke, K., and Hultink, E. J. 2010. Managing diffusion barriers when launching new products. Journal of Product Innovation Management 27(4): 537-553.

Tarafdar, M., Pullins, E. B., and Ragu-Nathan, T. S. 2015. Technostress: Negative effect on performance and possible mitigations. Information Systems Journal 25(2): 103-132.

Thomson, M. 2006. Human brands: Investigating antecedents to consumers' strong attachments to celebrities. Journal of Marketing 70(3): $104-119$.

Thompson, D. V., Hamilton, R. W., and Rust, R. T. 2005. Feature fatigue: When product capabilities become too much of a good thing. Journal of Marketing Research 42(4): 431-442.

Thomson Reuters 2016. Disruptive, game-changing innovation: 2016 state of innovation. Available at

http://images.info.science.thomsonreuters.biz/Web/ThomsonReutersScience/\% 7B81d76ae6-9d3b-453c-8f7cb76a3c80046d\%7D_2016_State_of_Innovation_Report.pdf.

V

Van Beuningen, J., de Ruyter, K., Wetzels, M., and Streukens, S. 2009. Customer self-efficacy in technology-based self-service assessing between-and within-person differences. Journal of Service Research 11(4): 407-428.

Van Doorn, J., Lemon, K. N., Mittal, V., Nass, S., Pick, D., Pirner, P., and Verhoef, P. C. 2010. Customer engagement behavior: Theoretical foundations and research directions. Journal of Service Research 13(3): 253-266. 
Venkatesh, V., and Davis, F. D. 2000. A theoretical extension of the technology acceptance model: Four longitudinal field studies. Management Science 46(2): 186-204.

- - - Thong, J. Y., and Xu, X. 2012. Consumer acceptance and use of information technology: Extending the unified theory of acceptance and use of technology. MIS Quarterly36(1): 157 - 178.

Verhoef, P. C., Lemon, K. N., Parasuraman, A., Roggeveen, A., Tsiros, M., and Schlesinger, L. A. 2009. Customer experience creation: Determinants, dynamics and management strategies. Journal of Retailing 85(1): 31-41.

---, Reinartz, W. J., and Krafft, M. 2010. Customer engagement as a new perspective in customer management. Journal of Service Research 13(3): $247-252$.

Verplanken, B., and Aarts, H. 1999. Habit, attitude, and planned behaviour: Is habit an empty construct or an interesting case of automaticity? European Review of Social Psychology 10: $101-134$.

VISA 2014. VISA merchant data standards manual. Available at: https://usa.visa.com/dam/VCOM/download/merchants/Visa-MerchantData-Standards-Manual-Nov-2014.pdf.

Von Krogh, G., Haefliger, S., Spaeth, S., and Wallin, M. W. 2012. Carrots and rainbows: Motivation and social practice in open source software development. MIS Quarterly36(2): 649 - 676.

\section{W}

Wang, J., and Wang, X. 2012. Structural equation modeling: Applications using Mplus. John Wiley \& Sons, West Sussex, United Kingdom.

Wetzels, M., Odekerken-Schröder, G., and van Oppen, C. 2009. Using PLS path modeling for assessing hierarchical construct models: Guidelines and empirical illustration. MIS Quarterly33(1): 177 - 195.

Williams, D., Yee, N., and Caplan, S. E. 2008. Who plays, how much, and why? Debunking the stereotypical gamer profile. Journal of ComputerMediated Communication 13(4): 993-1018.

Williams, R. 2012. Using the margins command to estimate and interpret adjusted predictions and marginal effects. Stata Journal 12(2): 308-331. 
Wood, W., Quinn, J.M. and Kashy, D.A. 2002. Habits in everyday life: Thought, emotion, and action. Journal of Personality and Social Psychology 83(6): $1281-1297$.

-- , Tam, L. and Witt, M.G. 2005. Changing circumstances, disrupting habits. Journal of Personality and Social Psychology 88(6): 918 - 933.

Wunderlich, P., Kranz, J., Totzek, D., Veit, D., and Picot, A. 2013. The impact of endogenous motivations on adoption of it- enabled services: The case of transformative services in the energy sector. Journal of Service Research 16(3): $356-371$.

$X$

Xbox 2015. Halo 5: Guardians is now available for digital pre-order and predownload on Xbox one. Available at:

https://majornelson.com/2015/10/14/halo-5-guardians-is-now-availablefor-digital-pre-order-on-xbox-one/.

Y

Yee, N. 2006. Motivations for play in online games. CyberPsychology \& Behavior 9(6): 772-775.

Yim, C.K., D.K. Tse and K.W. Chan. 2008. Strengthening customer loyalty through intimacy and passion: Roles of customer-firm affection and customer-staff relationships in services. Journal of Marketing Research 45(6): 741-756.

Yoo, Y. 2013. The tables have turned: how can the information systems field contribute to technology and innovation management research? Journal of the Association for Information Systems 14(5): 227-238.

\section{Z}

Zellner, A. 1962. An efficient method of estimating seemingly unrelated regressions and tests for aggregation bias. Journal of the American Statistical Association 57(298): 348-368. 


\section{Valorization Addendum}

This dissertation examines how users engage with digital service innovation in terms of how they feel about the innovation, what they think about the innovation and how they actually use the innovation. In three empirical chapters, I examine these different, yet complementary facets of engagement while focusing on a different type of digital service innovation. The innovations I examine differ in terms of the degree of change they can bring to the user experience: a new-to-the-market service in Chapter 2, a new version of a service in Chapter 3 and introducing new features in an existing service in Chapter 4. The context of Chapter 2 is contactless mobile payment (i.e., a primarily functional service), the context of Chapter 3 is multiplayer video gaming (i.e., a primarily hedonic service), while the context of Chapter 4 is online socialization (i.e., a service both functional and hedonic). Therefore, the findings of these chapters have important implications for service providers introducing digital service innovations of different types and magnitude. This section expands on the relevance of the results for a managerial audience, while clarifying potential target groups and applications.

\section{Chapter 2: Engagement with a New-to-the-Market Digital Service Innovation}

While many managers praise innovation as a key strategic priority that allows companies to stay competitive and that can also impact the bottom line, the harsh reality of the market is that most newly introduced innovations fail. More often than not users are the ones deciding the market success of innovations. Hence, for companies introducing new-to-the-market services it is of paramount importance to understand why and how potential users interact with digital service innovation and what elements of the service experience affect their engagement with the innovation. This chapter focuses on contactless mobile payment (CMP) and shows that users interact with this service to satisfy their psychological needs for autonomy le.g., are there enough stores supporting CMP?), competence (e.g., do users possess the skills to use CMP?) and relatedness (e.g., would users' friends and family want them to use CMP?). If these psychological needs are satisfied, then users can develop habitual behaviors. Such behaviors can vary in terms of time le.g., do users spend more or less via CMP from one week to the next), in terms of location (e.g., do users pay with their mobile only in one specific store or across multiple stores?) and in terms of merchant category le.g., do users pay with their mobile only in 
supermarkets, or also in restaurants and bars?). The results in this chapter show that when users develop stable habitual behaviors in terms of location (i.e., they use CMP more across all the supporting stores) they also tend to say more positive things about CMP, they evaluate their whole experience as more positive and they ultimately spend more via CMP. Managers and policy makers can apply these results in multiple ways.

First of all, CMP is provided through a service ecosystem comprising of multiple actors: users (i.e., consumers with smartphones equipped for CMP), supporters (i.e., stores in brick-and-mortar locations with payment terminals accepting CMP) and enablers (i.e., companies offering CMP terminals, smartphones or payment applications). The different actors might have different objectives for being part of the ecosystem. For example, a bank or a mobile services operator offering a payment application would like that consumers use CMP in as many retail locations as possible, while a supermarket supporting that payment application would like that consumers use CMP in its own, and not the competitors', retail locations. My results suggest that the ecosystem thrives (i.e., users feel more positively about CMP. think more positively about CMP and spend more via CMP) when consumers usage of CMP is more dispersed across locations. Hence, it becomes extremely important for the companies in the ecosystem to achieve a common understanding that usage could be encouraged across all the supporting locations. This could be achieved by inviting not only competing, but also complementary supporters in the ecosystem le.g., an airline, a hotel and a car rental service provider) or by coupling usage with a loyalty program (e.g., the more the consumer uses the innovation across locations, the more benefits are unlocked).

Second of all, irrespective of their motives for joining the ecosystem, enabling and supporting actors need to make sure the users' psychological needs are satisfied as that would lead to the formation of habitual behaviors fostering user engagement. CMP supporters might focus on satisfying users' needs for competence by e.g., in-store advertising explaining how CMP works or by encouraging in-store trials through CMP-only terminals. CMP enablers might focus on satisfying users' needs for autonomy by clearly communicating and encouraging usage at a multitude of locations supporting CMP. That could be implemented by integrating geolocation with the CMP application and informing users of CMP opportunities in the vicinity could they allow push notifications. 
Third and last, this chapter provides some important insights for companies contemplating joining an existing, or even setting up their own payment ecosystem. Given that the digital service innovation is new-to-the-market, my recommendation for a potential new entrant would be to join an existing, thriving ecosystem (e.g., Apple Pay). Such a company would benefit from the already established habitual behaviors in terms of location, while only having to invest in the CMP supporting terminals. As appealing as setting up an own ecosystem might be to some managers, the investment le.g., developing the payment application) would have to take into account the subsequent challenges of developing beneficial habitual behaviors (e.g., satisfying users' psychological needs and encouraging dispersed usage across locations).

\section{Chapter 3: Engagement with a Sequential Digital Service Innovation}

Especially when it comes to hedonic services such as those offered by the entertainment industry (e.g., e-books, movies, video games) developing and nurturing successful franchises (e.g., each new Harry Potter book, each new James Bond movie or each new Call of Duty video game) is a key managerial priority. With development costs increasing and consumer attention spans decreasing, keeping users engaged with new versions of a service has become a key managerial concern. Consequently, this chapter focuses on a new title in a successful multiplayer video game franchise and shows that while individual users can have very different behavioral engagement trajectories (i.e., some users will play a lot, whereas others will play very little), a common engagement trajectory can be determined across all users within one month after the game's introduction. This common engagement trajectory implies that across all users, the level of behavioral engagement is highest during the first week after the introduction, but then decreases from the first until the fourth week. The findings in this chapter have important implications for service providers introducing new versions of digital services.

First of all, managers need to acknowledge the importance of the time period immediately following the introduction of a new version on how engaged users stay with the service. While it is natural to expect that engagement levels will decrease, it is important for managers to be aware that nurturing a high level of engagement across all users during the first week after introduction can be beneficial for keeping (at least some of) the users engaged even one year later. That would be beneficial as it will keep users interested in the service close to 
the introduction of the next version. There are multiple applications that could be considered to foster initial engagement such as encouraging pre-orders by providing unique content (e.g., limited edition items) or offering incentives to stimulate usage (e.g., additional experience points if users play on specific days).

Second of all, even if the rate of change in engagement is negative, a less steep decrease in engagement during the first month can still ensure greater engagement later on. Therefore, after having introduced a new version, service providers can monitor the rate of change during the first weeks after launch and assess its potential success. Could the negative rate of change be too steep, managers can introduce engagement boosters le.g., new maps, items, or gameplay modes for video games; additional footage for movies and additional content for e-books).

Third and last, the findings of this chapter also indicate that the behavioral user engagement trajectory developed during the introduction period can lead to a fulfilling user experience one year later. Managers could invest in satisfying functional, hedonic and social user needs during the first week after the introduction, thus boosting the initial engagement level. For video games, that could be achieved through publishing user and team achievements either statically le.g., allowing users to publish their in-game rankings on social medial or dynamically (e.g., allowing users to live-broadcast their in-game or spectator experience). For movies, that could be achieved by encouraging viewers to share their cinema attendance on social media le.g., through custom Snapchat filters).

\section{Chapter 4: Engagement with a Gradual Digital Service Innovation}

Many digital services nowadays, be they predominantly functional le.g., Office 360), predominantly hedonic (e.g., Pokemon Go) or both functional and hedonic (e.g., Skype) offer a ceaseless version to which new features are added land from which sometimes old features are removed) over time. Service providers hope that new features can refuel users' engagement with the service and even attract new users le.g., Facebook introduction of a live broadcast feature directly competing with YouTube). Nevertheless, new features partly change how the service looks and what the service does, thus changing the user experience (i.e., how users interact with the service). This chapter focuses on an existing online socialization service and shows that users do not always see 
new features as something positive (i.e. a challenge that can improve their experience), but can also see it as something negative (i.e., a threat that can deteriorate their experience). Users manage the perceived change in their experience by employing coping strategies le.g., trying to directly address the change by trying the new features out, expressing their emotions about the change by venting on social media or asking friends for help with the change). Users' belief that they have the ability to deal with the change affects how they cope the more complex the innovation (i.e., the more features are added at the same time). The findings in this chapter have important implications for service providers introducing new features in existing digital services.

First of all, service providers could aim to convince their users to evaluate new features as something positive, meant to improve their experience (i.e., frame the change as a challenge and make users eager to pursue it). For instance, with the introduction of each new feature interactive tutorials could be offered to highlight what is new, explain what changes for the user in an easy-tounderstand manner and why those changes are supposed to be beneficial for the user experience. Many service providers provide detailed descriptions of what the new features comprise (e.g., via the license agreements users have to accept with each new update), but very few (e.g., Facebook, Google) make the additional step of simply and clearly explaining what has changed and what that means for the user.

Second of all, even if users see the new features as a threat li.e., a change to be avoided), service providers can still help users employ coping strategies to manage the perceived change. The findings in this chapter suggest that when users actively try-out the new features they can feel more positively about the innovation (i.e., they become more passionate about it) as well as think more positive about the innovation (i.e., they find the innovation more useful). Hence, after communicating what has changed, service providers could encourage their users to actively try-out the new features. Gamification elements could be employed for that purpose: encouraging users to use the new feature by providing simple tasks they can complete and incentivizing participation (e.g., the ability to compare with friends, additional content etc.).

Third and last, managers could be aware that when introducing more complex innovations in an existing service (i.e., multiple new features) users' perception of their ability to deal with the change becomes salient and can reduce their 
employment of coping strategies. While actively trying out the new features is still beneficial for driving engagement irrespective of the innovation complexity, service providers could encourage the employment of other coping strategies depending on the type of engagement they would like to drive. For instance, if a more complex innovation is introduced, allowing users to vent their emotions via social media will lead to them seeing the innovation as more useful. Companies can encourage that by providing users with the possibility to provide feedback and share it on their social networks.

In conclusion, this dissertation shows that service providers who want to foster their users' engagement with digital service innovation need to understand that the changes brought forth by innovation can alter the users' experiences in both positive, as well as negative ways. 


\section{Summary}

Service innovation is a top strategic priority for managers as it facilitates company competitiveness and can have an impact on profitability. With the proliferation of information and communication technology (ICT), digitalization has become a key enabler for service innovation as it allows service providers to introduce innovation at a faster pace. In spite of companies' efforts to improve their users' experiences through digital service innovation, it is not yet clear how that impacts user engagement with the service (i.e., how users feel about the service, what they think about it and how they ultimately use it). Therefore, in this dissertation I take the perspective of consumers as actual users of services and examine why and how they interact with digital service innovation and what elements of the resulting experience affect their llongterm) engagement with the service. I do so through three empirical chapters each exploring a different, yet complementary facet of user engagement with a digital service (i.e., on an affective, behavioral and / or cognitive level), thus achieving a broader and deeper understanding of this extremely relevant contemporary phenomenon.

In Chapter 2, I examine a new-to-the-market digital service innovation: the introduction of contactless mobile payment (CMP), a service that allows users to pay with smartphones instead of cash or bank card in retail locations. I argue that to increase their engagement with the CMP service users need to develop stable habitual behaviors (e.g., over time, locations or merchant categories) and that such behaviors are facilitated by the satisfaction of psychological needs (e.g., for autonomy, for competence or for relatedness). I combine objective (i.e., usage behavior) and subjective (i.e., user surveys) data from consumers participating in a CMP roll-out and show that satisfying users' need for competence is key to the development of stable habitual behaviors. Furthermore, I show that habitual behaviors pertaining to stability in location (i.e., consumers using CMP dispersed across supporting retail locations) drive affective, behavioral and cognitive user engagement with the new-to-themarket service innovation.

In Chapter 3, I examine a sequential digital service innovation: the introduction of a new version of a first-person shooter video game in a popular franchise. I argue that while behavioral user engagement with such an innovation can vary for each user over time, a homogenous user developmental trajectory across 
all users can influence subsequent engagement and the user experience. I draw on objective (i.e., telemetric) longitudinal data and show that a common developmental trajectory featuring an initially positive behavioral engagement level and a negative rate of change in this engagement can be observed across users in the first weeks after the new version was introduced. Furthermore, I show that the growth factors (i.e., the initial engagement level and the rate of change) enhance user engagement with the video game and have some positive influence on how gratified users are with the experience one year after the introduction.

In Chapter 4, I examine a gradual digital service innovation: the introduction of an updated version that adds new features to an existing online socialization service. I argue that users appraise how the innovation changes their experience as something predominantly threatening or challenging. Consequently, users attempt to manage the change by employing coping strategies (e.g., problem-focused, emotion-focused or social support coping) and by leveraging a coping resource (i.e., self-efficacy). Subjective data (i.e., user surveys) from field and an experimental study show that employing problem-focused coping can positively influence cognitive engagement irrespective of innovation complexity (i.e., the number of new features added) being made salient or not. Nevertheless, making users aware of the complexity of the innovation in the existing service activates their self-efficacy with negative influences on the coping strategies employed.

This dissertation builds on rich contexts, data and methods and paves the way towards achieving a better understanding of why le.g., satisfying different types of psychological needs, cognitive appraisal) and how (e.g., developing habitual behaviors, employing coping strategies) users interact with digital service innovation. The resulting experience can have long-term influence on affective, cognitive and / or behavioral user engagement. 


\section{Curriculum Vitae}

Robert Petrut Andrei Ciuchita was born in Craiova, Romania on the $29^{\text {th }}$ of June 1987. In 2006 he graduated from the Ion C. Bratianu high school in Pitesti, Romania with a specialization in mathematics and informatics. In 2009, Robert obtained his Bachelor of Science (BSc) degree in Economics with a major in Marketing from the Bucharest University of Economic Studies. During his undergraduate studies he spent one semester as an Erasmus exchange student at the School of Business of Reykjavik University in Iceland. Aside from his BSc studies, Robert worked as a copywriter and subsequently as an account manager at BrandFusion, a pioneering Romanian strategic brand consultancy. In 2011, Robert received his Master of Science (MSc) degree in Strategic Marketing from the School of Business and Economics of Maastricht University. During his graduate studies he spent one semester as an exchange student at the School of Business of Renmin University of China in Beijing. Aside from his MSc studies, Robert took part in multiple service innovation projects at the Service Science Factory of Maastricht University.

In October 2011, Robert started as a PhD candidate at the Service Science Factory and the Department of Marketing \& Supply Chain Management of Maastricht University. His research on user engagement with digital service innovation was supervised by Prof. Dr. Gaby Odekerken-Schröder and Dr. Dominik Mahr. A project on collaborative value creation, collateral to his dissertation, was published in 2013 at the Journal of Service Research. During his PhD, Robert spent one semester as a visiting scholar at the Robert H. Smith School of Business of the University of Maryland (College Park) in the USA.

Robert has presented his research at leading conferences such as EMAC, Winter AMA, ISMS Marketing Science, Frontiers in Service and SERVSIG. Furthermore, he has been a fellow of the EMAC Doctoral Colloquium, PDMAUIC Innovation Doctoral Consortium, Let's Talk about Service Workshop, KIN²RESEARCH Organizing for Digital Innovation Workshop and the Ratio Colloquium for Young Social Scientists (RCYSS).

As of September 2016 Robert has been a postdoctoral researcher at the Department of Marketing \& Supply Chain Management of Maastricht University. 
